NIST Special Publication I I74

\title{
Smart Firefighting Workshop Summary Report March 24-25, 2014 Arlington, Virginia
}

Anthony Hamins

Nelson Bryner

Albert Jones

Galen Koepke

Casey Grant

Anand Raghunathan

http://dx.doi.org// 0.6028/NIST.SP.I I 74

THE

FIRE PROTECTION

RESEARCH FOUNDATION

Research in support of the NFPA mission

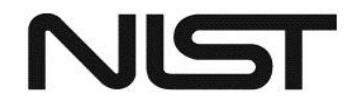

National Institute of Standards and Technology U.S. Department of Commerce 
NIST Special Publication II 74

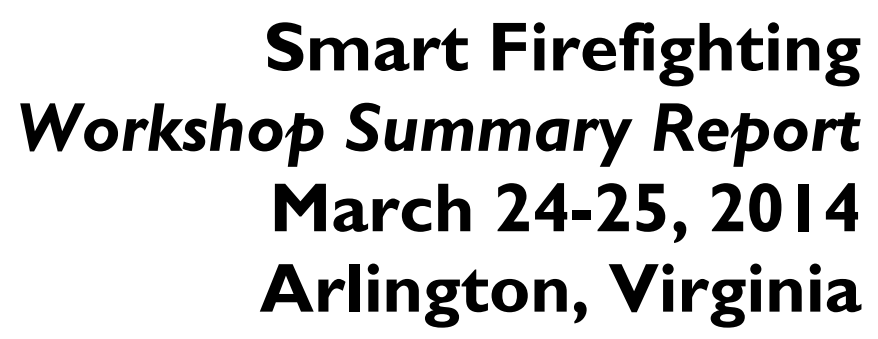

Anthony Hamins

Nelson Bryner

Fire Research Division

Engineering Laboratory

Albert Jones Systems Integration Division Engineering Laboratory

Galen Koepke Electromagnetics Division

Physical Measurement Laboratory

Casey Grant Fire Protection Research Foundation Quincy, MA

Anand Raghunathan Energetics Incorporated Columbia, MD

This publication is available free of charge from: http://dx.doi.org//0.6028/NIST.SP.I I 74

August 2014

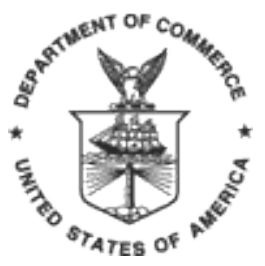

U. S. Department of Commerce Penny Pritzker, Secretary

National Institute of Standards and Technology Willie May, Acting Under Secretary of Commerce for Standards and Technology and Acting Director 
Certain commercial entities, equipment, or materials may be identified in this document in order to describe an experimental procedure or concept adequately. Such identification is not intended to imply recommendation or endorsement by the National Institute of Standards and Technology, nor is it intended to imply that the entities, materials, or equipment are necessarily the best available for the purpose.

National Institute of Standards and Technology Special Publication 1174

Natl. Inst. Stand. Technol. Spec. Publ. 1174, 102 pages (August 2014)

CODEN: NSPUE2

This publication is available free of charge from: http://dx.doi.org/10.6028/NIST.SP.1174 
SMART FIREFIGHTING WORKSHOP SUMMARY REPORT

THIS PAGE LEFT INTENTIONALLY BLANK 


\begin{abstract}
This report summarizes the results of the Smart Firefighting Workshop held on March 24 and 25, 20I4, in Arlington, Virginia and sponsored by the National Institute of Standards and Technology (NIST). The Workshop provided a forum to help identify and understand the R\&D needs for implementation of smart firefighting, highlighting use of existing technologies, development and deployment of emerging technologies including cyber-physical systems (CPS), and use of standards for data collection, exchange, and situational awareness tools. The workshop brought together experts from various industry, educational, and governmental organizations involved in the cyber physical systems and firefighting areas. This report summarizes the workshop findings including prioritization of research needs according to those that have the greatest potential to enhance the safety and effectiveness of fire protection and the fire service. Small groups in each breakout session selected a high-priority task and completed detailed implementation plans for them.
\end{abstract}




\section{Acknowledgements}

This report summarizes the results of the Smart Firefighting Workshop held on March 24 and 25, 20I4, in Arlington, Virginia. The workshop was sponsored by the National Institute of Standards and Technology (NIST). Thanks go to Energetics Incorporated's workshop team members Laurie Aldape, Mauricio Justiniano, Rebecca Massello, Shawna McQueen, and Walt Zalis for their assistance in facilitating the workshop and preparing this report. The Workshop and this report would not have been possible without the specialized knowledge and insight contributed by the participants, representing recognized experts in various aspects of firefighting and cyber-physical systems. These experts took time from their busy schedules to participate in the Workshop and share their insight, which forms the basis for the workshop results. The Workshop participants are listed in Appendix A. 


\section{Table of Contents}

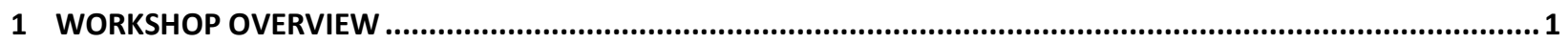

1.1 Challenges and Opportunities for Cyber-Physical Systems, the Fire Service, and Fire Protection .......................1

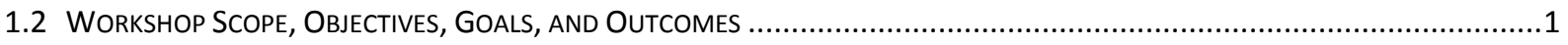

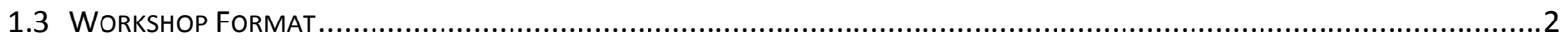

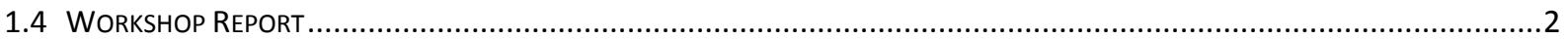

2 INTEGRATING CPS INTO FIRE PROTECTION AND THE FIRE SERVICE....................................................

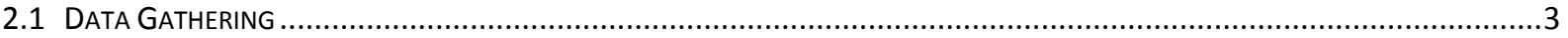

2.1.1 Overview and Importance of CPS for Fire Protection and the Fire Service ......................................

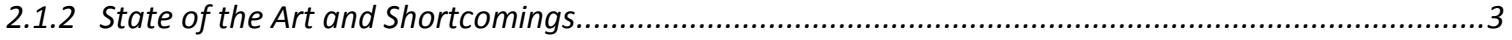

2.1.3 Development Areas............................................................................................................ 7

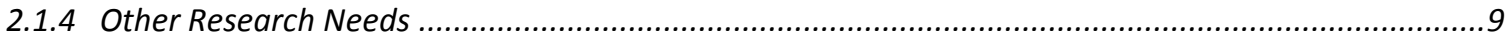

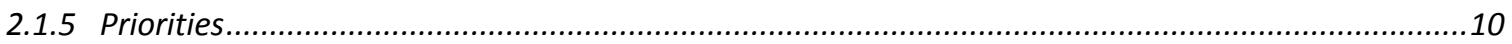

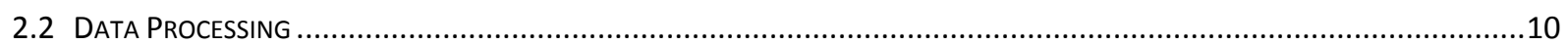

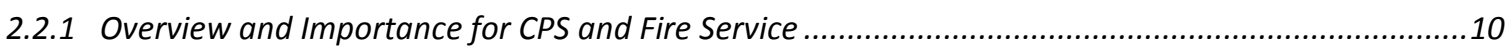

2.2.2 State of the Art and Shortcomings......................................................................................... 11

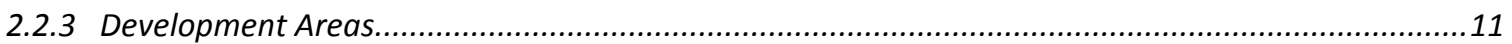

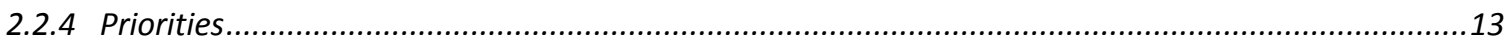

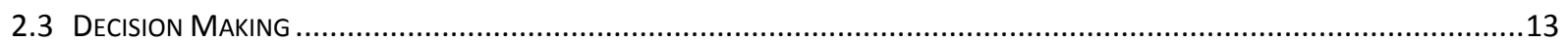

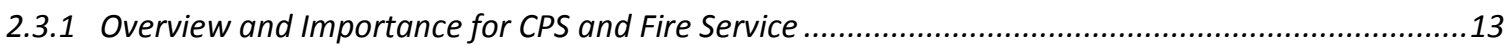

2.3.2 State of the Art and Shortcomings........................................................................................ 13

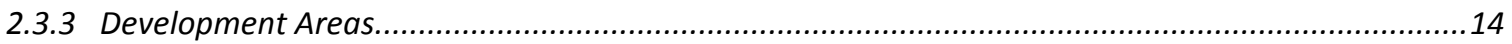

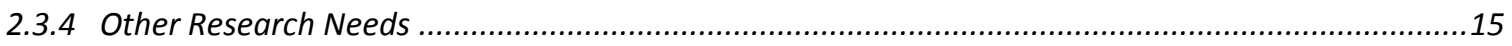

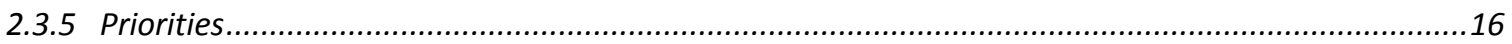

3 STRUCTURAL AND NON-STRUCTURAL FIREFIGHTING CROSS-CUTTING TOPICS........................................17

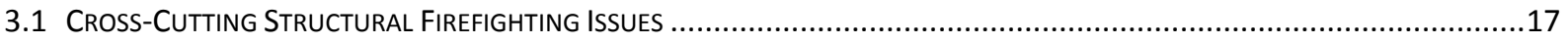

3.1.1 Overview and Importance for CPS and Fire Services in Structure Fires.....................................17

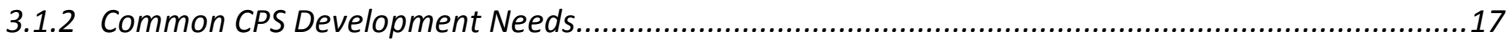

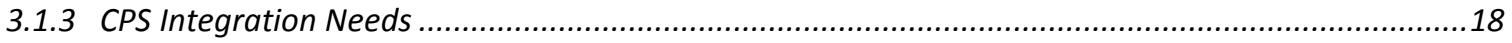

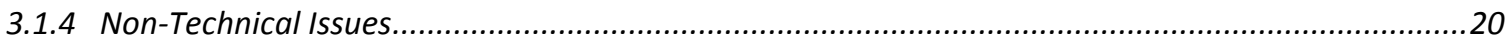

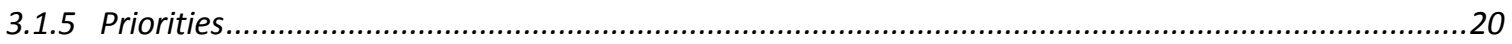

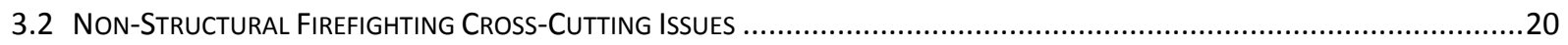

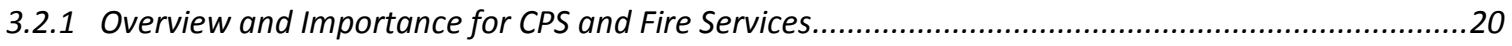

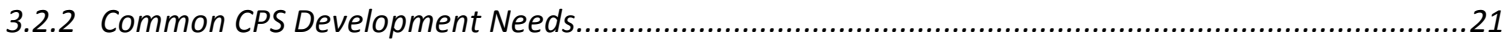

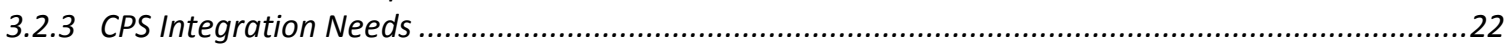

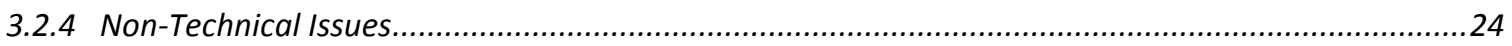

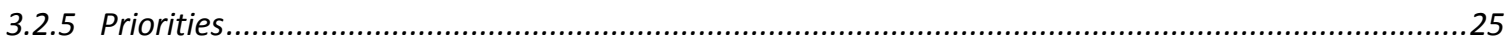

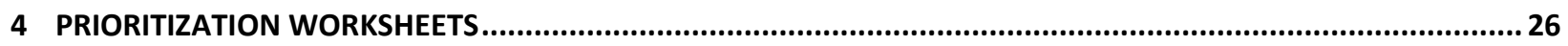

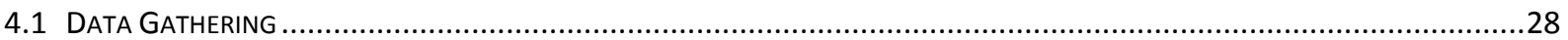

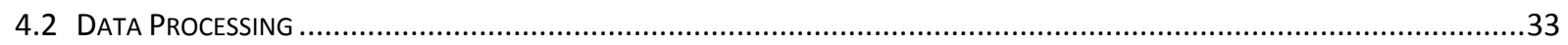

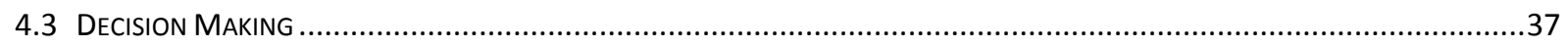

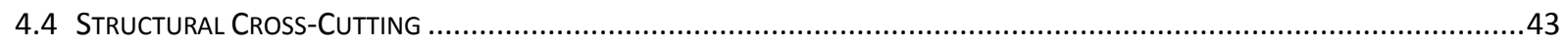

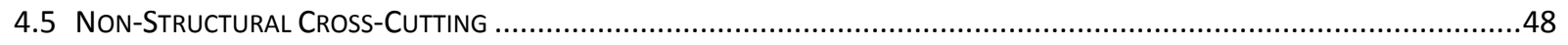

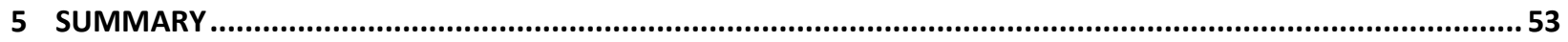

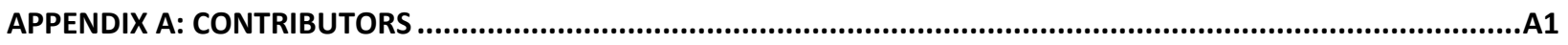

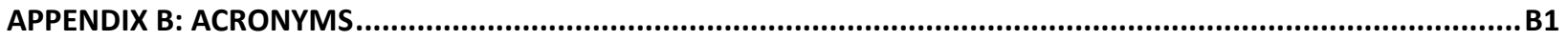

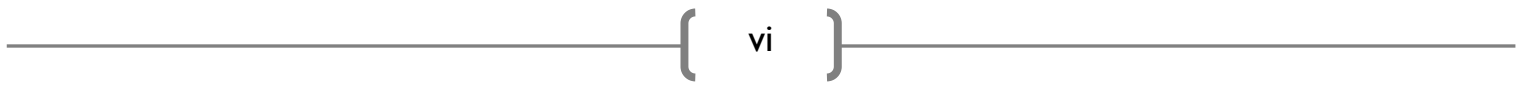


APPENDIX C: WORKSHOP AGENDA

\section{List of Figures}

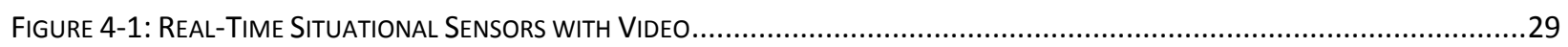

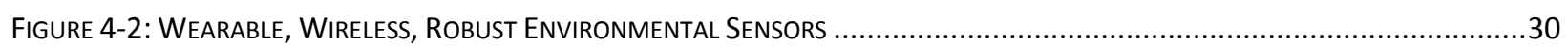

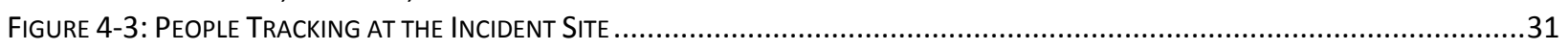

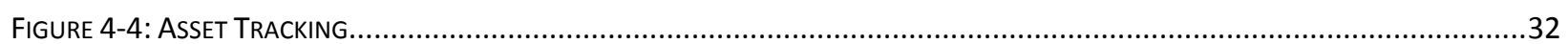

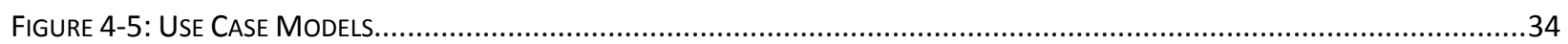

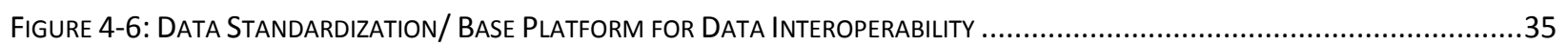

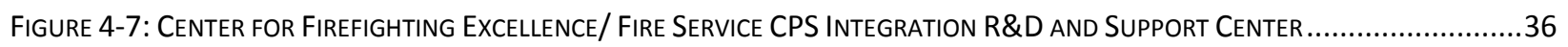

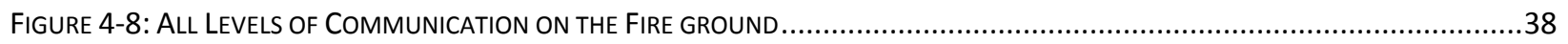

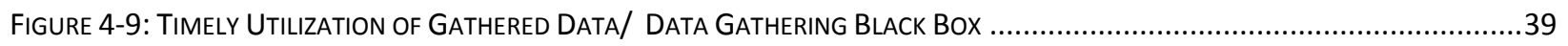

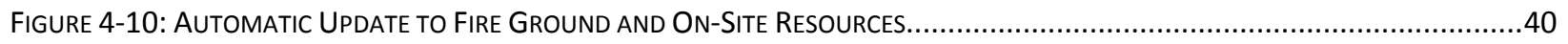

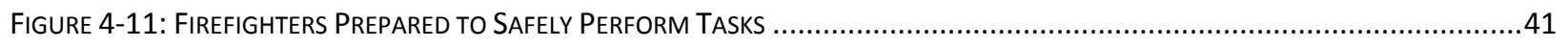

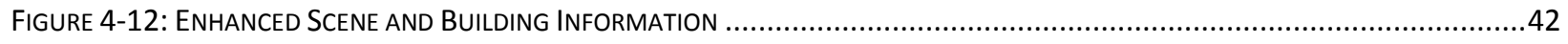

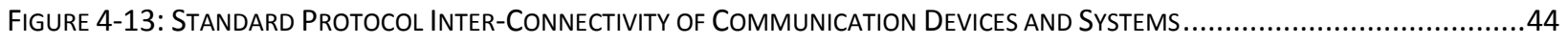

FIGURE 4-14: SITUATIONAL AWARENESS TECHNOLOGIES AND TRAINING ........................................................................45

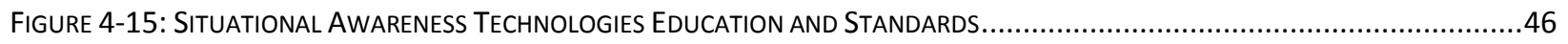

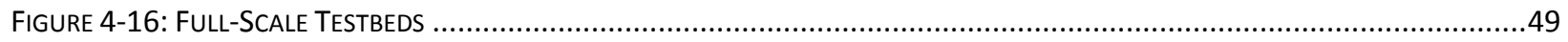

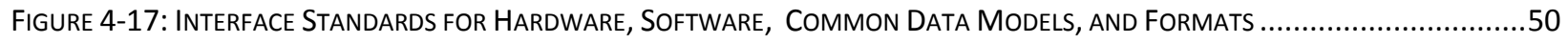

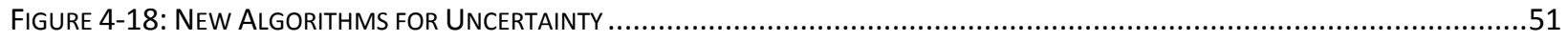

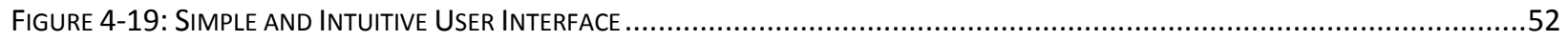

\section{List of Tables}

TAble 2-1: Data Gathering Technology Status: Before Arriving to the Fire Ground .................................................

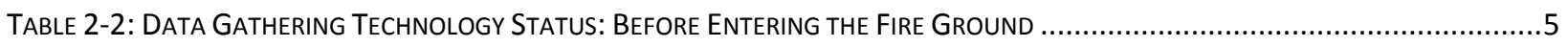

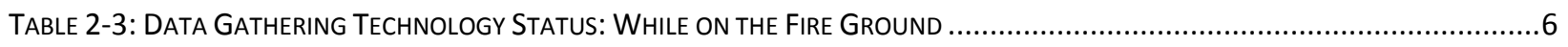

TABle 2-4: DatA Gathering Technology Status: After LeaVing FiRe Ground ...........................................................

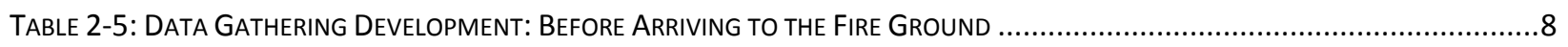

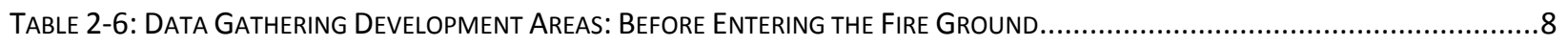

TAble 2-7: Data Gathering DeVelopment Areas: While on the Fire Ground........................................................

TABle 2-8: Data Gathering DeVelopment Areas: After Leaving Fire Ground ........................................................

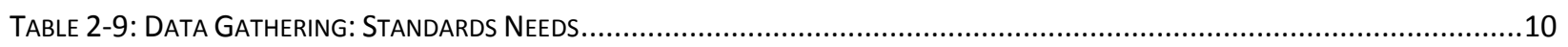

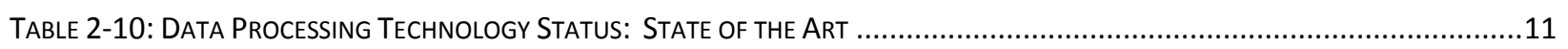

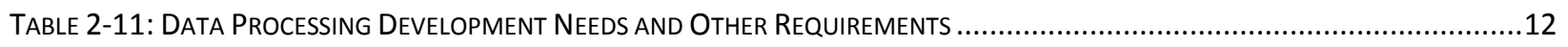

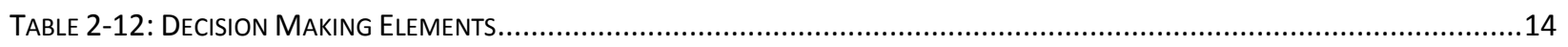

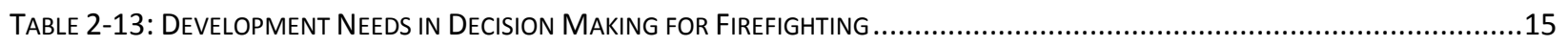

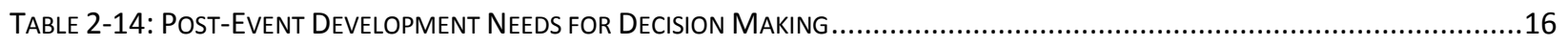

TAble 3-1: Cross-Cutting Structural Issues: CPS DeVelopment NeEdS ACross Building Structures ...............................18

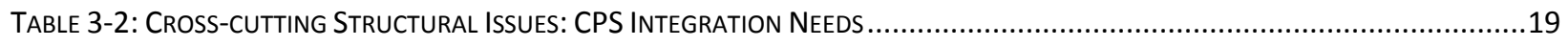

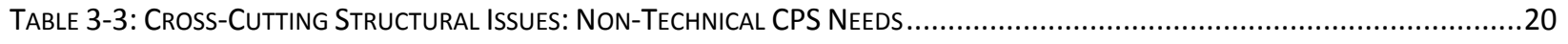

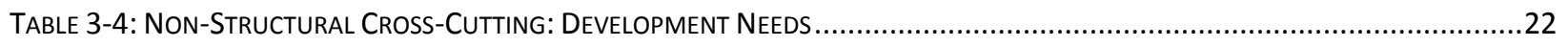

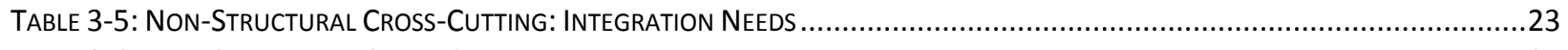

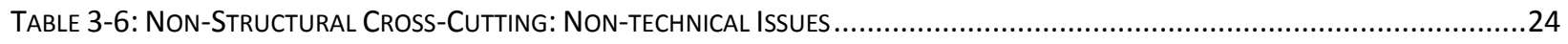

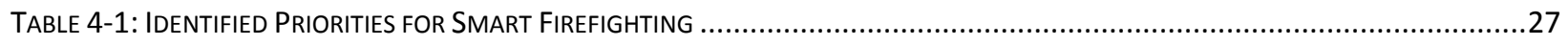

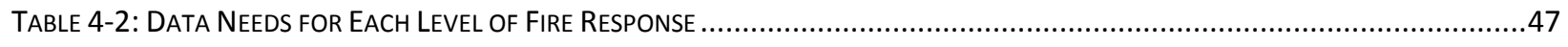

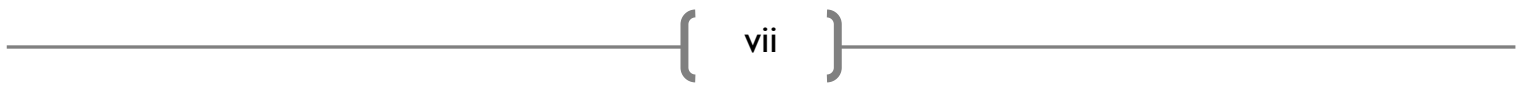


SMART FIREFIGHTING WORKSHOP SUMMARY REPORT

THIS PAGE LEFT INTENTIONALLY BLANK 


\section{Workshop Overview}

\subsection{Challenges and Opportunities for Cyber-Physical Systems, the Fire Service, and Fire Protection}

In 2012, the fire departments in the United States responded to more than $480,000^{\prime}$ structure fires. These fires resulted in approximately 2,470 civilian fatalities, 14,700 injuries, and property losses of approximately $\$ 10$ billion dollars. In addition, more than $31,000^{2}$ firefighters were injured on the fire ground. ${ }^{3}$ New opportunities to fuse emerging sensor and computing technologies with building control systems and firefighting equipment and apparatus are emerging. The resulting cyber-physical systems will revolutionize firefighting by collecting data globally, processing the information centrally, and distributing the results locally. Engineering, developing, and deploying these systems will require new measurement tools and standards among other technology developments. This project focuses on the needed tools and standards in three areas: smart building and robotic sensor technologies, smart firefighter equipment and robotic mapping technologies, and smart fire department apparatus and equipment. The results of this project will help (I) mitigate total social costs of fires in communities and buildings and (2) integrate cyber-physical systems (CPS) to realize innovative fire protection technologies.

Firefighters operate in an ever increasing sensor-rich environment that is generating vast quantities of data, the majority of which goes unused. There is ongoing research and development (R\&D) to create technologies that can better exploit the collected data and relay relevant information to emergency first responders. The "smart firefighting" of tomorrow is envisioned as fully processing collected information and transmitting germane information in a timely manner to improve the safety and functionality of every firefighter. Behind the advances in sensor performance and equipment-enhanced firefighting are profound questions of how best to enable effective use of this data deluge. The burgeoning area of CPS is an area of study that will help bridge this gap and promises to revolutionize fire protection and the field of firefighting.

This workshop is part of a collaborative effort between the National Institute of Standards and Technology (NIST) and The Fire Protection Research Foundation, (the research affiliate for the National Fire Protection Association - NFPA) to develop a research roadmap for smart firefighting. The workshop focused on addressing the most effective use of the immense quantity of data available from buildings, communities, and the fire ground; the computational power to compute and communicate that data; the knowledge base and algorithms to most effectively process the data; conversion of data into significant knowledge/beneficial decision tools; and effective communication of the information to those who need it, when they need it - on the fire ground and elsewhere.

\subsection{Workshop Scope, Objectives, Goals, and Outcomes}

The Smart Firefighting Workshop was held on March 24 and 25, 2014, in Arlington, Virginia, providing a forum to help identify and understand the R\&D needs for implementation of smart firefighting. Implementation shall be achieved through greater use of existing technologies; development and deployment of emerging technologies including CPS; and use of standards for data collection, exchange, and situational awareness tools. Furthermore, this technical area is consistent with NIST Strategic

I. NFPA, "Fire Loss in the United States During 2012," M. J. Karter, Jr., Quincy, MA, 02 169-747I, September 20I2, www.nfpa.org.

2. NFPA, "Firefighter Injuries in the United States," M. J. Karter, Jr. and J. L. Molis, Quincy, MA, 02169-747I, October 2013, www.nfpa.org.

3. In 2012 , firefighter injuries totaled 69,400 , of which 31,490 or $45 \%$ occurred on the fire ground. 
Roadmap for Innovative Fire Protection 4 . As a part of that roadmap, NIST identified smart firefighting as a research area with significant potential for enhancing the safety and effectiveness of fire protection and the fire service. This workshop complements the overarching fire research roadmap.

The following were the workshop goals:

I. Establish dialogue among subject matter experts familiar with the unique characteristics of firefighting, fire protection and CPS,

2. Promote a better understanding of data opportunities available for fire protection and the fire service, and

3. Begin to galvanize a collective vision among stakeholders for a Smart Firefighting Research Roadmap.

\subsection{Workshop Format}

The workshop brought together experts from various industry, educational, and governmental organizations involved in the cyber physical systems and firefighting areas. The workshop opened with several presentations discussing firefighting topics including integrating CPS, addressing state-of-the-art technology and techniques, and clarifying challenges. After these general presentations, participants moved into one of five smaller breakout groups to discuss various questions specific to each breakout topic. Two of the breakout groups were cross-cutting, addressing data gathering, data processing and decision making for both structural and non-structural firefighting (e.g., wildland and wildland-urban interface firefighting). The five breakout groups were as follows:

- Group I: Data Gathering

- Group II: Data Processing

- Group III: Decision Making

- Group IV: Structural Firefighting (Cross-Cutting)

- Group V: Non-Structural Firefighting (Cross-Cutting)

The specific questions addressed by each breakout session are presented in Sections 2 and 3 of this report. After brainstorming sessions, the workshop participants prioritized the previously identified research needs according to those that have the greatest potential to enhance the safety and effectiveness of fire protection and the fire service. Small groups in each breakout session selected a high-priority task and completed detailed implementation plans for them.

\subsection{Workshop Report}

This report follows the organization of the workshop. The present section provides an overview; Section 2 presents the results of Groups I, II, and III; and Section 3 presents the results of Groups IV and $\mathrm{V}$. Section 4 comprises worksheets that reflect the different questions and topics addressed by each group. Section 5 provides a brief summary of the workshop. The appendices provide additional information on the workshop, including the list of participants, a list of helpful acronyms, the workshop agenda, and copies of the overview briefings provided at the opening of the workshop.

4. NIST, "Reduced Risk of Fire in Buildings and Communities: A Strategic Roadmap to Prioritize and Guide Research,” NIST Special Publication II30, April 2012. 


\section{Integrating CPS into Fire Protection and the Fire Service}

This Section presents the results of Groups I, II, and III and addresses integrating CPS into fire protection and the fire service. The focus is on data with separate subsections on data gathering, data processing and data utilization for decision making.

\subsection{Data Gathering}

The Data Gathering breakout session focused on issues surrounding the identification, collection, and communication of data related to firefighting prediction, detection, and prevention. Discussion topics included:

- Current data gathering methodologies

- Additional types of data, data repositories, emerging data collection technologies, novel communication modes, media, protocols, and/or information standards needed to enhance safety and effectiveness

- Development of research projects and standards related to the ideas identified in the previous two bullets

These topics were discussed within the context of the four temporal phases of firefighting:

- Before arriving at the fire ground

- Before entering the fire ground

- While on the fire ground

- After leaving the fire ground

These ideas were then prioritized and fleshed out into development plans provided in Section 4 of this report.

\subsubsection{Overview and Importance of CPS for Fire Protection and the Fire Service}

Data are generated and needed throughout the temporal stages of a fire event. Access to the data could provide information to reduce the risk of fire, help firefighters assess the situation before arriving to the fire scene, detect vital changes while at the scene, and enable the compilation of lessons learned and best practices after leaving the scene. The advancement and integration of CPS can enable critical improvements in data gathering for fire protection and firefighters, which should ultimately help save lives, minimize damage, and reduce risks to firefighters.

\subsubsection{State of the Art and Shortcomings}

Many data gathering technologies and approaches are currently in use by firefighters or could be adapted for future use by firefighters. However, each technology or approach has its own shortcomings. Group I identified data gathering technologies and approaches, and their shortcomings, at the four temporal stages of the fire (noted above). For example, before arriving to the fire ground, firefighters might respond to a fire alarm or a Good Samaritan call, not knowing whether it is a false alarm or whether there are any inhabitants in the building. While on the fire ground, radio communications can provide information in real time, but they are often hindered by lack of reception and incomplete transmission. After leaving the fire ground, loss estimates are carried out, but they are not based on real data and rely on subjective information, often rendering them inaccurate. The following tables list the technologies and approaches identified during the workshop. 
TABle 2-I: DAtA GAthering Technology Status: Before ARriving to the Fire GROUND

\section{Data Identification}

Data Communication

Home smoke detectors

- Shortcomings:

- Prone to nuisance/false alarms

- Battery replacement needed

- Hard to stop

O Annoying sound

$\circ$ Retrofit interconnectivity is expensive

\section{Global positioning system} (GPS)

- Shortcoming:

- GPS not on all apparatuses

\section{Building real-time occupancy} information

- Shortcoming:

- High costs

- Technology available in few buildings because of cost

\section{Good Samaritan calls}

- Shortcomings:

○ Unspecified receiver of information

- Information often incomplete or difficult to act upon

False alarm management (aligned with environmental events)

- Shortcomings

- Response required for all calls

Fire alarm - before entering

- Shortcoming:

- Lack of information about scene

- building occupants inside

- building profile/size/height

- construction hazards

- location of hydrants

\section{Demographic data}

- Shortcomings:

- Need to specify number of inhabitants

- Need to specify age of inhabitants

- Need to specify disabilities of inhabitants

- Undefined source databases that are accessible in real time

\section{Google maps}

- Advantage:

○ Building foot print provided

- Shortcoming:

- Not real-time data

- Resolution limited

Building environment data (e.g., temperature, $\mathrm{CO}_{2}$, humidity)

- Shortcoming:

- Available data trapped within building systems

\section{Smoke alarm data}

- Shortcomings:

- Difficult to identify location of first alarm

- Obstacles in accessing the alarm location

\section{Large database}

- Shortcomings:

○ Difficult to integrate multiple databases

- Expensive to populate

- Difficult to change structure once implemented

\section{Information from 9 I I caller}

- Shortcoming:

- Not always coherent or accurate

Computer Aided Dispatch (CAD) mobile data computer (MDC)

- Shortcomings:

- Attention diverted to paper chart

- Pop-up screens

\section{Building fire system data}

- Shortcomings:

- Non-standard delivery mechanisms

o Non-standard display formats

Emergency situation user training

- Shortcomings:

O Inconsistent quality

- Non-standard frequency

\section{Vehicle crash data}

- Shortcomings:

- Data privacy issues

o Transmit format compatibility 


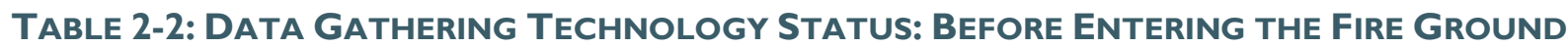

\begin{tabular}{|c|c|c|}
\hline Data Collection & Data Identification & Data Communication \\
\hline $\begin{array}{l}\text { Building history } \\
\text { - Shortcoming: } \\
\circ \text { Data usually not current } \\
\text { In situ sensors } \\
\text { - Shortcomings: } \\
\circ \text { Information versus data } \\
\circ \text { Undefined performance } \\
\text { standards } \\
\circ \text { Common syntax not specified } \\
\circ \text { Non-existent interface } \\
\text { standards } \\
\text { Equipment status (e.g., } \\
\text { condition of communications, } \\
\text { sensors, and building } \\
\text { equipment) } \\
\text { - Shortcomings: } \\
\circ \text { Building retrofit for enhanced } \\
\text { CPS not economical } \\
\circ \text { System overloaded } \\
360^{\circ} \text { assessment } \\
\text { - Shortcoming: } \\
\circ \text { Physical obstruction hazards }\end{array}$ & $\begin{array}{l}\text { Data hierarchy } \\
\text { - Shortcoming: } \\
\text { O Unclear how to prioritize }\end{array}$ & $\begin{array}{l}\text { Commercial high-rise } \\
\text { - Shortcomings: } \\
\text { ○ Lack of fire panel } \\
\text { integration with building } \\
\text { management system (i.e., } \\
\text { cannot be read on route) } \\
\text { Data accuracy of alarm } \\
\text { information (e.g., zone, } \\
\text { floor, number of alarms) }\end{array}$ \\
\hline
\end{tabular}




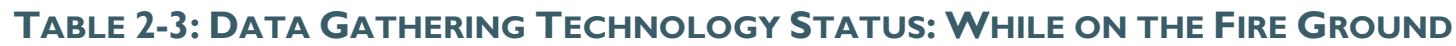

\begin{tabular}{|c|c|c|}
\hline Data Identification & Data Collection & Data Communication \\
\hline $\begin{array}{l}\text { Visual inspection } \\
\text { - Shortcoming: } \\
\text { o Incomplete information } \\
\text { collected } \\
\circ \text { Poor level of accuracy }\end{array}$ & \multirow{2}{*}{$\begin{array}{l}\text { Bystanders/victims } \\
\text { - Shortcoming: } \\
\circ \text { Difficult to interpret data } \\
\text { Physiological robust sensors } \\
\text { and wireless communications } \\
\text { - Shortcomings: } \\
\circ \text { Inadequate sensors } \\
\circ \text { Unable to determine firefighter } \\
\text { location } \\
\circ \text { Need wireless communications } \\
\circ \text { Need to improve environmental } \\
\text { hazard identification }\end{array}$} & $\begin{array}{l}\text { Electronic } \\
\text { communications } \\
\text { - Shortcomings: } \\
\circ \text { Lack of interoperability } \\
\circ \text { Lack of operation } \\
\text { (reception transmission) }\end{array}$ \\
\hline \multirow[t]{2}{*}{$\begin{array}{l}\text { Threat sensing (e.g., } \\
\text { smoke/heat detection, } \\
\text { bio/chemical attack, active } \\
\text { shooter) } \\
\text { - Shortcomings: } \\
\circ \text { Difficult to integrate existing } \\
\text { data } \\
\circ \text { Unable to predict }\end{array}$} & & \multirow[t]{6}{*}{$\begin{array}{l}\text { Voice communications } \\
\text { - Advantage: } \\
\circ \text { Able to convey information } \\
\text { in real time } \\
\text { - Shortcomings: } \\
\circ \text { Incomplete transmission }\end{array}$} \\
\hline & \multirow[b]{2}{*}{$\begin{array}{l}\text { Web-based data } \\
\text { communications } \\
\text { - Shortcomings: } \\
\circ \text { Access not available in remote } \\
\text { areas } \\
\circ \text { Difficult to protect data } \\
\circ \text { No access during widespread } \\
\text { power outage }\end{array}$} & \\
\hline \multirow[t]{4}{*}{$\begin{array}{l}\text { Rapid intervention team } \\
\text { (RIT) } \\
\text { - Shortcoming: } \\
\circ \text { Difficult to locate firefighter } \\
\circ \text { Lack of tools for personal } \\
\text { protective equipment (PPE) } \\
\text { selection and use for multi- } \\
\text { hazard response }\end{array}$} & & \\
\hline & $\begin{array}{l}\text { Command chart } \\
\text { - Shortcomings: } \\
\circ \text { User-generated } \\
\circ \text { Unit/firefighter accountability }\end{array}$ & \\
\hline & $\begin{array}{l}\text { Firefighter physiological } \\
\text { monitoring } \\
\text { - Shortcomings: } \\
\circ \text { High cost } \\
\circ \text { Need to protect } \\
\text { information/privacy }\end{array}$ & \\
\hline & $\begin{array}{l}\text { Infrared camera and thermal } \\
\text { imaging } \\
\text { - Shortcomings: } \\
\circ \text { Limited information provided } \\
\circ \text { Information often misunderstood }\end{array}$ & \\
\hline
\end{tabular}

Table 2-4: DAta Gathering Technology Status: After Leaving FiRe Ground

\begin{tabular}{|l|l|l|}
\hline \multicolumn{1}{|c|}{ Data Identification } & \multicolumn{1}{|c|}{ Data Collection } & \multicolumn{1}{|c|}{ Data Communication } \\
\hline \begin{tabular}{l|l} 
Loss estimates \\
- Shortcomings:
\end{tabular} & $\begin{array}{l}\text { Fire reports } \\
\text { - Shortcoming: } \\
\text { O Subjective }\end{array}$ & $\begin{array}{l}\text { Lessons learned in digital } \\
\text { format }\end{array}$ \\
$\begin{array}{l}\text { Inaccurate } \\
\text { O Not based on data }\end{array}$ & & $\bullet$ Shortcomings: \\
\end{tabular}




\subsubsection{Development Areas}

One of the most critical data gathering needs before arriving to the fire ground is the ability to obtain more accurate real-time information about the alarm/situation. Critical information could include the building's layout, contents, and number of occupants, as well as standards for fire system data delivery, information display, data integration, and testing. While standardization increases the likelihood of technology adoption, it must be done thoughtfully so as to not restrict innovation and creativity.

Before entering the fire ground, it would be beneficial to have data from a $360^{\circ}$ autonomous situation assessment. Various technology applications could address this need including possibly unmanned vehicles.

While on the fire ground, key developments could include wireless, wearable, rugged, and robust environmental sensors. These sensors could be used to track firefighters at the incident site, providing real-time locations of responders and critical information during firefighter-down events, including data on the building's thermal environment.

After leaving the fire ground, there is a need for operational databases that provide automated data management and reporting systems such as the National Fire Operations Reporting System (N-FORS), which is currently under development. N-FORS is used to manage the National Fire Plan, a mandated program begun in $200 \mathrm{I}$ to provide accountability for hazardous fuels reduction, burned area rehabilitation projects, and community assistance activities. ${ }^{5}$

Additional concepts are presented in Tables 2-5 to 2-8.

\footnotetext{
${ }^{5}$ National Fire Plan Operations \& Reporting System - http://www.doi.gov/pmb/owf/nfpors.cfm.
} 
TABle 2-5: DAtA GATHering DeVelopment AREAS: Before ARriving to the Fire GROUND6

\section{Additional Data Needs}

- More real-time information about situation (e.g., sensors, live video) $\bullet \bullet \bullet \bullet \bullet \bullet \bullet \bullet \bullet \bullet$

- More information about building contents

- Data/sensors in residential dwelling units versus commercial units (e.g., cost, privacy)

- Estimates of staffing needs for large-scale events in terms of workload/rehabilitation to estimate appropriate operational periods

\section{Desired Data Collection \\ Technologies}

- Improved decision making (automatic or assisted) to alleviate valuable time lost as data are gathered (e.g., location of the fire) and firefighting strategy is developed

- Development of real-time notification of out-of-service system (e.g., alarm, sprinkler, standpipe, smoke control)

\section{Desired Novel Collection}

Modes/Information Standards

- Development of standards for fire system data delivery and information display $\bullet \bullet \bullet \bullet$

- Integration and testing of protocols and standards

- Standard emergency application for centralized/standardized information gathering (i.e., people report from the field with text, audio, images, etc.) •

- Ability to quickly identify vehicle propulsion system (i.e., fuel) on scene

- Development of building design for fire safety $\bullet$

- Enforcement of existing technology (e.g., sprinklers)

TABle 2-6: DAtA Gathering DeVelopment AREAS: Before ENTERING the FiRe Ground

\begin{tabular}{|c|c|c|}
\hline Additional Data Needs & $\begin{array}{c}\text { Desired Data Collection } \\
\text { Technologies }\end{array}$ & $\begin{array}{c}\text { Desired Novel Collection } \\
\text { Modes/lnformation } \\
\text { Standards }\end{array}$ \\
\hline $\begin{array}{l}\text { Develop risk-benefits analysis } \\
\text { based on occupancy type, } \\
\text { building age, construction type, } \\
\text { hazards, fire conditions }\end{array}$ & $\begin{array}{l}\text { - Improve sensor accuracy } \\
\text { completeness } \\
\text { ○ Affordable } \\
\text { o Rugged } \\
\text { - Build } 360^{\circ} \text { autonomous situation } \\
\text { assessment with unmanned aerial } \\
\text { vehicle } \\
\text { - Improve building occupant sensors } \\
\text { for residential/ commercial units }\end{array}$ & - None provided \\
\hline
\end{tabular}

\footnotetext{
${ }^{6}$ Note: In this and subsequent tables, each colored dot represents a participant-identified CPS priority with the greatest potential to benefit the fire service.

- Blue represents a CPS participant vote.

- Green represents a firefighter participant vote.

- Orange represents an industry participant vote.

- Red represents a government participant vote.

- Yellow represents a research participant vote.
} 
TABLE 2-7: DATA GATHERING DeVELOPMENT AREAS: WhILE ON THE FIRE GROUND

\begin{tabular}{|c|c|c|}
\hline Additional Data Needs & $\begin{array}{c}\text { Desired Data Collection } \\
\text { Technologies }\end{array}$ & $\begin{array}{c}\text { Desired Novel Collection } \\
\text { Modes/lnformation } \\
\text { Standards }\end{array}$ \\
\hline $\begin{array}{l}\text { - People tracking, site incident } \\
\text { tracking (e.g., real-time location } \\
\text { of responders, man-down } \\
\text { events) } \\
\text { - Vertical and horizontal geo- } \\
\text { location for radios to track } \\
\text { firefighters } \\
\text { - Sensors for key task, data } \\
\text { capture } \\
\text { o Working on fire (WoF) } \\
\text { o Victim requirements } \\
\text { o Vent } \\
\text { - Sensors/data capture } \\
\text { o Vehicle } \\
\text { o Pump engaged } \\
\text { - Water flowing/not flowing } \\
\text { Asset tracking (e.g., fire } \\
\text { respondent equipment) } \\
\text { o Correlation to individual user } \\
\text { o Real-time location } \\
\text { notification } \\
\text { O Open standards base } \bullet\end{array}$ & $\begin{array}{l}\text { Wireless, wearable, and robust } \\
\text { environmental sensors } \\
\text { - Algorithms for translating sensor } \\
\text { data into useable information, } \\
\text { validation of data } \\
\text { - Real-time and recorded knowledge } \\
\text { of firefighter thermal environment } \\
\text {. }\end{array}$ & $\begin{array}{l}\text { - Standards development } \\
\text { o Allow for innovation before } \\
\text { premature standardization } \\
\text { o Define interoperability versus } \\
\text { reliability while considering } \\
\text { proprietary technology } \\
\text { - Development of nationwide } \\
\text { reliable emergency wireless data } \\
\text { communications infrastructure } \\
\text { - }\end{array}$ \\
\hline
\end{tabular}

TABle 2-8: DAtA GAThering DeVelopment Areas: After Leaving Fire Ground

\begin{tabular}{|c|c|c|}
\hline Additional Data Needs & $\begin{array}{c}\text { Desired Data Collection } \\
\text { Technologies }\end{array}$ & $\begin{array}{c}\text { Desired Novel Collection } \\
\text { Modes/lnformation } \\
\text { Standards }\end{array}$ \\
\hline $\begin{array}{l}\text { - Ability to detect whether } \\
\text { firefighter's PPE needs attention/ } \\
\text { cleaning } \\
\text { - Ability to detect whether PPE is } \\
\text { contaminant-free after cleaning }\end{array}$ & $\begin{array}{l}\text { - Expand N-FORS approach } \\
\text { O Integrate other systems such as } \\
\text { Department of Homeland } \\
\text { Security (DHS)/ Federal } \\
\text { Emergency Management Agency } \\
\text { (FEMA) } \\
\text { O Increase automatic capture of } \\
\text { operational data } \\
\text { - Appropriate data density }\end{array}$ & $\begin{array}{l}\text { - Improved interoperability of } \\
\text { data systems }\end{array}$ \\
\hline
\end{tabular}

\subsubsection{Other Research Needs}

The integration of data gathering CPS in smart firefighting is hindered by a lack of standards (Table 2-9). The most critical standards needs are for data sharing. Other important standards needs include wireless sensor protocols to connect wireless sensor networks, operational data about fire department performance metrics, and a common fire panel protocol. When arriving at the fire ground, firefighters could benefit from information about a building or residence, such as the number of occupants and any mobility issues. Standards are also needed to protect the privacy of personal information. 
TABLE 2-9: DATA GATHERING: STANDARDS NEEDS

\section{Areas of Development}

- Data sharing standards $\bullet \bullet \bullet \bullet \bullet \bullet \bullet \bullet$

- Wireless sensor protocols for connecting wireless sensor networks $\bullet \bullet$

- Operational data (e.g., fire department performance metrics) ••

- Common fire panel protocol including physical connection

- Networked sensor performance standards

- Hygiene and structural standards of fire stations to improve response time

- Fire data communications equipment standards

- Privacy of personal/home data and security standards

- Fire department capability standards

\subsubsection{Priorities}

Of the identified needs for data gathering in Tables 2-5 to 2-9, the following eight were identified as the most important. The items in italics were selected for further elucidation as part of the program plans discussed in Section 4.

- Real-time situational sensors with video

- Wearable, wireless, robust environmental sensors

- People tracking efforts at the incident site

- Asset tracking

- Data sharing standards

- Improvements to N-FORS: DHS/FEMA; operational data

- Standard for fire system data delivery and information display

- Standards development for data gathering

\subsection{Data Processing}

The Data Processing session focused on issues surrounding the handling of data collected for firefighting prediction, detection, and prevention. Discussion topics included:

- Current data processing methodologies for translation, sensor fusion, data preparation, and data analytics

- Needs in data translation, sensor fusion, data preparation, and data analytics to augment firefighter response to an event

- Development of research projects and standards related to the ideas identified in the previous two bullets

The topics above were discussed within the context of the four phases of data processing:

- Protocol translation

- Sensor fusion

- Data preparation

- Data analytics

These ideas were then prioritized and fleshed out into development plans.

\subsubsection{Overview and Importance for CPS and Fire Service}

The integration and accurate analysis of data could provide invaluable information to firefighters to enhance overall operations, incident response, and safety. Sensor data from equipment (e.g., PPE, 
unmanned vehicles, fire trucks) could assist the coordination of manpower and equipment location, improve real-time decision making, and simplify operations and maintenance. Comprehensive preplanning could be enhanced with advance information provided to firefighters and incident commanders. Detailed analysis of the collected data could also improve predictive abilities (e.g., likely fire events, active fire path and spread rate, and medical issues with firefighters).

\subsubsection{State of the Art and Shortcomings}

Currently, a significant amount of data are gathered and processed by individual systems/equipment, creating processing "silos." Though this works for a specific application, it often presents difficulties when attempting to communicate/work with disparate systems. This limitation can restrict operations on the fire ground where data are usually processed by the firefighter in real time, resulting in many dead-end data points. Integrating the data into a data stream could improve decision making, incident management, or post-event analysis.

Equipment interoperability is also complicated by receiving outputs in both digital and analog formats within a single firehouse, fire district, or region. Since most firehouse and emergency dispatch communications systems grew out of CAD-based systems, CAD is the backbone of most systems and is the primary platform for protocol translation. Some issues with the traditional hardware used for data processing include filtering out noise in the data and developing devices that are rugged enough to reliably transmit data in and out of harsh environments. Both development and enforcement of codes and standards heavily influence the technology that is developed and implemented.

Additional state of the art of data processing concepts and their shortcomings are presented in Tables 2-10.

\section{Table 2-I0: Data Processing Technology Status: State of the ART}

\begin{tabular}{|c|c|c|}
\hline Interoperability & Protocol Translation & Data Accuracy \\
\hline $\begin{array}{l}\text { - Much of the equipment has limited } \\
\text { interoperability. } \\
\text { - There are many "dead end" data } \\
\text { points - useful data that are not } \\
\text { getting streamed anywhere. } \\
\text { - A combination of both digital and } \\
\text { analog outputs exists. } \\
\text { - Implementation of technology is } \\
\text { building-code driven. } \\
\text { - Much of the data are processed at } \\
\text { the human level (on site at the fire). }\end{array}$ & $\begin{array}{l}\text { - Legacy systems are often used- } \\
\text { CAD is the backbone of most } \\
\text { systems. } \\
\text { - Data are processed in silos, not } \\
\text { toward solving a specific } \\
\text { problem. } \\
\text { - Pre-processing could be done } \\
\text { ahead of time but is scenario- } \\
\text { driven. }\end{array}$ & $\begin{array}{l}\text { - Building information (e.g., interior } \\
\text { schematics) is often out of date. } \\
\text { - Better data are needed on } \\
\text { explosive limits and temperatures. }\end{array}$ \\
\hline
\end{tabular}

\subsubsection{Development Areas}

The primary goal of data processing for smart firefighting should be producing actionable intelligence before, during, and after an incident. This means that data must be compiled, processed, and communicated in such a way that they are accessible, understandable, and actionable at various operating levels (e.g., firefighter, chief, incident commander, dispatchers) and phases (e.g., before the fire, on the fire ground, after the fire). Since firefighting events are scenario-driven, this will require the development of use case models as a framework for data analysis, providing frameworks to process data in the context of solving problems rather than in silos.

Producing meta models that integrate data and provide equipment and system interconnectivity and interoperability will require common data communication languages, standard formats for reporting and storing data, and a comprehensive data dictionary. While standardization and open-source tools are 
desired from a data processing standpoint, care must be taken not to inhibit technology innovation or violate data privacy concerns. Data processing frameworks must also incorporate systems to verify the validity and authenticity of the data, since the reliability and trustworthiness of the inputs and outputs is crucial to firefighting operations. Table 2-II identifies other development needs.

TAble 2-I I: Data Processing DeVelopment Needs and Other ReQuiRements

\begin{tabular}{|c|c|c|c|}
\hline Use Case Models & Data Standardization & Research & Other Requirements \\
\hline $\begin{array}{l}\text { - Produce "actionable } \\
\text { intelligence" } \\
\text { - Identify key } \\
\text { indicators for } \\
\text { dashboards or } \\
\text { command boards } \\
\text { - Make data } \\
\text { "consumable" at } \\
\text { various levels (e.g., } \\
\text { chief, firefighter) } \\
\text { - Define minimum cut } \\
\text { sets of data type and } \\
\text { reliability needed to } \\
\text { inform IC decisions } \\
\text { based on scenario } \\
\text { - Develop use models } \\
\text { as framework for } \\
\text { data analysis } \\
\text { - Define relevant data } \\
\text { for event type } \\
\text { - Explore options and } \\
\text { consequences }\end{array}$ & $\begin{array}{l}\text { - Define standard data and } \\
\text { format } \\
\text { - Investigate pre-event } \\
\text { data needs (e.g., common } \\
\text { language, reporting, and } \\
\text { storage protocols) } \\
\text { - Develop data } \\
\text { management (e.g., data } \\
\text { dictionaries and } \\
\text { standards/protocols) } \\
\text { - Define an approach to } \\
\text { standardize the input and } \\
\text { output of the data } \\
\text { protocols and databases } \\
\text { - Define plain text non- } \\
\text { proprietary data formats } \\
\text { - Establish common } \\
\text { formats to address } \\
\text { location accuracy (e.g., } \\
\text { national grid) }\end{array}$ & $\begin{array}{l}\text { - Create a "Center for } \\
\text { Fire Fighting } \\
\text { Excellence" as a } \\
\text { central resource } \\
\text { standardized, } \\
\text { shared analytical } \\
\text { tools } \\
\text { Conduct analysis of } \\
\text { post-fire data and } \\
\text { lessons learned } \\
\text { Develop models that } \\
\text { are self-configurable } \\
\text { - Develop technology } \\
\text { for tracking and } \\
\text { allocating assets (e.g., } \\
\text { across region, state) }\end{array}$ & 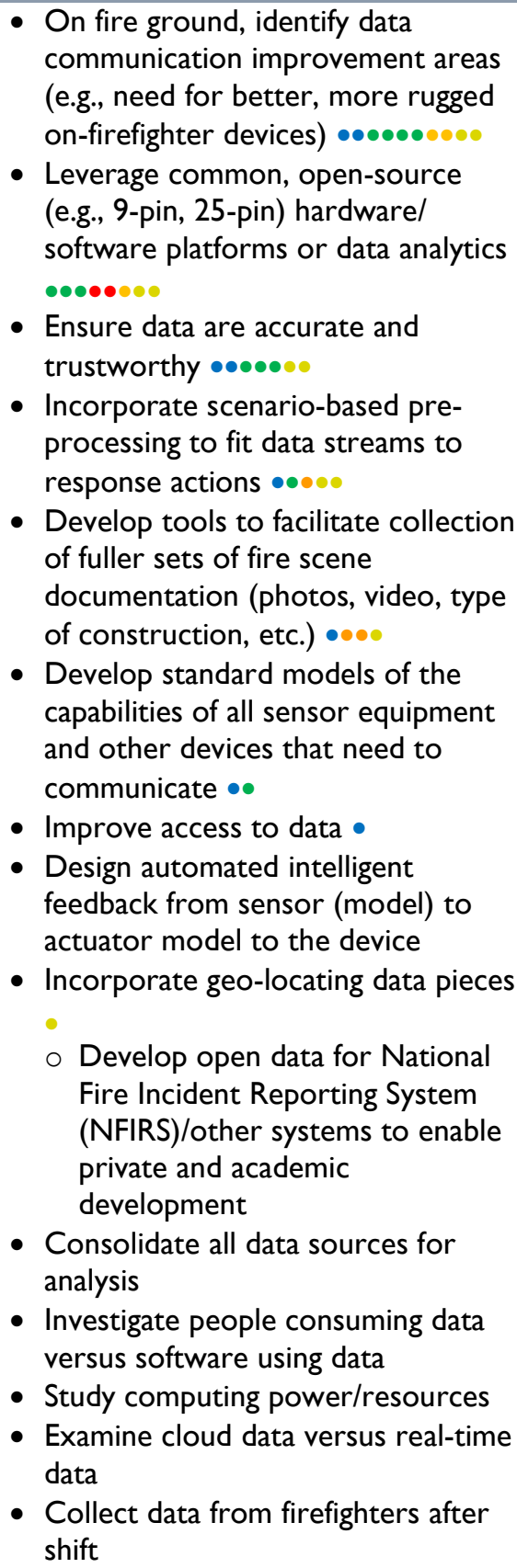 \\
\hline
\end{tabular}




\subsubsection{Priorities}

Of the identified needs for data processing in Table 2-I I, the following six were identified as the most important. Those fleshed out into program plans later in Section 4 are in italics.

- Use case models

- Data standardization for data processing

- Center for firefighting excellence

- On fire ground, identify data communication improvement areas (e.g., need for better, more rugged on-firefighter devices)

- Leverage common, open-source (e.g., 9-pin, 25-pin) hardware/ software platforms or data analytics

- Ensure data is accurate and trustworthy

\subsection{Decision Making}

The Decision Making breakout session focused on issues surrounding the people, technology, and data involved in executing an action or behavior before and during an incident and in post-incident evaluation. Discussion topics included:

- Identification of the types of required decisions, decision makers, and input data for the first three temporal phases below

- Decision making development needs to advance firefighting techniques in the first three temporal phases below

- Identification of current and future capabilities needed to capture all fire-related events that transpired on the fire ground for after-action evaluation and training purposes

Discussion of the topics above was initially intended to cover the four temporal phases of firefighting:

- Before arriving to the fire ground

- Before entering the fire ground

- While on the fire ground

- After leaving the fire ground

However, after considering relevance to the incident commander versus individual firefighters, the discussion topics were adjusted to the needs for decision making in firefighting in general.

The collected ideas were then prioritized and fleshed out into development plans.

\subsubsection{Overview and Importance for CPS and Fire Service}

Good decision making in firefighting is crucial to safe and effective firefighting efforts-it could be the difference between safe and dangerous operations. Decision making is affected by many factors, including the data available to decision makers, effectiveness of decision protocols, and expertise of decision makers.

\subsubsection{State of the Art and Shortcomings}

The crucial elements - the types of decisions that must be made, who makes them, and the data that are needed to make decisions - currently used in fire-incident decision making were identified (Table 2-I2). Many of these ideas possess limitation in their ability to contribute to effective decision making during a fire event. 
TABLE 2- I2: Decision MAKINg ElementS

\begin{tabular}{|c|c|c|}
\hline In General & Incident Commander & Firefighter \\
\hline $\begin{array}{l}\text { - Constant updating of fire ground } \\
\text { incident information to all } \\
\text { responding parties } \\
\text { - Natural focus on firefighting activity } \\
\text { O Alarm } \\
\text { o On-scene } \\
\text { o Suppression } \\
\text { O Information overload } \\
\text { - Pre-response planning needs to be } \\
\text { in place to focus on } \\
\text { O Preplan } \\
\text { O Demographics } \\
\text { O Construction } \\
\text { O Route }\end{array}$ & 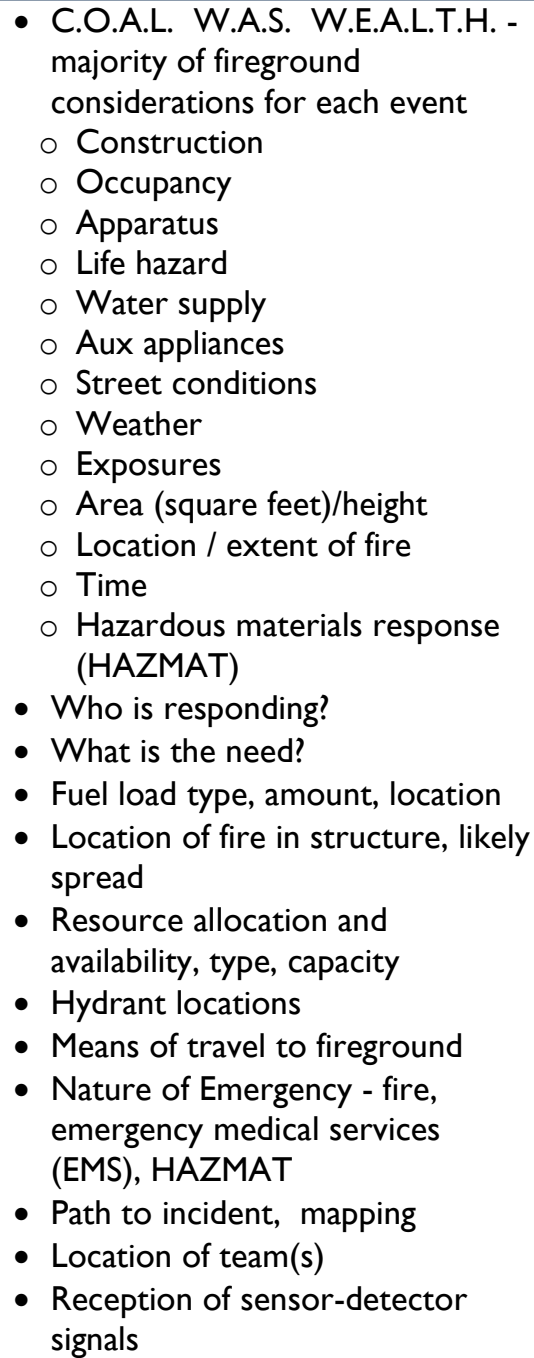 & $\begin{array}{l}\text { - Determination of the need for } \\
\text { additional resources } \\
\text { - Fire spread-characterization } \\
\text { of the potential for rapid fire } \\
\text { movement and follow-up } \\
\text { action } \\
\text { - Training in assessment and } \\
\text { responses to different fire } \\
\text { conditions }\end{array}$ \\
\hline
\end{tabular}

\subsubsection{Development Areas}

The primary goal of decision making is determining needed actions before and during an incident based on the collection and analysis of available data. The development needs for improving decision making include developing opportunities for providing richer, more comprehensive information to existing data collection methods. For example, enhanced capabilities to determine topography or ventilation conditions during an incident could enhance safety and effectiveness of firefighting efforts. Table 2-I3 identifies the types of information that needs collection in order to augment decision making during fire incidents. 
TABLe 2-I3: DeVelopment NeEdS In DeCISION MAKING fOR FiREFIGHTING

\begin{tabular}{|c|c|c|c|}
\hline \multicolumn{4}{|c|}{ General Development Needs } \\
\hline $\begin{array}{l}\text { - Accountability } \\
\text { - Determination of floor } \\
\text { - Threat identification } \\
\text { - Education of a new } \\
\text { generation of firefighters } \\
\text { - Effective and timely use } \\
\text { of gathered data } \\
\text { - Clearly defined } \\
\text { communication } \\
\text { networks, including } \\
\text { points of contact } \\
\text { - Identification of unseen } \\
\text { hazards } \\
\text { - Improvement of all } \\
\text { levels of } \\
\text { communications on the } \\
\text { fireground } \bullet \bullet \bullet \bullet \bullet \bullet \bullet \bullet \bullet \bullet\end{array}$ & $\begin{array}{l}\text { - Ventilation conditions } \\
\text { - Performance of risk } \\
\text { assessments to } \\
\text { determine what or } \\
\text { who is at risk } \\
\text { - Safety of firefighters, } \\
\text { fire team, fire ground } \\
\text { - Development of } \\
\text { toxicant sensors to } \\
\text { make a decision when } \\
\text { to remove self- } \\
\text { contained breathing } \\
\text { apparatus (SCBA) } \\
\text { during overhaul } \\
\text { - Establishment of data, } \\
\text { cues, and expectations } \\
\text { that support offensive } \\
\text { versus defensive fire } \\
\text { fighting } \\
\text { - Integrated simplicity } \\
\text { - Resource management } \\
\text { - Determine the human } \\
\text { computer interface } \\
\text { (HCI) to present right } \\
\text { data at right time in } \\
\text { right format to make } \\
\text { right decision } \bullet \\
\text { - }\end{array}$ & 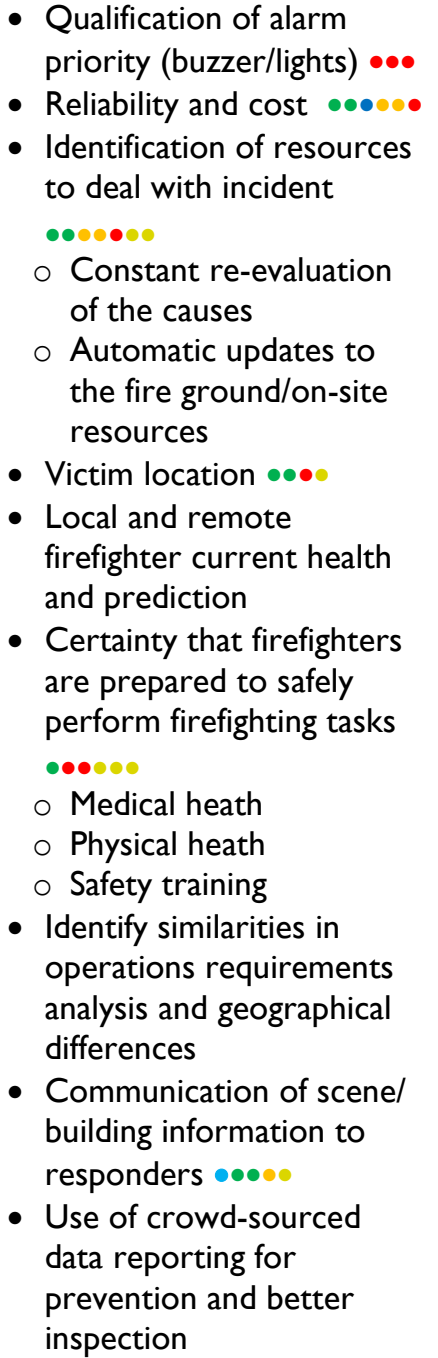 & $\begin{array}{l}\text { - Critical factors- } \\
\text { based decision } \\
\text { making }\end{array}$ \\
\hline
\end{tabular}

\subsubsection{Other Research Needs}

After a fire event is complete, evaluation of the incident helps to identify lessons learned. Some capabilities exist to capture the relevant fire-related events and actions. Yet numerous other ones need development to support comprehensive after-action evaluation for incident review and training purposes. Table 2-14 identifies those capabilities currently available and development needs for a better understanding of the fire incident. 
Table 2-I4: Post-Event DeVelopment Needs for Decision Making

\begin{tabular}{|c|c|}
\hline Available Now & Development Needed \\
\hline $\begin{array}{l}\text { - Google Earth } \\
\text { - Reports from the fire scene } \\
\text { - Log of all alarms, data exchanges, tracker } \\
\text { (current technology needs further } \\
\text { development) }\end{array}$ & $\begin{array}{l}\text { - Data gathering black box data } \\
\text { - Rideo capabilities for on the ground (incident review) } \\
\text { - Simulation for incident commanders can be designed } \\
\text { now } \\
\text { o Simulation for firefighters will take significantly more } \\
\text { computing power } \\
\text { - Provide feedback from reports (e.g., lessons learned now, } \\
\text { simulations in the future) } \\
\text { - Current building target hazard } \\
\text { o Occupancy and configuration } \\
\text { - Contents } \\
\text { - Criteria to determine firefighter fitness for service } \\
\text { - Physical health } \\
\text { - Resource allocation } \\
\text { - Medical health monitoring post-event } \\
\text { - Physiology } \\
\text { - Safety } \\
\text { - Incident simulations }\end{array}$ \\
\hline
\end{tabular}

\subsubsection{Priorities}

Of the identified needs for decision making in Tables $2-13$ to 2-14, the following eight were identified as the most important. Those fleshed out into program plans in Section 4 are noted in italics.

- Data gathering black box (like an airplane)

- Effective and timely use of collected data

- All levels of communication on the fire ground

- Automatic updates to fire ground and on-site resources

- Firefighters prepared to safely perform tasks

- Enhanced scene and building information

- Accountability

- Reliability and cost 


\section{Structural and Non-Structural Cross-Cutting Topics}

This Section presents the results of Groups IV and V. These groups considered integrating CPS into fire protection and the fire service from a cross-cutting perspective associated with both structural and nonstructural firefighting approaches.

\subsection{Cross-Cutting Structural Firefighting Issues}

The Structural Firefighting breakout session focused on the shared CPS requirements to advance firefighting effectiveness on buildings and other constructions. The participants discussed and identified ideas related to the following focus topics:

- Common CPS development needs for firefighting in commercial versus urban residential buildings and new versus retrofitted (existing) buildings

- Issues with CPS integration into structural firefighting techniques with respect to codes and standards, software technologies, feasibility demonstration, and implementation strategies

- Non-technical issues (e.g., training, economic issues, standards and codes processes, market trends, behavioral issues) that affect successful integration of CPS into structural firefighting capabilities

The collected ideas were then prioritized and fleshed out into development plans provided in Section 4 of this report.

\subsubsection{Overview and Importance for CPS and Fire Services in Structure Fires}

Whereas residential structural fires account for $25 \%$ of fires in the United States, $83 \%$ of civilian fire deaths are due to fires within a residential structure. In addition, $77 \%$ of fire injuries and $64 \%$ of direct dollar losses are also due to fires within residential structures. ${ }^{7}$ In total, structural fires (both residential and commercial) account for only $35 \%$ of reported U.S. fires, ${ }^{8}$ but the human and property losses associated with these events make development of smart firefighting techniques in building structures an important area of attention. As firefighting and CPS leaders determine how best to effectively use the immense quantity of data available concerning and from building structures, a focus must be given to enriching such a typically information-poor environment as a structural fire. Through targeted CPS technologies, firefighters can take advantage of previously non-existent opportunities, tracking data on characteristics such as thermal and smoke conditions within a structure during a fire, to better inform the firefighting decision making process. While significant research issues remain, exploiting CPS in structural firefighting strategies remains a major focus of upcoming research and practice.

\subsubsection{Common CPS Development Needs}

Table 3-I displays the CPS needs across different types of building structures during a fire event. The requirements for a specific building type are also presented.

\footnotetext{
${ }^{7}$ U.S. Fire Administration, "Residential Structure and Building Fires," October 2008, https://www.usfa.fema.gov/downloads/pdf/statistics/Residential_Structure_and_Building_Fires.pdf.

${ }^{8}$ NFPA, "Fire Loss in the United States During 2012," M. J. Karter, Jr., Quincy, MA, September 2013, http://www.nfpa.org/ /media/Files/Research/NFPA\%20reports/Overall\%20Fire\%20Statistics/osfireloss.pdf.
} 
TAble 3-I: Cross-Cutting Structural Issues: CPS DeVelopment Needs ACross BUILDING STRUCTURES

\begin{tabular}{|c|c|}
\hline $\begin{array}{l}\text { Building } \\
\text { Type }\end{array}$ & CPS Development Needs \\
\hline $\begin{array}{l}\text { Structural } \\
\text { Cross-Cutting } \\
\text { Needs }\end{array}$ & $\begin{array}{l}\text { - Improve the understanding of structures and fire } \\
\text { - Gather data to rectify the lack of existing information available in older infrastructure } \\
\text { - Establish communications networks between firefighter and building } \\
\text { - Enhance the limited ability for building owners to invest in new systems } \\
\text { - Increase knowledge on building populations } \\
\text { - Build models to predict fires in structures based on their conditions } \\
\text { - Develop a building information model with easy access via mobile devices } \\
\text { - Eliminate barriers to indoor communication and location determination (lack of connection) } \\
\text { - Improve sensors in PPE to sense environment } \\
\text { - Remove reliance on human uploading data to network database infrastructure } \\
\text { - Develop software to help people see through smoke to egress paths } \\
\text { - Develop method to monitor exits - all aspects } \\
\text { - Provide real-time access to private or protected information within building structure } \\
\text { - Improve interoperability of different systems } \\
\text { - Present and disseminate clear information } \\
\text { - Integrate sensor electronics/hardware in firefighter PPE, considering sensor weight and cost } \\
\text { - Develop tampered/unbiased sensors } \\
\text { - Piggyback communications and standalone network } \\
\text { - Develop self-learning networks to provide reliable data after an incident and provide } \\
\text { - Predundancy } \\
\text { - Update training and education using CPS in firefighting strategies }\end{array}$ \\
\hline $\begin{array}{l}\text { Commercial } \\
\text { Building Needs }\end{array}$ & $\begin{array}{l}\text { - Evacuation (residential) versus relocation (commercial) } \\
\text { - Provide simultaneous location and mapping } \\
\text { - Design radios that work to support commercial infrastructure }\end{array}$ \\
\hline $\begin{array}{l}\text { Residential } \\
\text { Building Needs }\end{array}$ & $\begin{array}{l}\text { - Resolve privacy and monitoring requirements, which vary per building, especially in } \\
\text { residential structures } \\
\text { - Address the lack of oversight or maintenance requirements }\end{array}$ \\
\hline $\begin{array}{l}\text { New Building } \\
\text { Needs }\end{array}$ & $\begin{array}{l}\text { - Advance sustainable design for safety monitoring of new buildings } \\
\text { - Implement smart size-up from the start }\end{array}$ \\
\hline $\begin{array}{l}\text { Retrofitted } \\
\text { Building Needs }\end{array}$ & $\begin{array}{l}\text { - Address the lack of buy-in on sprinkler retrofit side } \\
\text { - Document capabilities of additional sensor and CPS systems } \\
\text { - Close off areas for retrofit adaptation } \\
\text { - Provide consistent building information updates }\end{array}$ \\
\hline
\end{tabular}

\subsubsection{CPS Integration Needs}

Even if the common CPS needs identified in Table 3-I are designed and fully developed, the technology will need technical integration with existing operations equipment to ensure that the enhanced firefighting techniques are effective. Specific integration challenges are detailed below in Table 3-2. 
TABle 3-2: CROSS-CUTtING StRUCtURAL ISSUES: CPS INTEGRATION NEEDS

\begin{tabular}{|c|c|c|c|}
\hline Codes and Standards & $\begin{array}{c}\text { Software and Hardware } \\
\text { Technologies }\end{array}$ & $\begin{array}{c}\text { Feasibility } \\
\text { Demonstration }\end{array}$ & $\begin{array}{l}\text { Implementation } \\
\text { Strategies }\end{array}$ \\
\hline 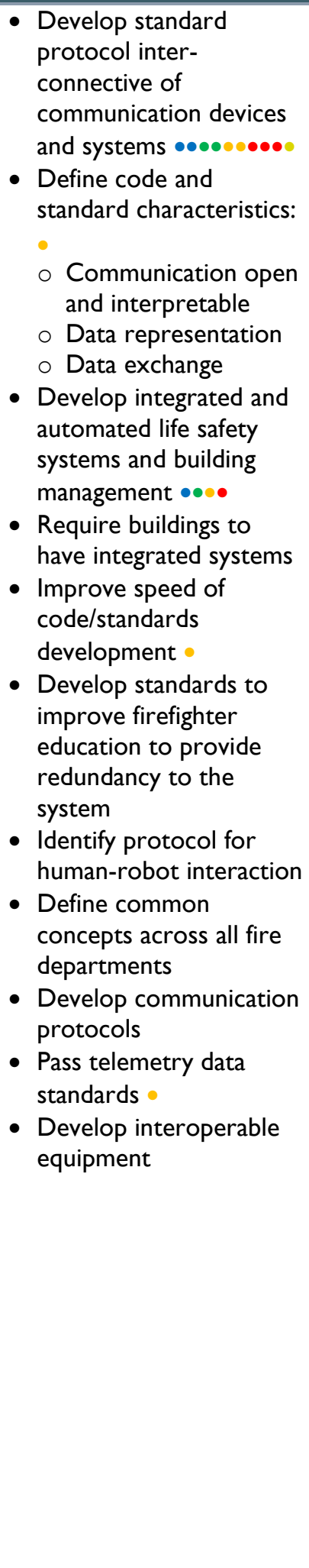 & 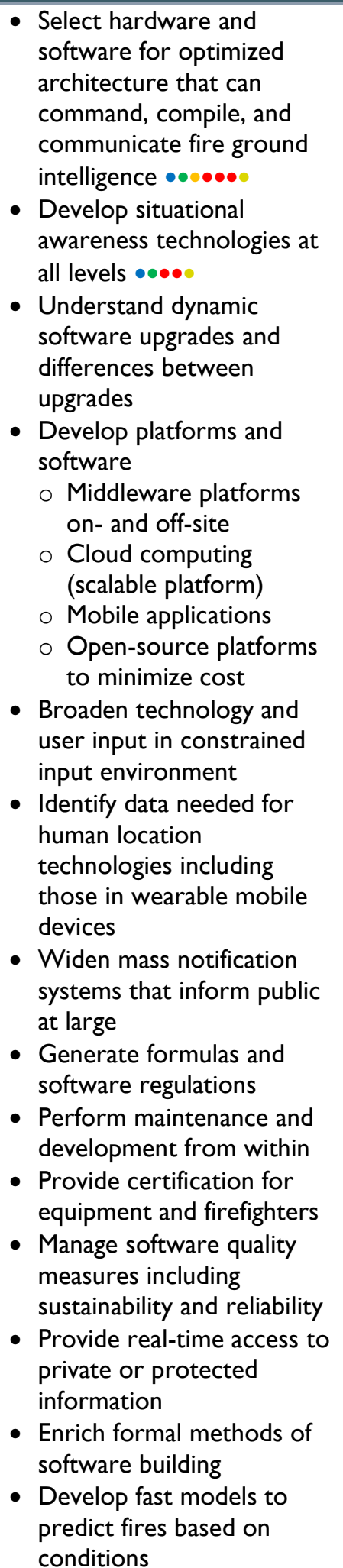 & 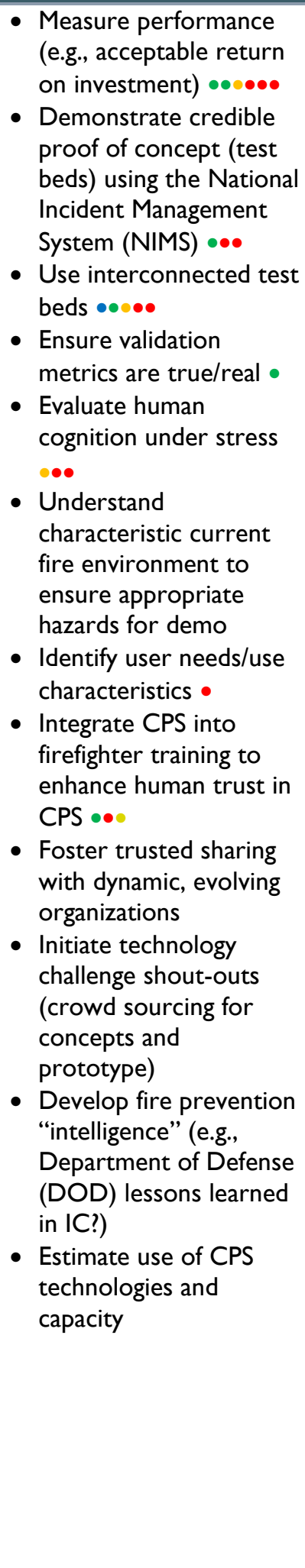 & $\begin{array}{l}\text { - Implement training } \\
\text { and education } \\
\text { - Initiate technology } \\
\text { implementation } \\
\text { challenge } \\
\text { - Develop virtual } \\
\text { environments and } \\
\text { serious games for } \\
\text { firefighting } \\
\text { - Develop ad hoc } \\
\text { network versus } \\
\text { full coverage } \\
\text { - Encourage } \\
\text { insurance } \\
\text { incentives to } \\
\text { perform building } \\
\text { mapping and add } \\
\text { new sensors }\end{array}$ \\
\hline
\end{tabular}




\subsubsection{Non-Technical Issues}

In addition to the shared CPS needs and the integration challenges previously identified, there are general issues that should be taken into consideration to successfully implement the CPS technologies into the fire service. The non-technical needs-policy issues, economic issues, vendor issues, market trends, and cultural/behavioral issues - are detailed in Table 3-3.

TABle 3-3: Cross-Cutting Structural Issues: Non-Technical CPS NeEdS

\section{General Needs}

- Develop methods to evaluate the measurement of performance -

- Address cost savings concerns of elected officials and executives

- Answer "What is in it for me?" question for users and decision makers $\bullet$

- Broadcast positive media support

- Leverage DHS, law enforcement, and military databases

- Provide more event analysis post-incident

- Include evaluation of adaptability to CPS/smart firefighting strategies in recruitment process of future firefighters

- Address issues with proprietary data $\bullet$

- Determine liability issues for CPS -

\subsubsection{Priorities}

Of the identified needs for data processing in Tables 3-2 to 3-3, the following six were identified as the most important. Those fleshed out into program plans in Section 4 are noted in italics.

- Standard protocol inter-connectivity of communication devices and systems

- Situational awareness technologies at all levels

- Training and education

- Program architecture allowing easy transition of data

- Performance measurement

- Interconnected test beds for smart structural firefighting pilots

\subsection{Non-Structural Cross-Cutting Issues}

The Non-structural Firefighting breakout session focused on the shared CPS requirements to advance the effectiveness of firefighting in all situations that do not involve structures (e.g., vehicles; emergency services, EMS; wildland-urban interface, WUI; hazardous materials, HAZMAT). The topics discussed focused on:

- CPS development needs for firefighting in the WUI, EMS, HAZMAT, or other first responder applications

- CPS integration in WUI or EMS/HAZMAT/first responder applications with respect to codes and standards, software technologies, feasibility demonstrations, and implementation strategies

- Non-technical issues (e.g., training, economic issues, standards and codes processes, market trends, behavioral issues) that affect successful integration of CPS into WUI and EMS/HAZMAT/ first responder applications

The collected ideas were then prioritized and fleshed out into development plans.

\subsubsection{Overview and Importance for CPS and Fire Services}

The WUI encompasses housing and other structures that are either collocated with or abut wildland vegetation and forest. Communities in these areas are susceptible to fires, which may be caused by the 
increasing number of structures, long-term drought, climate change, or build-up of wildland fuel. When a fire or emergency occurs, first responders, EMS, and HAZMAT personnel are on the scene to address the incident and ensure public safety. The more information that these responders have available for a given situation, the better they can assess and respond. However, responders often may not have all the information for a particular incident until they arrive on scene, requiring quick assessment, decision, and response.

New and existing technologies are providing benefits to the fire service in this area and will continue to provide benefits as CPS offers more data with the increased use of sensors, as well as new capabilities. These data could potentially help first responders, EMS, and HAZMAT personnel assess a situation before they arrive on scene, better make decisions on how to address a situation, and keep firefighters and the public safe from harm. ${ }^{9}$

\subsubsection{Common CPS Development Needs}

As CPS continues to develop and be integrated into WUI, EMS, HAZMAT, and first responder applications, a number of issues and developmental needs must be considered. Information provided by CPS can help the fire service dynamically track fires, incidents, and firefighting personnel, as well as improve prioritization of risks and responses. However, new CPS tools and techniques should have minimal impact on existing capabilities and functions and should provide for interoperability and ease of use. Additional developmental needs and considerations are provided in the Table 3-4.

\footnotetext{
${ }^{9}$ NIST, “Wildland-Urban Interface Fire Research Needs: Workshop Summary Report," NIST Special Publication II50, May 2013.
} 
Table 3-4: Non-Structural Cross-Cutting: Development Needs

\begin{tabular}{|c|c|c|}
\hline WUI & $\begin{array}{c}\text { Both WUI- and EMS-Related } \\
\text { Needs }\end{array}$ & $\begin{array}{l}\text { EMS/HAZMAT/ } \\
\text { First Responder }\end{array}$ \\
\hline $\begin{array}{l}\text { - Consider how to implement using } \\
\text { current radio technology without } \\
\text { affecting communications capability } \\
\text { - Organize the data into higher-level } \\
\text { concepts for human system } \\
\text { interaction } \\
\text { - Develop better, more efficient and } \\
\text { effective/cost-effective } \\
\text { communications and technologies } \\
\text { - Adopt Blue Force Tracking: } \\
\text { O Support firefighting personnel } \\
\text { safety by employing cheap, simple, } \\
\text { effective tracking technology to } \\
\text { locate active firefighters at all times } \\
\text { O Design more effective/robust } \\
\text { communications to provide needed } \\
\text { safety information } \\
\text { - Provide evacuation notification } \\
\text { - Develop weather models } \\
\text { - Improve situational awareness } \\
\text { resource allocation } \\
\text { - Use autonomous field-deployed forest } \\
\text { fire sensors } \\
\text { - Update mapping of wildland-urban } \\
\text { incidents dynamically }\end{array}$ & $\begin{array}{l}\text { - Organize data according to operational } \\
\text { - And safety risks } \\
\text { uncertain inputs for processing and data } \\
\text { management } \\
\text { - Integrate data from multiple sensors to } \\
\text { support on-scene decision making } \\
\text { - Integrate existing information and } \\
\text { guidance into new products (i.e., } \\
\text { Department of Transportation } \\
\text { guidebook on I6 lifesaving initiatives) } \\
\text { - Develop architecture standards to allow } \\
\text { open access and transmission of data } \\
\text { - Develop data sharing and } \\
\text { interoperability standards: } \\
\text { o Develop standard information models } \\
\text { O Integrate with existing standards } \\
\text { - Ensure PPE applications are the same } \\
\text { - Develop consistent interface standards } \\
\text { to improve interoperability for data and } \\
\text { hardware } \\
\text { - Develop common training and standards } \\
\text { - Improve situational awareness with } \\
\text { unmanned aerial vehicle (UAVs)/ } \\
\text { unmanned aircraft system (UASs)/ } \\
\text { unmanned ground vehicle (UGV) } \\
\text { behport } \\
\text { equipment tracking systems (e.g., spot } \\
\text { messenger) }\end{array}$ & $\begin{array}{l}\text { - Identify HAZMAT } \\
\text { location, type (i.e., } \\
\text { materials), and vehicle } \\
\text { needed for accident } \\
\text { response } \\
\text { - Embed analysis in } \\
\text { current PPE and tools } \\
\text { - Use through-the-wall } \\
\text { sensing to identify } \\
\text { personnel on the } \\
\text { ground }\end{array}$ \\
\hline
\end{tabular}

\subsubsection{CPS Integration Needs}

As noted above, a number of technical developmental needs must be considered in CPS development and integration. For example, new technologies should provide for interoperability and common data models and platforms, while providing simple and easy-to-use interfaces. Testbeds and metrics will be needed to demonstrate the feasibility of new technologies and applications. Additionally, the fire service will need appropriate training for these technologies. Table 3-5 below provides a list of technical developmental needs and considerations. 
TABLE 3-5: NON-STRUCTURAL CROSS-CUTTING: INTEGRATION NEEDS

\begin{tabular}{|c|c|c|c|}
\hline Topic Area & WUI & Both WUI- and EMS-Related Needs & $\begin{array}{c}\text { EMS/ HAZMAT/ } \\
\text { First } \\
\text { Responders }\end{array}$ \\
\hline $\begin{array}{l}\text { Codes and } \\
\text { Standards }\end{array}$ & $\begin{array}{l}\text { - None } \\
\text { provided }\end{array}$ & $\begin{array}{l}\text { - Interface standard and hardware/software common data } \\
\text { models and formats } \\
\text { - Aim for open standard, interoperable, non-proprietary } \\
\text { - Keep expectations realistic during the preliminary stages } \\
\text { - Define data type, format, quality } \\
\text { - Consider local systems' need for technology that integrates } \\
\text { with larger systems without interfering with operations } \\
\text { - Integrate standards into the decision making process to } \\
\text { reduce human error } \\
\text { - Address privacy standards and concerns } \\
\text { - Support remote sensing for WUI standards compliance, } \\
\text { insurance as driver }\end{array}$ & - None provided \\
\hline $\begin{array}{l}\text { Software } \\
\text { Technologies }\end{array}$ & $\begin{array}{l}\text { Ensure } \\
\text { models are } \\
\text { realistic and } \\
\text { have feasible } \\
\text { expectations } \\
\text { while being } \\
\text { validated }\end{array}$ & $\begin{array}{l}\text { - Develop new algorithms with artificial intelligence that are } \\
\text { capable of dealing with uncertainty } \\
\text { - Build simple and intuitive user interface/user experience } \\
\text { (UI/UX) } \\
\text { - Adapt to future use of cloud computing } \\
\text { - Develop adaptive algorithms for dynamic situations } \\
\text { - Address security, reliability, and robustness } \\
\text { - Incorporate scalability of users and system } \\
\text { - Develop new data model for modeling the emergency scene }\end{array}$ & - None provided \\
\hline $\begin{array}{l}\text { Feasibility } \\
\text { Demonstrations }\end{array}$ & $\begin{array}{l}\text { None } \\
\text { provided }\end{array}$ & $\begin{array}{l}\text { - Develop full-scale testbed for sensor integration through } \\
\text { user demonstration and testing } \\
\text { O Develop realistic testbeds and scenario for feasibility } \\
\text { demonstration } \\
\text { - Define metrics to determine success or failure in feasibility } \\
\text { demonstrations } \\
\text { - Focus on pre-demonstration training to ensure effective } \\
\text { CPS deployment } \\
\text { - Introduce a level of complexity that will be helpful in } \\
\text { determining feasibility } \\
\text { - Establish better forums to demonstrate new capabilities, } \\
\text { bringing users together with vendors/ government/academia } \\
\text { - Implement comparative analysis strategy (control versus } \\
\text { test) }\end{array}$ & - None provided \\
\hline $\begin{array}{l}\text { Implementation } \\
\text { Strategies }\end{array}$ & $\begin{array}{l}\text { None } \\
\text { provided }\end{array}$ & $\begin{array}{l}\text { - Remember the work environment and available resources } \\
\text { - Link implementation to incident complexity } \\
\text { - Integrate into tools and equipment without degradation of } \\
\text { capabilities - } \\
\text { - Improve approach to technology transfer in the Forest } \\
\text { - Service (no roadmap) } \\
\text { - Provide consistency with some flexibility } \\
\text { - Pefine training requirements and models, including who } \\
\text { - Provide ongoing support for sustainability and upgradeability }\end{array}$ & $\begin{array}{l}\text { Make a } \\
\text { compelling } \\
\text { case/value-add to } \\
\text { both the agency } \\
\text { and the public } \\
\text { about the value } \\
\text { of these action } \\
\text { items } \\
\text { Obtain } \\
\text { stakeholder buy- } \\
\text { in, do public } \\
\text { outreach }\end{array}$ \\
\hline Other & $\begin{array}{l}\text { - } \text { None } \\
\text { provided }\end{array}$ & $\begin{array}{l}\text { - Deploy training for use of systems and quality assurance } \\
\text { (QA) standards for data input into systems } \\
\text { - Better connections between relevant research fields and } \\
\text { industry } \\
\text { - Determine how data quality is evaluated } \\
\text { - Determine deployment methods, including who carries } \\
\text { specific equipment along with its priority needs - }\end{array}$ & $\begin{array}{l}\text { - Integrate systems } \\
\text { into the decision } \\
\text { making process } \\
\text { - Reduce human } \\
\text { error }\end{array}$ \\
\hline
\end{tabular}




\subsubsection{Non-Technical Issues}

Non-technical needs also arise when attempting to integrate new CPS technology into existing WUI, EMS, HAZMAT, and first responder applications (e.g., determining funding organization and technology owner, developing new cost-effective technologies, and convincing the fire service of the advantages and dependability of the technologies). Additional non-technical developmental needs and considerations are provided in Table 3-6.

TABle 3-6: Non-Structural CROSS-CutTING: NON-TECHNICAL ISSUES

\begin{tabular}{|c|c|c|}
\hline Policy & Economics & Cultural and Behavioral \\
\hline - Obtain policymaker buy-in & $\begin{array}{l}\text { - Address resource constraints } \\
\text { - Address budget and competing } \\
\text { priorities } \\
\text { - Consider affordability of } \\
\text { software/hardware } \\
\text { - Improve the business case for } \\
\text { integrating CPS into firefighting } \\
\text { equipment - } \\
\text { - Consider cost-effectiveness of } \\
\text { implementations }\end{array}$ & $\begin{array}{l}\text { Determine funding source and } \\
\text { owner of technology (e.g., } \\
\text { local, federal, county, state, } \\
\text { public-private) } \\
\text { - Consider behavioral issues, } \\
\text { i.e., how do you improve the } \\
\text { human factor? } \\
\text { - Consider turf, competing } \\
\text { - } \text { - Incoriorities, and agenda } \\
\text { into issues - } \\
\text { - Consider privacy concerns } \\
\text { - Convince users that the } \\
\text { technology can be trusted }\end{array}$ \\
\hline Education/Training & Sustainability & Other \\
\hline $\begin{array}{l}\text { - Provide education on benefit and } \\
\text { outreach to firefighting community } \\
\text { - Understand the learning curve of new } \\
\text { technology } \\
\text { - Provide tiered training (e.g., user, } \\
\text { manager, administrator) } \\
\text { - Define clearly the range of application } \\
\text { - Provide support that is easy to access } \\
\text { and understand } \\
\text { - Ensure training includes common } \\
\text { sense approaches and does not rely } \\
\text { solely on technologies and } \\
\text { experience }\end{array}$ & $\begin{array}{l}\text { - Incorporate sustainability (e.g., } \\
\text { life cycle cost) } \\
\text { - Provide contingency solutions } \\
\text { should technology fail } \\
\text { - Ensure flexibility for equipment } \\
\text { updates and retrofits. } \\
\text { - Provide continuous training or } \\
\text { validation (i.e., educational } \\
\text { sustainability) } \\
\text { - Consider need to sustain data } \\
\text { accuracy }\end{array}$ & $\begin{array}{l}\text { - Ensure operation and } \\
\text { interpretation of technology is } \\
\text { intuitive } \\
\text { - Provide firefighters with } \\
\text { appropriate and timely } \\
\text { information during a fire } \\
\text { event } \\
\text { - Ensure seamless integration of } \\
\text { CPS with firefighters } \\
\text { - Demonstrate benefits and } \\
\text { develop strategy to support } \\
\text { technology transfer } \\
\text { - Develop strategy to } \\
\text { implement technology in } \\
\text { remote areas } \\
\text { - Generate and document } \\
\text { uncertainty/accuracy of } \\
\text { output }\end{array}$ \\
\hline
\end{tabular}




\subsubsection{Priorities}

Of the identified needs for data processing in Tables 3-4 to 3-6, the following eight were identified as the most important. Those fleshed out into possible program plans in Section 4 are noted in italics.

- Feasibility demonstrations and testbeds

- Interface standards for hardware, software, and data exchange models

- User interface

- Algorithms for uncertainty

- Policymaker buy-in

- Metrics that determine success or failure in feasibility demonstrations

- Budgets (i.e., who pays for and owns the technologies: local, federal, county, state, publicprivate)

- Address budget and competing priorities 


\section{Prioritization Worksheets}

The previous sections provided a list of the priority topics for smart firefighting from each breakout session. Of those topics, specific priorities that have the greatest potential in enhancing fire service safety and effectiveness were expanded into development plans by identifying specific tasks, milestones, performance targets, challenges, and potential stakeholders. A summary of all the priority topics from each breakout are presented in Table 4-I. Figures 4-I through 4-19 provide the results of the expansion of selected topics (in bold text). 10

\footnotetext{
10 Text generated during the workshop sessions was formatted and placed within Figure 4-I through Figure 4- 19 within Section 4. The text, which describes possible implementation plans, was a product of workshop participants working in small groups. Text was not edited for consistency between different breakout groups.
} 
TABLE 4-I: IDENTIFIED PRIORITIES FOR SMART FIREFIGHTING

\begin{tabular}{|c|c|c|}
\hline Breakout & Priority & Votes \\
\hline \multirow{8}{*}{$\begin{array}{l}\text { Data } \\
\text { Gathering }\end{array}$} & Real-time situational sensors with video (Figure 4-I) & $\bullet \bullet \bullet \bullet \bullet \bullet \bullet \bullet \bullet$ (I I ) \\
\hline & Wearable, wireless, robust environmental sensors (Figure 4-2) & $\bullet \bullet \bullet \bullet \bullet \bullet \bullet(10)$ \\
\hline & Data-sharing standards & $\bullet \bullet \bullet \bullet \bullet \bullet \quad(9)$ \\
\hline & Improvements to N-FORS: DHS/FEMA; operational data & $\bullet \bullet \bullet \bullet \bullet(7)$ \\
\hline & Standard for fire system data delivery and information display & $\bullet \bullet \bullet \bullet \bullet(6)$ \\
\hline & People tracking efforts at the incident site (Figure 4-3) & $\bullet \bullet \bullet \bullet(6)$ \\
\hline & Standards development for data gathering & $\bullet 00000(6)$ \\
\hline & Asset tracking (Figure 4-4) & $\bullet \quad(3)$ \\
\hline \multirow{6}{*}{$\begin{array}{l}\text { Data } \\
\text { Processing }\end{array}$} & Use case models (Figure 4-5) & $\bullet \bullet \bullet \bullet \bullet \quad(12)$ \\
\hline & Data standardization for data processing (Figure 4-6) & $\bullet \bullet \bullet \bullet \bullet \bullet \bullet \quad(\mathrm{II})$ \\
\hline & $\begin{array}{l}\text { Identification of data communication improvement areas on fire ground (e.g., } \\
\text { need for better, more rugged on-firefighter devices) }\end{array}$ & $\bullet$ \\
\hline & $\begin{array}{l}\text { Leveraging of common, open-source (e.g., 9-pin, 25-pin) hardware/software } \\
\text { platforms or data analytics }\end{array}$ & (8) \\
\hline & Accurate and trustworthy data & $\bullet \bullet \bullet \bullet \bullet \quad(7)$ \\
\hline & Center for firefighting excellence (Figure 4-7) & $\bullet$ \\
\hline \multirow{8}{*}{$\begin{array}{l}\text { Decision } \\
\text { Making }\end{array}$} & All levels of communication on the fire ground (Figure 4-8) & $\bullet \bullet \bullet \bullet \bullet \bullet \bullet \bullet \bullet \bullet \bullet(I 2)$ \\
\hline & Data gathering black box'l (Figure 4-9) & $\bullet \bullet \bullet \bullet \bullet \bullet \bullet ~(7)$ \\
\hline & Effective and timely use of collected data ${ }^{10}$ (Figure 4-9) & $\bullet \bullet \bullet(6)$ \\
\hline & Automatic update to fire ground and on-site resources (Figure 4-I0) & $\bullet \bullet \bullet \bullet \bullet \bullet \bullet(7)$ \\
\hline & Firefighters prepared to safely perform tasks (Figure 4-I I) & $\bullet \bullet \bullet \bullet \bullet(6)$ \\
\hline & Accountability & $\bullet \bullet \bullet \bullet \bullet(6)$ \\
\hline & Cost and reliability & $\bullet \bullet \bullet \bullet \bullet(6)$ \\
\hline & Enhanced scene and building information (Figure 4-I2) & $\bullet \bullet \bullet(5)$ \\
\hline \multirow{6}{*}{$\begin{array}{l}\text { Cross- } \\
\text { cutting: } \\
\text { Structural } \\
\text { Firefighting }\end{array}$} & $\begin{array}{l}\text { Standard protocol inter-connectivity of communications devices and } \\
\text { systems (Figure 4-13) }\end{array}$ & $\bullet \bullet \bullet \bullet$ \\
\hline & Implement training and education (Figure 4-I4) & $\bullet \bullet \bullet(8)$ \\
\hline & Program architecture allowing easy transition of data & $\bullet \bullet \bullet \quad(7)$ \\
\hline & Performance measurement & $\bullet \bullet(6)$ \\
\hline & Interconnected testbeds for smart structural firefighting pilots & $\bullet \bullet(5)$ \\
\hline & $\begin{array}{l}\text { Develop situational awareness technologies at all levels (Figure 4-I4 } \\
\text { and Figure 4-15) }\end{array}$ & $\bullet \bullet(5)$ \\
\hline \multirow{8}{*}{$\begin{array}{l}\text { Cross- } \\
\text { cutting: } \\
\text { Non- } \\
\text { Structural } \\
\text { Firefighting }\end{array}$} & Policy maker buy-in & $\bullet \bullet \bullet \bullet \bullet \bullet \bullet \bullet \bullet \bullet \bullet(I I)$ \\
\hline & Defined metrics to determine success or failure in feasibility demonstrations & $\bullet \bullet \bullet \bullet \bullet \bullet \bullet(7)$ \\
\hline & $\begin{array}{l}\text { Develop full-scale testbed for sensor integration through user } \\
\text { demonstration and testing (Figure 4-16) }\end{array}$ & $\bullet \bullet \bullet \bullet \bullet(6)$ \\
\hline & $\begin{array}{l}\text { Interface standards for hardware, software, common data models, } \\
\text { and formats (Figure 4-17) }\end{array}$ & $\bullet \bullet \bullet(5)$ \\
\hline & $\begin{array}{l}\text { Determination of funding source and owner of technology (e.g., local, federal, } \\
\text { county, state, public-private) }\end{array}$ & $\bullet \bullet \bullet(5)$ \\
\hline & Consideration of budget and competing priorities & $\bullet \bullet(4)$ \\
\hline & $\begin{array}{l}\text { New algorithms, with artificial intelligence, that are capable of } \\
\text { dealing with uncertainty and change (Figure 4-18) }\end{array}$ & $\bullet(3)$ \\
\hline & Simple and intuitive user interface (Figure 4-19) & $\bullet \quad(3)$ \\
\hline
\end{tabular}

"I These two topics were combined into one prioritization worksheet. 


\subsection{Data Gathering}

The Data Gathering topics selected for program development is presented below and expanded in Figures 4-I to 4-4.

- Figure 4-I: Real-time situational sensors with video

- Figure 4-2: Wearable, wireless, robust environmental sensors

- Figure 4-3: People tracking efforts at the incident site

- Figure 4-4: Asset tracking 


\section{Figure 4- I: REAL-Time SituAtional SENSORS WitH Video}

\section{Brief Description:}

Remote control devices or drone robots could be used to collect additional situational information, including video, prior to human intervention in an incident. The building data, electronically transferred to the incident commander (IC) at an electronic control board, could include the number of occupants, location of occupants, structural status, and IC

\section{PROGRAM APPROACH}

\section{Major Tasks}

- Gather qualitative information on sensor specifics and environmental thresholds for operation

- Coordinate stakeholders for development of plan and timeline

- Develop prototype, field test product, and validate production/implementation

\section{Major Milestones}

- $0-3$ years: Gather qualitative information and plan with timeline

- 3-5 years: Develop prototype and perform lab and field tests

- 5+ years: Produce and implement sensors

\section{Performance Targets}

- Accuracy prioritized over precision

- Must operate in IDLH (immediately dangerous to life and health) environment

- Must operate in high thermal environment

- Wireless operation must work

- Must operate when wet

\section{Limits}

- Incident commander and firefighter still need to think and reason through situation

- Acceptance by fire service, training and implementation required

- May only work in newer built environments

\section{FUTURE}

\section{Future Changes}

- Continuous updates in accordance with technology

- Apply a visionary mindset - What is possible?

\section{Future Operations or CPS Issues}

- Cost

- Different needs for keeping current for each building

- Fire service training

- Maintenance of system, including testing

\section{Challenges}

- Communications technology: Feasibility of wireless technology; new environments could be wired; selection of radio spectrum; interoperability

- Sensor: High costs; severe environments; must be reliable; must be easy to deploy, use, and replace

- Data collection: Concerns with buy-in and privacy issues; need to determine who collects data and data storage location (e.g., cloud); need simple format for information and video

- Existing databases: Incompatibility with new technology; coordination of upgrades; inconsistent data elements collected (currently consistent for monitoring company)

\section{STAKEHOLDER ROLES AND RESPONSIBILITIES}

- Fire Service: Meet requirements generated from firefighters and officers; provide continuous input and testing

- Government: Provide funding (e.g., science and technology grants, NIST, DHS)

- CPS experts: Develop user-friendly products; continuously improve products consistent with technology

- Vendors/manufacturers: Produce product 


\section{Figure 4-2: WeARABle, Wireless, Robust ENVIRONMENTAL SENSORS}

\section{Brief Description:}

Environmental sensors should be developed and integrated in firefighting PPE. Sensors would provide firefighters and IC with real-time data indicating environmental conditions and potential hazards faced by a firefighter.

\section{PROGRAM APPROACH}

\section{Major Tasks}

- Develop sensors

- Develop algorithms

- Integrate sensors with PPE

- Ensure stakeholders have input in the development of CPS components during the entire design cycle

- Develop standards for the sensors

\section{Major Milestones}

- 0-3 years: Define existing sensor technologies

- 3-5 years:

- Demonstrate wearable system

o Conduct field trials/testing

\section{Performance Targets Limits}

- Meets defined criteria for durability and reliability

- Provides accuracy while being cost-effective

- Is easy to maintain

- Is ergonomic/lightweight

\section{FUTURE}

\section{Future Changes}

- Quantification of exposure environment

- Adaptation to future medical research, PPE, and other equipment

\section{Challenges}

- Communications technology: Must function in and out of structures

- Sensor: Must have high thermal and chemical particulate tolerances; must tolerate radioactive flux; must measure metabolic/physiological changes

- Data collection: Determine the longevity need of the data during the fire incident

\section{Future Operations or CPS Issues}

- Privacy/confidentiality of data generated

- Cost

- Maintenance

\section{STAKEHOLDER ROLES AND RESPONSIBILITIES}

- Fire Service: Perform trial testing

- R\&D: Apply existing technology

- Standards: Establish NFPA/Underwriters Laboratory certifications 


\section{Figure 4-3: People Tracking at the Incident Site}

\section{Brief Description:}

Location and tracking of responders will enable better situational awareness for IC. Incident commanders can then see whether resources are deployed as expected and respond rapidly in the event of rescue need.

\section{PROGRAM APPROACH}

\section{Major Tasks}

- Determine state-of-the-art tracking technology and methodology

- Review requirements and further develop business models

- Develop technology in order of prioritized use cases

- Iteratively test technology

- Pilot and deploy technology and methodology

\section{Major Milestones}

- Establish steering committee and working groups

- List state-of-the-art technology and additional requirements

- Define viable business model

- Demonstrate progress for each technical element via component testing in relevant environment

- Draft standards

- Integrate testing and piloting

\section{Performance Targets Limits}

- Locate personnel within established tolerances as defined by incident commanders

- Achieve minimal deployment latency

- Display minimal data latency

- Meet cost requirements and document value added

\section{FUTURE}

\section{Future Changes}

- Indoor location technology breakthroughs

- Mandates for product use

\section{Future Operations or CPS Issues}

- A means of preventing overwhelming the incident commander during large-scale events

- Data delivery mechanisms in radio frequency-challenged environments

\section{STAKEHOLDER ROLES AND RESPONSIBILITIES}

- Major city Fire Service: Provide user requirements and testbed (International Association of Fire Chiefs [IAFC], International Association of Fire Fighters [IAFF], and National Volunteer Fire Council [NVFC])

- Manufacturers: Develop tracking technology display and situation awareness technology

- International Code Council (ICC) / International Building Code (IBC), NFPA: Develop standards and regulations

- Government: Provide funding 


\section{FIgURE 4-4: ASSET TRACKING}

\section{Brief Description:}

Asset and compliance tracking is enabled by placing small button-sized sensors, battery-operated or energyharvested, on assets. The sensors enable digital recordkeeping for compliance and automation of particular equipment before, during, and after a fire event. Asset tracking enables geo-location of fire fighter assets, age tracking, maintenance, repair tracking, and pairing of assets.

\section{PROGRAM APPROACH}

\section{Major Tasks}

- Identify current program for tracking (e.g., manual or automated process, time and cost expended currently)

- Identify profile of assets, listing relationship to individuals

- Develop a scalable program based on department and size

- Develop an easy and intuitive process for deleting or adding new assets and monitoring battery life replacement (mobile console)

- Build robust sensors that last a minimum of five years and manage water intrusion, vibration/shock, abrasion, and chemical and thermal extremes

- Identify costs per site

\section{Performance Targets}

- 0-3 years:

- Test current wireless sensor network radio frequency performance

- Test durability in fire environments

- Identify beta test sites (e.g., small, medium, large)

- Conduct voice-ofcustomer interviews
- Accuracy of device sensors (i.e., they always work)

- Self-test and check-in of devices once movement is detected (e.g., sleep state depending on use case)

- Fault tolerance diagnostics

- Radio frequency performance in fire environments

- Implementation of voiceof-customer changes

\section{Limits}

- Radio frequency range limits

- Temperature limits

- Robust sensors that last a minimum of five years and manage water intrusion, vibration/shock, abrasion, and chemical and thermal extremes

\section{FUTURE}

\section{Future Changes}

- Asset tracking enables new software and workflow management

\section{Future Operations or CPS Issues}

- Security (ensuring encryption)

- Training

- Maintenance

\section{Challenges}

- Communications technology: Ensuring radio frequency bands are not saturated

- Sensors: Connecting to a personal area network (PAN) or local area network (LAN) environment

- Data collection: Managing and setting up the business rules for data collection and storage over time

- Existing Databases: Addressing need for a cloud integration, which entails support for a wireless (cellular) device for monitoring assets in the field
STAKEHOLDER ROLES AND RESPONSIBILITIES

- Resource management/logistics organizations - Individual firefighters 


\subsection{Data Processing}

The Data Processing topics selected for program development is presented below and expanded in Figures 4-5 to 4-7.

- Figure 4-5: Use case models

- Figure 4-6: Data standardization/ Base platform for data interoperability

- Figure 4-7: Center for firefighting excellence/ Fire Service CPS Integration R\&D and Support Center 


\section{Figure 4-5: Use CASE MODELS}

\section{Brief Description:}

A technical framework is needed for delivering "actionable intelligence," including risk-based profiles, predictive scenarios, and use and test cases. The framework will facilitate smart firefighting across a broad spectrum of activities, from analysis of building data for pre-event planning and response to post-event processing. The framework should extract patterns, allow for machine learning, and learn from device behavior. (For example, the system accepts the firefighter's verbal input, provides instantaneous feedback from multiple sensors, and provides actionable intelligence for firefighter's decisions.)

\section{PROGRAM APPROACH}

\section{Major Tasks}

- Provide guidance for abstraction of actionable intelligence needs for development of design scenario (e.g., use cases, test cases, risk profiling)

- Develop base case scenarios for decision making and response (e.g., determine the information needed for each set of conditions)

- Define the environments for expected device behavior (i.e., behavior in the set of conditions defined above)

- Build a set of actionable intelligence engines based on data and processing needs (e.g., Fire Department City of New York [FDNY]-type analytics, fire ground decision making, event scenarios for compacting/ deciding data needs)

- Expand to multi-platform interaction and communication

- Conduct verification and validation

\section{Major Milestones \\ Performance Targets}

- None provided

- Develop scenario guidelines within 3 years

- Develop and test realistic scenarios (e.g., 10 each emergency and non-emergency) within 5 years

- Develop actionable intelligence engines within 10 years

- Expand to multiplatform within 15 years

- Wide-scale rollout within 20 years

\section{Limits}

- Amount of data that firefighter can process during an event

- Reliability of data relative to informing reliable/intelligent decisions

- Getting all stakeholders to work well together for the common good (e.g., business, technology)

\section{FUTURE}

\section{Future Changes}

- None provided

\section{CHALlenges}

- Hardware: Ensuring interoperability; filtering of noise/ transmission of data; communications network reliability

- Software: Defining a common language; ensuring software heterogeneity; defining engine and model semantics; performing verification/validation; interpreting results

- Overall: Satisfying compatibility, integration, and interoperability needs

\section{Future Operations or CPS Issues}

- None provided

\section{STAKEHOLDER ROLES AND RESPONSIBILITIES}

- Operational firefighter: End of hose and IC - to provide knowledge of actions and data needs

- FF analytics personnel: Knowledgeable in fire, building, other data

- Data processing expertise

- Human-machine interface expertise

- Textual and environmental context expertise

- Building owner/manager

- Technology developers

- Modeling/simulation expertise 


\section{Figure 4-6: DATA StANDARDiZATION/ BASE PlatForm FOR DATA INTEROPERABILITY}

\section{Brief Description:}

Interoperability is important for the smart data usage for pre-planning, fire incident management, and postincident analysis. Interoperability in this worksheet focuses on common interfaces for accessing the payload data and formats for the data to be universally read, manipulated, and stored.

\section{PROGRAM APPROACH}

\section{Major Tasks}

- Define data interoperability goals and scope

- Analyze data source and streams and identify applicable industry and related standards

- Identify and evaluate existing best practices from other fields

- Synthesize and specify best practices as applied to smart firefighting

\section{Major \\ Milestones}

- None provided working groups

- Early industry adoption

- Availability of devices and systems to enable comprehensive preplanning, real-time incident management, and efficient postincident analysis

\section{FUTURE}

\section{Future Changes}

- The Internet of Things (IOT) will heavily influence CPS and smart firefighting direction

\section{Future Operations or CPS Issues}

- None provided

\section{STAKEHOLDER ROLES AND RESPONSIBILITIES}

- Fire Service

- Standards development organizations

- Industry

- Academia and research centers

- Ownership of standards development; cross-cutting concerns from communications to data format to equipment certification

- Expense and adoption by the fire protection services

- Intellectual property rights

- Technology hurdles: hardware, software, compatibility and integration for new and existing systems 


\section{Figure 4-7: Center for Firefighting Excellence/ Fire Service CPS INTEGRATION R\&D AND SUPPORT CENTER}

\section{Brief Description:}

The center will become an entity for establishing and sharing information, guidelines, and recommendations for smart firefighting. It will be accessible to all fire services and industry members seeking to learn and develop CPS solutions for smart firefighting. This resource center would establish guidelines, recommendations, industry standards, etc. for areas related to data processing, utilization, and evaluation.

\section{PROGRAM APPROACH}

\section{Major Tasks}

- Develop a business model and structure for establishing a center for shared knowledge and information

- Strategize methods for increased integration of CPS into fire services

- Establish interoperability and data standards, guidelines, and recommendations

- Identify common data utilization requirements and needs across fire services

- Develop a repository of use scenarios and models

- Develop lessons learned and best practices globally

- Act as first point of contact for fire services for CPS components and use models

\section{Major Milestones}

- 0 - I years: Develop a business model and budget

- 2-3 years: Establish funding and governance

- 3-5 years: Build the center

- 5-6 years: Collect practices and build a resource base of information and standards for fire services

\section{FUTURE}

\section{Future Changes}

- None provided

\section{Challenges}

- Organizational: Securing funding, developing the center, securing leadership, and developing the organization

- Costs: Ensuring data and resource access are costneutral to the fire services

- Integration: Identifying a strategy for integrating with other services (e.g., police, military, EMS, public works); obtaining early stakeholder buy-in to lessen disruption to current practices

\section{Future Operations or CPS Issues}

- None provided

STAKEHOLDER ROLES AND RESPONSIBILITIES

- Fire Services

- Industry members

- CPS experts

- Academic partners

- Standards organizations

- Government and non-government organization (NGO) entities (the National Institute of Standards and Technology, National Fire Protection Association, Institution of Fire Engineers, Center for Public Safety Excellence, Inc., etc.) 


\subsection{Decision Making}

The Decision Making topics selected for program development is presented below and expanded in Figures 4-8 to 4-I2.

- Figure 4-8: All levels of communication on the fire ground

- Figure 4-9: Timely utilization of gathered data / Data Gathering Block Box/

- Figure 4-10: Automatic updates to fire ground and on-site resources

- Figure 4-I I: Firefighters prepared to safely perform tasks

- Figure 4-I2: Enhanced scene and building information 


\section{Figure 4-8: All LeVels of Communication ON the Fire Ground}

\section{Brief Description:}

Communications can be described as the fundamental core of the fire service, starting with building inspection and pre-planning to fire ground operations through post-fire critiques and investigations. Communication is accomplished through several vehicles: hand, verbal, electronic (e.g., wireless), and written.

\section{PROGRAM APPROACH}

\section{Major Tasks}

- Develop methods to gather and filter all data elements to ensure functionality to the fire service at all levels

- Investigate building history and floor plans

- Provide constantly updated incident information (verbal or electronic)

- Responding: traffic, weather

o On-scene: conditions, actions, needs, accountability, progress, biometric sensing

- Post-incident reporting

\section{Major Milestones}

- 3-5 years:

- Periodic evaluation and rework to improve the constantly evolving process

\section{Performance Targets Limits}

- Develop a usable product for the fire service

- Develop customizable solutions
- One size does not fit all

- Every municipality is unique

\section{FUTURE}

\section{Future Changes}

- Technology developed as the application becomes more widely accepted

- Standards developed to regulate technology without restricting advancements in technology

\section{Challenges}

- Pre-emergency and post-event: Gathering appropriate information to use as a resource

- During event: Transmitting and receiving the information in a timely fashion with good quality

- Non-firefighter data user applications: Handling applicability of building information to all public service agencies (e.g., EMS, police, building and core enforcement)

- User interface delivery methods: Ease of information delivery to communications devices (e.g., radios, data terminals)

\section{Future Operations or CPS Issues}

- Functionality and cost leading to cultural acceptance

\section{STAKEHOLDER ROLES AND RESPONSIBILITIES}

- Fire service: Identify needs and process

- Technology developers: Develop and deliver the information in a functional format via a usable medium 


\section{Figure 4-9: Timely Utilization OF Gathered Data/ Data Gathering BLACK BOX}

\section{Brief Description:}

A key challenge for smart firefighting is ensuring that all the data being generated are actually used. This requires best practices and technology for data integration that respect the real day-to-day needs of firefighters, across multiple dimensions. Solutions must be sensitive to limited fire service budgets, which may not be able to implement an all-or-nothing approach.

\section{PROGRAM APPROACH}

\section{Major Tasks}

- Identify fire departments that are interested in participating in pilots

- Inventory and integrate existing technology

- Explore sensor, communications, and imaging technology in other industries

- Share results with planners and builders

- Through pilots, identify the most essential and effective ways to improve situational awareness

- Break down best practices along the axes of data type (or data source), data prioritization, and data usage (or type of analysis)

\section{Major Milestones}

- 0-I year: Establish a data integration pilot

- 3-5 years: Complete end-to-end demonstration with data integration, black box, etc. for variety of situations

- 5+ years: Build a set of recommendations for best practices for fire departments to implement, partially or fully, for data management
Performance Targets

- Integration of existing alarm systems, building information, SCBA, PPE

- Measureable impact on reducing firefighter and civilian injury over an established period of time

\section{Limits}

- Fire departments should not need to implement a full integrated system to get value from these recommendations and technology

\section{FUTURE}

\section{Future Changes}

- None provided

\section{Future Operations or CPS Issues}

- None provided

\section{Challenges}

- Pre-emergency and post-event: None provided

- During event: None provided

- Non-fire fighter data user applications: None provided

- User interface delivery methods: None provided

\section{STAKEHOLDER ROLES AND RESPONSIBILITIES}

- Firefighters: Identifying critical data for tactical responses and personal safety

- Incident commanders: Identifying data needed for strategy, post-analysis, and situational awareness of entire scene

- Technology developers: Hardware and software experts to define what is feasible and develop analytical algorithms 


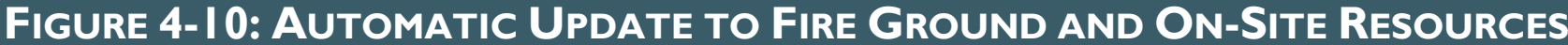

\section{Brief Description:}

Fire scenes are fluid environments where conditions, personnel, and resources are constantly changing. In order to respond to the dynamic nature of the fire scene, incident commanders require continuous information updates to make informed decisions and re-evaluate incident action plans (IAPs). CPS would gather, organize, and prioritize information in the background. The incident commander could access information, alerts, and prompts at any time, and/or the system could provide hazardous condition alerts.

\section{PROGRAM APPROACH}

\section{Major Tasks}

- Identity needs, system of priorities, and alerts/prompts points

- Develop sensors and communications networks for fire ground informationgathering from apparatus, firefighters, building, weather, and equipment

- Develop analytical and verification modules for information processing

- Develop interface to display processed information

- Conduct full-scale testing under fire conditions or actual operational use

\section{Major Milestones}

- 0-3 years:

- Needs, priorities, and alerts/prompts established through consensus process

o Current sensor technologies identified and adapted to needs

- 3-5 years:

- Future needs for specific sensor technologies identified and associated research initiated

o Prototype analytical and verification modules and display interfaces available for testing

- 5+ years: Prototype systems evaluated during field burns

\section{Performance Targets}

- Collection of temperature, thermal flux, and gas concentrations to identify IDLH for firefighter and fire teams

- Personal tracking of firefighters and fire teams on scene

- IDLH and location information available to incident commander as needed and in response to alerts/prompts

\section{FUTURE}

\section{Future Changes}

- Equipment needs to be smaller and lighter than current technology

- Information needs to be targeted to specific fire teams

\section{Future Operations or CPS Issues}

- Security - possibility of someone else looking at data - System reliability - more important than security

\section{STAKEHOLDER ROLES AND RESPONSIBILITIES}

- Fire service (ICloperational personnel): Develop priority alerts/prompts and ensure project maintains focus on fire service needs (e.g., cost-effective, simple, reliable)

- Engineers: Identify reliable measurement science to collect required information from fire ground including from apparatus, firefighters, building, weather and equipment

- CPS: Develop methodologies to collect, verify, process, report, and display information; develop interfaces, software, and analytics officer, monitor touch screen 15"-19" for incident command firefighter, series of lights (e.g., red, yellow, green) 


\section{Figure 4-I I: Firefighters Prepared to SAfely Perform TAsks}

\section{Brief Description:}

Physiological monitoring should connect, interface, or supplement medical and fitness programs to ensure firefighters can safely perform work (i.e., they are medically fit). Data can be collected at baseline fitness training and during past incidents to monitor and improve health and safety.

\section{PROGRAM APPROACH}

\section{Major Tasks}

- Assemble, coordinate, and adopt current technology

- Human-computer interface must be emphasized with firefighters and be deeply involved in design

- Explore additional sensors (e.g., physiological or exposure) for relevant parameters (e.g., electrocardiogram, blood pressure, carbon monoxide, toxins)

\section{Major Milestones}

- Offer commercially available methodology

- Document adoption

- Develop use model/ competition to draw in large participation.
Performance Targets

- Seamless technology to support excellent medical, physical, cognitive, and behavioral performance

- Foster competition and collaboration within and between departments and stations
Limits

- Appropriate feedback provided on key hazards

- Not a stand-alone technology, will require human analysis and decision making

\section{FUTURE}

\section{Future Changes}

- Vitals monitoring provides enormous potential for data mining to supplement on-going research

- Technology would support/enhance adoption or implementation of standard

\section{Challenges}

- Pre-emergency and post-event: model for Americans (e.g., heroes); Compatibility with advances in medical and fitness

- During event: Most challenging time; some data may be useful to collect (e.g., exposure, events) for post-event (e.g., rehabilitation); most data are not actionable during events; at the scene, firefighter assumed to be medically and physically fit to do job; connects with current telemedicine - widely applicable

- Non-fire fighter data user applications: Many law enforcement agencies, military

- User interface: Delivery methods

\section{Future Operations or CPS Issues}

- Union/administration issue

- Privacy issue (e.g., Health Insurance Portability and Accountability Act [HIPAA])

- What information when/where/to whom

\section{STAKEHOLDER ROLES AND RESPONSIBILITIES}

- Fire service: Firefighters, firefighters' families, and fire departments

- Medical providers

- Commercial partners: FitBit, Zepher 


\section{FIGURE 4-I 2: ENHANCED SCENE AND BUILDING INFORMATION}

\section{Brief Description:}

There are several critical factors that must be identified in order to determine an IAP. These include physical layout (e.g., occupancy, configuration, contents), topography, weather, and visual data.

\section{PROGRAM APPROACH}

\section{Major Tasks}

- Develop approach for digitizing, archiving, uploading, and retrieving building floor plans of publicly occupied/ inspected properties

- Develop the ability to retrieve current and expected weather data as geographic information system (GIS) layer

- Expand the ability to retrieve video feeds from public cameras

- Assimilate real-time WUI fire prediction data as GIS layer

\section{Major Milestones}

- Create a repository housing the digital layout of all commercial and inspected structures

- Generate topographical maps for all response areas

- Design user interface layers for digitized data

\section{Performance Targets}

- Standardized format of digitized GIS layer data based on open architecture

- Appropriate client side mobile data computer (MDC) display

\section{Limits}

- Indication of uncertainty in accuracy of data

\section{FUTURE}

\section{Future Changes}

- Increased investment in real-time data

\section{Future Operations or CPS Issues}

- None provided

\section{Challenges}

- Pre-emergency and post-event: None provided

- During event: None provided

- Non-firefighter data user applications: None provided

- User interface delivery methods: None provided
STAKEHOLDER ROLES AND RESPONSIBILITIES

- GIS professionals

- Building officials

- Transportation departments 


\subsection{Structural Cross-Cutting}

The Structural Cross-Cutting topics selected for program development is presented below and expanded in Figures 4-I3 to 4-I5.

- Figure 4-13: Standard protocol inter-connectivity of communication devices and systems

- Figure 4-I4: Situational awareness technologies and training

- Figure 4-15: Situational awareness technologies education and standards

Additional information was provided about the needs for situational awareness technologies and related training, education, and standards (Table 4-2). This additional information is applicable to Figure 4-I5. 


\section{Figure 4- I 3: Standard Protocol InTER-Connectivity of COMmUNicAtion DEVICES AND SYSTEMS}

\section{Brief Description:}

Intelligent interoperable systems are needed to most efficiently use resources and effectively respond to incidents. The ideal system would include many features: clear voice communication in all conditions, resistance to different environmental conditions, local thresholding for digital data, and a standardized dashboard.

\section{PROGRAM APPROACH}

\section{Major Tasks}

- Identify data sets that are most important for fire service

- Detail data sets and key metrics

- Develop the sensor(s) needed and standardize output

- Deliver strategy

\section{Major Milestones}

- List top 10 data sets

- Develop standardsbased sensors to stream data in real time

- Build testbeds that can test interoperability

- Standardize protocol

\section{FUTURE}

\section{Future Changes}

- None provided

\section{Challenges}

- Communications: Accessing sensor data

- Computation: Determining data storage and processing location

- Targeted decision making: Preventing overload of information for the users

- Technology limitations: Ensuring serviceability of equipment

- Pre-emergency: Identifying appropriate level of monitoring

- During event: Developing ability to interpret, receive, and rely on data

- Post-event: Analyzing systems' performance, feeding outcomes back into the process

\section{Future Operations or CPS Issues}

- Trust of data

\section{STAKEHOLDER ROLES AND RESPONSIBILITIES}

- Fire service: Define data sets or points

- Manufacturers: Provide solutions

- Third parties: Test and certify 


\section{Figure 4- I 4: SituAtional AWARENESS TECHNOLOgies AND TRAINING}

\section{Brief Description:}

For effective and safe firefighting, it is essential to know the occupation, location, and health of firefighters; understand the dynamic fire environment; and receive an individualized information flow according to the role.

\section{PROGRAM APPROACH}

\section{Major Tasks}

- Identify gaps in training and close them

- Develop trusted means to identify and locate live occupants

- Develop trusted means to identify and locate fire ground responders

- Develop/identify key environmental data to measure and means to aggregate and analyze those data to make them actionable

\section{Major Milestones}

- 0-3 years:

o Conduct proof-of-concept demonstration of training exercises

- Investigate/support locator for Americans with Disabilities Act (ADA) occupants

- Create/support technology challenges/demonstrations

- Workshop with FF/developers to identify environmental data

- 3-5 years:

- Create/support technology challenges for civilian locator

- Review existing DOD technologies

- Identify performance metrics

- Use developed sensor technology in demonstration

\section{Performance Targets Limits}

- General acceptance/test/ openness to new technology

- Pre/past measurement of unoccupied entryl occupant recovery

- Integration/fielding of sensors in a percentage of targeted users

\section{FUTURE}

\section{Future Changes}

- None provided

\section{Future Operations or CPS Issues}

- Privacy issues

\section{Challenges}

- Communications: Data gathering

- Computation: Identifying best methods to analyze data to extract useful information

- Targeted decision making: Reaching all participants of fire grade

- Technology Limitations: Facilitating location (e.g., ability to reliably locate humans within a structure)

\section{STAKEHOLDER ROLES AND RESPONSIBILITIES}

- NIMS experts: Slice data to appropriate levels (of fire grade personnel)

- Training and cognition experts: Pre-event planning

- Fire service: Post-event feedback 


\section{FIgURE 4-I 5: SituATIONAL AWARENESS TECHNOLOgIES EDUCATION AND STANDARDS}

\section{Brief Description:}

Enhanced situational awareness could improve the ability of the fire service at all levels (e.g., firefighter, incident commander) to understand the structural fire environment. Greater understanding would enable these personnel to use a wide range of sensor data to increase FF effectiveness and safety.

\section{PROGRAM APPROACH}

\section{Major Tasks}

- Develop curricula that reflect the current understanding of fire dynamics, building construction, suppression and ventilation, and technology's caps and limitations

- Develop a national/public-private partnership for disseminating the educational information

- Develop a current or new standard information package for sensing/communication technologies

- Develop data needs for each level of fire response (see Table 4-2)

\section{Major Milestones}

- Revision of NFPA 100 I standard with respect to development of new firefighting educational standards

- Size-up decision making enabled by situational awareness technology

- Integration of physics-based situational awareness with situational awareness technology-based sensor data

- Reduced cost in collecting and maintaining pre-plan data, risk reduction, reduced incident costs

\section{Performance Targets}

- Recertification of firefighters/fire officers with 5-year standard program

- Adoption by local government to deliver situational awareness technology infrastructure (within 10 years)

\section{Limits}

- Cost and timing constraints

- Reliability, sustainability, and maintainability

\section{FUTURE}

\section{Future Changes}

- Research- and service-based firefighter education to provide a foundation for the use of situational awareness technology

- Design data delivery protocol and system based on needs (e.g., firefighter versus fire officer versus fire chief)

\section{Challenges}

- Communications: Getting data out of the building to the apparatus

- Computation: Maintaining or increasing speed (key en route to the incident and onsite)

- Targeted decision making: Integrating situational awareness sensor

- Technology limitations: Meeting need for national/local networks or simulators and technology testbeds

- Pre-emergency: Addressing limited time and funding to support education

- During event: Developing an automatic and prioritized method to recognize system failure and data overload

- Post-event: Developing and sharing post-event reports as another data set

\section{Future Operations or CPS Issues}

- Lack of desire to adopt

- Data overload of incident commander

- Recognition of CPS failure or damage

STAKEHOLDER ROLES AND RESPONSIBILITIES

- Primary emergency responder organizations 
TABle 4-2: DATA NeEds for EACH LeVel OF Fire ResPonse

\begin{tabular}{|c|c|c|c|c|}
\hline & Pre-Incident & $\begin{array}{l}\text { Priority I } \\
\text { En Route }\end{array}$ & During Incident & Post-Incident \\
\hline $\begin{array}{l}\text { Situational } \\
\text { Awareness } \\
\text { Needs }\end{array}$ & $\begin{array}{l}\text { Duration: months to } \\
\text { days } \\
\text { (standards exist, easy } \\
\text { to implement) }\end{array}$ & $\begin{array}{l}\text { Duration: } 3-5 \text { minutes } \\
\text { (maximum impact) }\end{array}$ & $\begin{array}{l}\text { Duration: } 30 \text { minutes to } \\
\text { many hours } \\
\text { (improve operation) }\end{array}$ & Duration: days \\
\hline Firefighter & $\begin{array}{l}\text { - Pre-plans for built } \\
\text { infrastructure } \\
\text { - Drills and } \\
\text { education } \\
\text { - Material safety data } \\
\text { sheet (MSDS) } \\
\text { information }\end{array}$ & $\begin{array}{l}\text { - Apparatus } \\
\text { - Check of personnel } \\
\text { monitoring systems } \\
\text { (operational) } \\
\text { - Equipment for } \\
\text { HAZMAT }\end{array}$ & $\begin{array}{l}\text { - Current localized } \\
\text { sensor information } \\
\text { - Entry/egress } \\
\text { information } \\
\text { - Live personal data (e.g., } \\
\text { biometrics, location, } \\
\text { proximity) } \\
\text { - Ongoing hazard } \\
\text { information in structure }\end{array}$ & $\begin{array}{l}\text { - Level of } \\
\text { exposure }\end{array}$ \\
\hline $\begin{array}{l}\text { Company } \\
\text { Officer } \\
\text { (first arriving } \\
\text { captain, initial } \\
\text { incident } \\
\text { commander) }\end{array}$ & $\begin{array}{l}\text { - Pre-plans for built } \\
\text { infrastructure } \\
\text { - Access to CPS } \\
\text { information } \\
\text { - Define entry and } \\
\text { access to incident } \\
\text { - MSDS information }\end{array}$ & $\begin{array}{l}\text { - Site specifics of } \\
\text { indent (e.g., } \\
\text { HAZMAT) } \\
\text { - Building real-time } \\
\text { systems data to } \\
\text { truck (e.g., alarm } \\
\text { panel data) } \\
\text { - Current occupancy } \\
\text { and usage } \\
\text { - Existing data } \\
\text { - Contact information }\end{array}$ & \multirow{2}{*}{$\begin{array}{l}\text { - Ongoing hazard in and } \\
\text { near structure } \\
\text { - Severity assessment } \\
\text { - Technology assessment } \\
\text { - Crew integrity (i.e., } \\
\text { group cohesiveness) } \\
\text { - Localized sensor } \\
\text { information and special } \\
\text { 360-degree view for fire } \\
\text { fighters (e.g., alerts for } \\
\text { those in danger) } \\
\text { - Location of fire and rate } \\
\text { of change } \\
\text { - Perimeter set-up } \\
\text { - Command post set-up } \\
\text { (e.g., building and event } \\
\text { data) } \\
\text { - Recognition failure } \\
\text { levels of CPS system } \\
\text { - Ongoing hazard } \\
\text { information around } \\
\text { incident } \\
\text { - Determination of } \\
\text { additional monitoring to } \\
\text { be done (e.g., facilitate } \\
\text { set-up for new sensing) }\end{array}$} & \multirow[t]{2}{*}{$\begin{array}{l}\text { - Identification } \\
\text { of the } \\
\text { characteristics } \\
\text { of arson and } \\
\text { provision of } \\
\text { evidence to } \\
\text { law } \\
\text { enforcement } \\
\text { for } \\
\text { investigation }\end{array}$} \\
\hline $\begin{array}{l}\text { Chief Officer } \\
\text { (for larger } \\
\text { incidents) }\end{array}$ & $\begin{array}{l}\text { - Pre-plans for built } \\
\text { infrastructure } \\
\text { - Access to CPS info } \\
\text { - Occupancy and } \\
\text { usage } \\
\text { - MSDS information }\end{array}$ & $\begin{array}{l}\text { - Evaluation status } \\
\text { - Site specifics of } \\
\text { incident (e.g. } \\
\text { HAZMAT) } \\
\text { - Building real-time } \\
\text { systems data to } \\
\text { truck (alarm panel } \\
\text { data) } \\
\text { - Current occupancy } \\
\text { and usage } \\
\text { - Existing data } \\
\text { - Contact information }\end{array}$ & & \\
\hline $\begin{array}{l}\text { Offsite } \\
\text { Entities } \\
\text { (emergency } \\
\text { operations } \\
\text { center, } \\
\text { dispatch, } \\
\text { department of } \\
\text { operations } \\
\text { center) }\end{array}$ & $\begin{array}{l}\text { - Emergency } \\
\text { contacts for offsite } \\
\text { consequences (e.g., } \\
\text { city, county, } \\
\text { officials) } \\
\text { - MSDS information } \\
\text { - External data } \\
\text { sources (e.g., } \\
\text { weather) } \\
\text { - Occupancy and } \\
\text { usage } \\
\text { - CPS-related } \\
\text { information for } \\
\text { region }\end{array}$ & $\begin{array}{l}\text { - Building-specific } \\
\text { CPS information } \\
\text { gathered and } \\
\text { assimilated at } \\
\text { dispatch time for } \\
\text { delivery to } \\
\text { responders, } \\
\text { company officers, } \\
\text { and chief officers } \\
\text { - Volumes of } 91 \mathrm{I} \text { calls } \\
\text { - Determination of } \\
\text { provenance of data }\end{array}$ & $\begin{array}{l}\text { - Status monitoring and } \\
\text { determination of } \\
\text { incident support needs } \\
\text { - Mutual aid specialty } \\
\text { resources } \\
\text { - Notifications to public } \\
\text { and other entities }\end{array}$ & $\begin{array}{l}\text { - Status } \\
\text { monitoring }\end{array}$ \\
\hline
\end{tabular}




\subsection{Non-Structural Cross-Cutting}

The Non-structural Cross-cutting topics selected for program development is presented below and expanded in Figures 4-16 to 4-19.

- Figure 4-16: Full-scale testbeds

- Figure 4- 17: Interface standards in hardware, software, common data models, and formats

- Figure 4- 18: New algorithms for uncertainty

- Figure 4-19: Simple and intuitive user interface 


\section{Figure 4-I 6: Full-SCALE Testbeds}

\section{Brief Description:}

The application of new technologies to the fire service mission requires a process to demonstrate the application and the benefits derived from the technology. Having clear metrics and testbeds for feasibility demonstrations allows end users to make accurate comparisons between products, communicate their needs, influence industry-recognized criteria, and measure operational improvements.

\section{PROGRAM APPROACH}

\section{Major Tasks}

- Establish CPS advisory group to "own" the process

- Perform gap/needs analysis

- Identify key federal agencies and funding

- Solicit R\&D proposals from industry
Major Milestones

- 0-3 years:

- Conduct gap/needs analysis

- Identify current best practices in military and other industry

- 3-5 years:

- Develop prototype and beta test

- Develop standard and guidance for manufacturers and users

- 5+ years:

- Develop user community support system to sustain the process
Performance Targets

- Consensus on standards

- Scalable product that addresses rural, suburban, and urban fire service needs
Limits

- Tools not a replacement for common sense and experience

- Interoperability in multi-vendor environment

\section{FUTURE}

\section{Future Changes}

- Field deployment and user feedback

- Active R\&D program

- Increased R\&D and decreased costs as capabilities move to market

\section{Future Operations or CPS Issues}

- Information overloads for users

- Security and privacy

\section{Challenges}

- Communications: None provided

- Computation: None provided

- Targeted decision making: None provided

- Technology limitations: None provided

- Pre-emergency: None provided

- During event: None provided

- Post-event: None provided

\section{STAKEHOLDER ROLES AND RESPONSIBILITIES}

- Researchers: Provide gap analysis of existing standards and community stakeholder needs

- Standards developer: Produce industry standards

- Responder community: Develop awareness and provide testbed and demonstration sites

- Manufacturers: Commence R\&D activities 


\section{FIGURE 4-I 7: INTERFACE STANDARDS FOR HARDWARE, SOFTWARE, COMMON DATA MODELS, AND FORMATS}

\section{Brief Description:}

Interoperability standards for firefighting CPS need to be developed to improve efficiency of the systems and firefighting efforts.

\section{Program APPROACH}

\section{Major Tasks}

- Develop universal standards for data exchange through interconnection nodes through the CPS

- Develop interoperability and scalability standards for universal hardware application

- Develop software standards that meet data exchange interoperability standards

- Develop standards for the HMI experience
Major Milestones

- $\underline{0-3}$ years:

o Human interface standard for fire service

- 3-5 years:

o Interconnection standards

- Software standards data exchange

- 5-7 years:

o Interoperability and scalability standards

\section{FUTURE}

\section{Future Changes}

- Improved training standards

- Interoperable equipment

- Paradigm shift from conventional to smart firefighting

\section{Challenges}

- Communications: Identifying the useful data and types of data

- Computation: Developing capability to handle data volume and speed

- Targeted decision making: Managing reliability and trustworthiness (uncertainty)

- Technology limitations: Managing interoperability and scalability

- Pre-emergency: None provided

- During event: Prioritizing information to complement decision making

- Post-event: Using lessons learned to revise and improve standards

\section{Future Operations or CPS Issues}

- Culture

- Trust

- System dependency

STAKEHOLDER ROLES AND RESPONSIBILITIES

- Standards developing organizations

- Policymaking organizations/agencies

- Manufacturers

- End users (e.g., emergency response community) 


\section{Figure 4- I8: NeW AlgorithmS for UnCERTAinty}

\section{Brief Description:}

In the non-structural firefighter response environment, multiple unknown variables exist that would affect accuracy of CPS solutions. Algorithms must be developed to account for these unknowns.

\begin{tabular}{|c|c|c|c|}
\hline \multicolumn{4}{|c|}{ PROGRAM APPROACH } \\
\hline $\begin{array}{l}\text { Major Tasks } \\
\text { - Create knowledge base by } \\
\text { adequately describing the } \\
\text { firefighting domain } \\
\text { - Identify past events that could } \\
\text { be used as training } \\
\text { - Assemble ideas into a decision } \\
\text { support tool incorporating } \\
\text { human factors } \\
\text { - Develop user interface }\end{array}$ & $\begin{array}{l}\text { Major Milestones } \\
\text { - Conduct critical review } \\
\text { of past incidents and } \\
\text { technology (I-2 years) } \\
\text { - Identify needs and gaps } \\
\text { that create uncertainty } \\
\text { - Invent coding adaptive } \\
\text { algorithms } \\
\text { - Complete field testing }\end{array}$ & $\begin{array}{l}\text { Performance Targets } \\
\text { - A critical review of } \\
\text { models and incidents to } \\
\text { better understand factors } \\
\text { that affect fire behavior } \\
\text { - Development of software }\end{array}$ & $\begin{array}{l}\text { Limits } \\
\text { - Ability to quantify } \\
\text { uncertainty } \\
\text { - Limited by number of } \\
\text { inputs from existing } \\
\text { technology }\end{array}$ \\
\hline
\end{tabular}

\section{FUTURE}

\section{Future Changes}

- Framework to account for uncertainty

\section{Future Operations or CPS Issues}

- Culture of integrating decision support tool

- Trust of technology over human decision making

\section{Challenges}

- Communications: Only as good as data input

- Computation: Importance of speed (scalability)

\section{STAKEHOLDER ROLES AND RESPONSIBILITIES}

- Computer scientists

- Fire subject matter experts

- Funding agency: e.g., FEMA, FISP, Joint Fire Sciences Working Group 


\section{FIGURE 4- I 9: SIMPLE AND INTUITIVE USER INTERFACE}

\section{Brief Description:}

A well-designed user interface should provide the user with access to relevant technology and data using appropriate PPE.

\section{PROGRAM APPROACH}

\section{Major Tasks}

- Go through development process (e.g., testing, beta release, final release)

- Work with users to determine final product

- Use successful products as examples

- Involve the experts (e.g., Google, Apple, etc.)

\section{Major Milestones}

- Upgrade and improve existing user interfaces

- Evaluate feedback on beta and final releases

\section{Performance Targets Limits}

- Broad use and added value to fire service groups

- Mode of user interface utilization by fire service groups

- Functions with existing and new technology

\section{FUTURE}

\section{Future Changes}

- Safer, more effective work

- Better use of resources

\section{Future Operations or CPS Issues}

- Loss of "hands-on" experience and problem-solving skills

- Overreliance on the technology

\section{Challenges}

- Communications: Additional use on the job for feedback without interrupting or distracting firefighters

- Computation: Decision needed regarding client/server or client-only cloud

- Targeted decision making: Creation of a well-defined application scope

- Technology limitations: Inoperable touch screen with gloves; interference of background noise with voice interface

- Pre-emergency: Undefined data needs during an event

- During event: User interface may or may not be different; undefined method to provide relevant information in a timely manner

- Post event: Undefined beginning of post event; afteraction review
STAKEHOLDER ROLES AND RESPONSIBILITIES

\section{- Software vendors}

- Users

- Industry regulatory bodies 


\section{Summary}

Incorporation of CPS capabilities into the fire service could provide significant enhancements to improve the safety and effectiveness of fire protection and firefighting. In an effort to galvanize stakeholder attention on this topic the Smart Firefighting Workshop was held on March 24-25, 20I4, in Arlington, Virginia. This meeting assembled members of the fire service, CPS, and fire protection communities to identify key development areas - technical and non-technical - that are needed to take advantage of the volumes of data generated during all phases of a fire incident. The most beneficial concepts as identified by the workshop participants were prioritized and then expanded into potential program plans. Several common themes emerged including the following:

- Use of sensors on the fire ground to assist in situational awareness and personnel location

- Increased collection and utilization of data before the incident to aid in effective use of personnel and equipment

- Enhance interoperability between data systems

- Develop intelligent systems to assist with decision making

This report summarizes the results of the workshop and will serve to guide the development of a research roadmap on smart firefighting providing guidance for the research community as they consider developing programs focused on providing the science and standards needed to enable safer and more effective fire protection and firefighting. The material contained in this report will aid both the public and private sectors in development of policy, R\&D, and other firefighting related decision making. 


\section{Appendix A: Contributors}

Contributors listed alphabetically

Robert Athanas

Fire Department City of New York

Roger Barker

North Carolina State University

Andrew Berezowski

Honeywell Fire Systems

Steve Bridgewater

Siemens

Keith Bryant

Metro Chiefs Representative

Nelson Bryner

NIST

Brett Butler

Missoula Fire Sciences Laboratory, U.S. Forest

Service

Corey Butler

National Institute for Occupational Safety and

Health

\section{Alan Butsch}

Montgomery County Fire Rescue Service

Jeff Chen

Fire Department City of New York - Analytics Unit

John Cunningham

New Jersey Firefighter School/North American Fire

Training Directors

DK Ezekoye

University of Texas

Simon Frechette

NIST

Wendy Gifford

NestLabs

Nada Golmie

NIST

Jay Gore

Purdue University

Casey Grant

Fire Protection Research Foundation
Paul Greenberg

NASA

Kristen Greene

NIST

\section{Anthony Hamins}

NIST

Howard Harary

NIST

Bill Haskell

National Institute for Occupational Safety and

Health

Hylton Haynes

National Fire Protection Association

Everett Hinkley

U.S. Forest Service

Gavin Horn

University of Illinois

Art Hsu

United Technologies

Patrick Jackson

Rocky Mount Fire Department (NC)

Ashish Jain

Applied Communication Sciences

Al Jones

NIST

David Kerr

IFMA Representative

Clare King

Propell/Globe

Danny Kistner

McKinney Fire TX

Galen Koepke

NIST

Adam Krasuski

Main School of Fire Service Warsaw (Poland)

Amit Kulkarni

Honeywell Research Lab 


\section{Neil Lakomiak}

Underwriters Laboratories Inc.

Brian Lattimer

Virginia Tech

David M. Lewis

National Volunteer Fire Council Representative

Dan Madrzykowski

NIST

A.W Marshall

University of Maryland

Brian Martens

Harris Corporation

Eric Matson

Purdue University

Michael May

U.S. Department of Defense

Brian Meacham

Worcester Polytechnic Institute

Mark Micire

Defense Advanced Research Projects Agency

Richard Miller

International Association of Fire Chiefs

Lori Moore-Merrell

International Association of Fire Fighters

Eric Nickel

Palo Alto Fire Department

Philip Oakes

National Association of State Fire Marshals

Kristopher Overholt

NIST

Matt Paiss

San Jose Fire Department

Isaac Papier

Honeywell
Jason Pelski
Tyco

Dean Pickering

Harris

Edward Plaugher

International Association of Fire Chiefs

Jeff Roth

Fire Department City of New York

Deuir Smith

Skidmore College

Fumiaki Takahashi

Case Western Reserve University

Mary Theofanos

NIST

Steve Townsend

Carrolton Fire TX

Robert Tutterow

F.I.E.R.O.

Nalini Venkatasubramanian

University of California, Irvine

Peter Wang

Continuum Analytics

Ken Willette

National Fire Protection Association

Joseph Woznica

Fire Department City of New York- Bureau of Fire

Prevention

Jiann Yang

NIST

Justyna Zander

MathWorks

Robin Zevoter

Underwriters Laboratories Inc. 


\section{Appendix B: Acronyms}

\begin{tabular}{|c|c|}
\hline CAD & Computer Aided Dispatch \\
\hline CPS & cyber-physical system \\
\hline DHS & Department of Homeland Security \\
\hline DOD & Department of Defense \\
\hline EL & Engineering Laboratory \\
\hline EMS & Emergency Medical Service \\
\hline FDNY & Fire Department City of New York \\
\hline FEMA & Federal Emergency Management Agency \\
\hline FF & firefighter \\
\hline FIERO & Fire Industry Equipment Research Organization \\
\hline FPRF & Fire Protection Research Foundation \\
\hline GPS & Global Positioning System \\
\hline GIS & geographic information system \\
\hline HAZMAT & Hazardous Materials Response \\
\hline $\mathrm{HCl}$ & human-computer interface \\
\hline HIPAA & Health Insurance Portability and Accountability Act of 1996 \\
\hline IAFC & International Association of Fire Chiefs \\
\hline IAFF & International Association of Fire Fighters \\
\hline IAP & incident action plan \\
\hline IBC & International Building Code \\
\hline IC & Incident Commander \\
\hline ICC & International Code Council \\
\hline IDLH & immediately dangerous to life or health \\
\hline IFMA & International Fire Marshals Association \\
\hline IOT & internet of things \\
\hline LAN & local area network \\
\hline MDC & mobile data computer \\
\hline MSDS & Material Safety Data Sheet \\
\hline NFIRS & National Fire Incident Reporting System \\
\hline N-FORS & National Fire Operations Reporting System \\
\hline NFPA & National Fire Protection Association \\
\hline NGO & non-government organization \\
\hline
\end{tabular}

B-I 


$\begin{array}{ll}\text { NIMS } & \text { National Incident Management System } \\ \text { NIST } & \text { National Institute of Standards and Technology } \\ \text { NVFC } & \text { National Volunteer Fire Council } \\ \text { PAN } & \text { personal area network } \\ \text { PPE } & \text { personal protective equipment } \\ \text { QA } & \text { quality assurance } \\ \text { SCBA } & \text { self-contained breathing apparatus } \\ \text { UAS } & \text { unmanned aircraft system } \\ \text { UAV } & \text { unmanned aerial vehicle } \\ \text { UGV } & \text { unmanned ground vehicle } \\ \text { UI/UX } & \text { user interface/user experience } \\ \text { WoF } & \text { working on fire } \\ \text { WUI } & \text { Wildland-Urban Interface }\end{array}$




\title{
Appendix C: Workshop Agenda
}

\section{Monday - Tuesday, 24-25 March 2014 Sheraton Crystal City Hotel}

\author{
I 800 Jefferson Davis Hwy, Arlington, VA (Phone: 703-486-IIII)
}

Agenda last updated: 12 March 2014

\section{$A$ one and one-half-day interactive workshop in support of the project to \\ "Develop a Research Roadmap for Smart Fire Fighting"}

\section{BACKGROUND:}

The fire service and other emergency first responders are currently benefiting from enhancedexisting and newly-developed electronic technologies. Firefighters are now operating in an ever increasing sensor rich environment that is creating vast amounts of potentially useful data. The "Smart" firefighting of tomorrow is envisioned as being able to fully exploit select data to perform work tasks in a highly effective and efficient manner. Behind the advances of the new sensor and tool enhanced firefighter of tomorrow are profound questions of how to best enable effective use of this deluge of valuable information. This is an area that is informed by the field of "cyber-physical systems" and which promises to change the world of firefighting as we know it.

This workshop is being held to support a NIST funded research project to develop a "Research Roadmap for Smart Fire Fighting". This is focused on addressing how best to effectively use the immense quantity of data available from buildings, communities and on the fire ground, the computational power to compute and communicate that data, the knowledge base and algorithms to most effectively process the data, converting it into significant knowledge/beneficial decision tools, and effectively communicate the information to those who need it, when they need it --- on the fire ground and elsewhere.

\section{WORKSHOP GOALS AND ANTICIPATED OUTCOMES:}

The goals and outcomes from this workshop are:

(a) Establish dialogue among subject matter experts familiar with the unique characteristics of firefighting and cyber physical systems.

(b) Promote a better understanding of data opportunities available to the fire service.

(c) Clarify the collective vision of the ultimate research roadmap expected as deliverables for this project. 


\section{PlanNed Agenda (24-25 MARCH 2014$):$}

\begin{tabular}{|c|c|c|}
\hline 8:00 am & Introductory Remarks: Workshop Overview & Casey Grant, FPRF \\
\hline $8: 10 \mathrm{am}$ & Welcoming Remarks: The NIST Vision & Howard Harary, NIST \\
\hline $8: 20 \mathrm{am}$ & $\begin{array}{l}\text { Welcoming Remarks: Overview of Smart Fire Fighting and } \\
\text { Cyber Physical Systems }\end{array}$ & Anthony Hamins, NIST \\
\hline $8: 30 \mathrm{am}$ & $\begin{array}{l}\text { Presentation: Federal Government Vision for Integrating } \\
\text { Cyber Physical Systems with the Fire Service }\end{array}$ & Richard Voyles, OSTP \\
\hline $8: 50 \mathrm{am}$ & $\begin{array}{l}\text { Presentation: Our Changing World from a Fire Fighting } \\
\text { Perspective: } \\
\text { (a) Addressing State-of-the-Art; (b) Defining the Problem; (c) } \\
\text { Clarifying the Challenges; (d) Prioritizing the Details }\end{array}$ & Glenn Gaines, USFA \\
\hline $9: 10 \mathrm{am}$ & $\begin{array}{l}\text { Presentation: Our Changing World from a Cyber Physical } \\
\text { Systems Perspective: (a) Addressing State-of-the-Art; (b) } \\
\text { Defining the Problem; (c) Clarifying the Challenges; (d) } \\
\text { Prioritizing the Details }\end{array}$ & Sokwoo Rhee, NIST \\
\hline $9: 30 \mathrm{am}$ & $\begin{array}{l}\text { Presentation: Cyber Physical Systems and the Fire Service - } \\
\text { the FDNY Perspective }\end{array}$ & $\begin{array}{l}\text { Jeff Roth \& Jeff Chen, FDNY } \\
\text { Analytics }\end{array}$ \\
\hline 9:50 am & Networking Break & \\
\hline $10: 10 \mathrm{am}$ & $\begin{array}{l}\text { Panel Discussion: } \\
\text { Bringing Cyber Physical Systems to the Fire Service - Review } \\
\text { of Experience, Applications and Opportunities }\end{array}$ & $\begin{array}{l}\text { Moderator: Al Jones (NIST); } \\
\text { Panelists: } \\
\text { Glenn Gaines (USFA), } \\
\text { Eric Nickel (Palo Alto FD), } \\
\text { Patrick Jackson } \\
\text { (Rocky Mount FD), } \\
\text { Michael May (DoD), } \\
\text { Jeff Chen (FDNY Analytics), } \\
\text { Nalini Venkatasubramanian } \\
\text { (UC-Irvine) }\end{array}$ \\
\hline II:40 am & Presentation: Road mapping Vision and Chapter Outline & Nelson Bryner, NIST \\
\hline $12: 00 \mathrm{pm}$ & $\begin{array}{l}\text { Breakout Group Introduction: Breakout Group Assignment } \\
\text { Review } \\
\text { - Breakout Group I: Data Gathering } \\
\text { - Breakout Group II: Data Processing } \\
\text { - Breakout Group III: Decision Making } \\
\text { - Breakout Group IV: Cross-Cutting (Structural) } \\
\text { - Breakout Group V: Cross-Cutting (Non-Structural) }\end{array}$ & Casey Grant, FPRF \\
\hline $12: 10 \mathrm{pm}$ & Working Lunch & \\
\hline $\mathrm{I}: 10 \mathrm{pm}$ & $\begin{array}{l}\text { Breakout Session Preview: Introductions and Agenda } \\
\text { Review }\end{array}$ & Energetics- Plenary \\
\hline $\mathrm{l}: 25 \mathrm{pm}$ & Breakout Session I: State of the Art & Workshop Groups \\
\hline
\end{tabular}




\begin{tabular}{|l|l|l|}
\hline 2:10 pm & Breakout Session 2: Development Needs & Workshop Groups \\
\hline 3:00 pm & Breakout Session 3: Other Requirements & Workshop Groups \\
\hline 3:30 pm & Breakout Session Prioritization & Workshop Groups \\
\hline 3:45 pm & Break & \\
\hline 4:00 pm & Breakout Group Presentations & Plenary \\
\hline 4:50 pm & Day One Closing Remarks and Day Two Instructions & NIST \& Energetics \\
\hline 5:00 pm & Adjourn Day One & \\
\hline
\end{tabular}

\begin{tabular}{|l|l|l|}
\hline 8:30 am & Day Two Opening and Review of Day One Priorities & Plenary \\
\hline $9: 00 \mathrm{am}$ & Breakout Session 4: Small Group Work & Workshop Groups \\
\hline I0:30 am & Break & \\
\hline I0:45 am & Break-out Group Reports and Plenary Discussion & Plenary \\
\hline II:35 am & Closing Remarks & \\
\hline II:45 am & Adjournment & \\
\hline
\end{tabular}




\section{Appendix D: Overview Briefings}

Several presentations were given at the beginning of the workshop to set the stage for the discussions. Those presentations, provided in this appendix, are as follows:

- Introductory Remarks: Workshop Overview, Casey Grant, FPRF

- Welcoming Remarks: The NIST Vision, Howard Harary, NIST

- Welcoming Remarks: Overview of Smart Fire Fighting and Cyber Physical Systems, Anthony Hamins, NIST

- Federal Government Vision for Integrating Cyber Physical Systems with the Fire Service, Richard Voyles, OSTP

- Our Changing World from a Fire Fighting Perspective, Glenn Gaines, USFA

- Our Changing World from a Cyber Physical Systems Perspective, Sokwoo Rhee, NIST

- Cyber Physical Systems and the Fire Service - the FDNY Perspective, Jeff Roth \& Jeff Chen, FDNY Analytics 


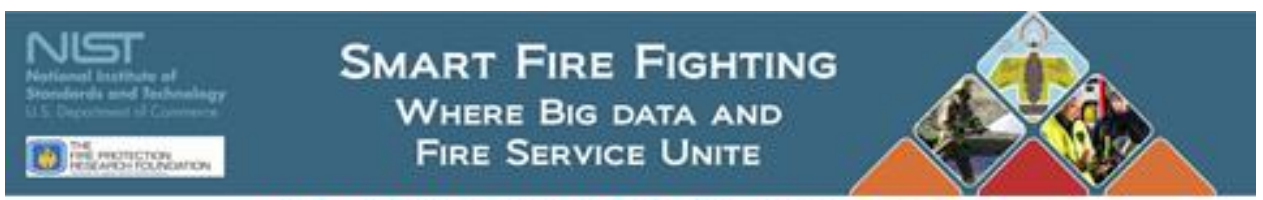

\section{4-25 MARCH2014 ARUNGTON, VA}

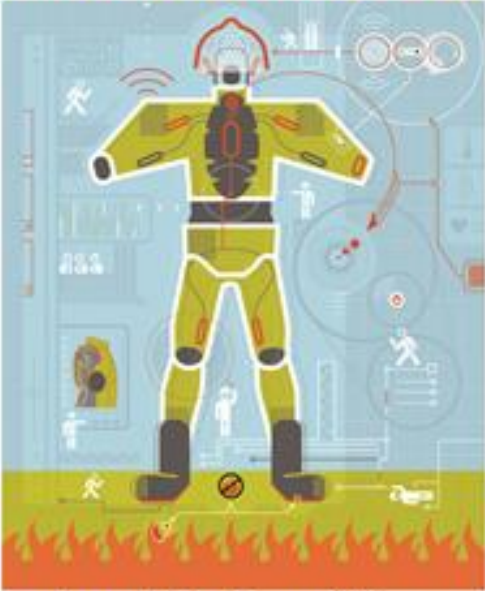

CaseyC. Grant, Research Director

Fire Protedion Research Foundation Quincy. Massachusetts USA
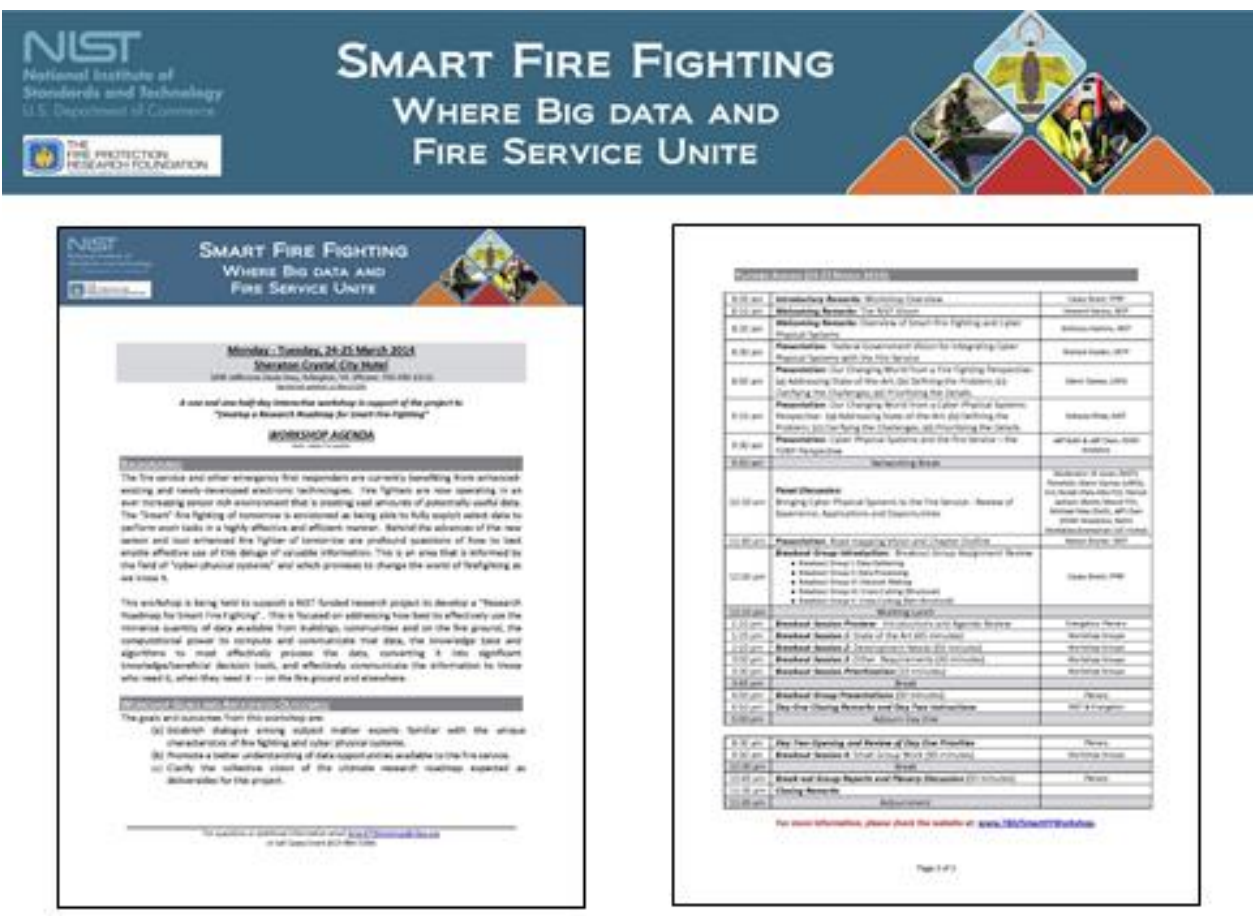


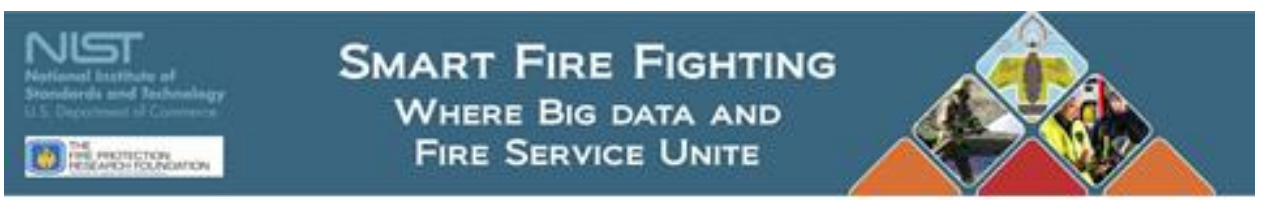

\begin{tabular}{|c|c|c|}
\hline 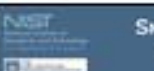 & 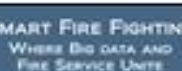 & \\
\hline$=$ & 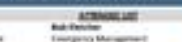 & -- \\
\hline$=$ & - & $=$ \\
\hline$=-$ & $=-$ & $=$ \\
\hline$=$ & $=$ & $=$ \\
\hline$=$ & $=-$ & $\equiv$ \\
\hline 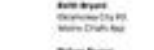 & $E=$ & $\equiv$ \\
\hline$=-$ & $=$ & $=-$ \\
\hline$=$ & $=$ & $=$ \\
\hline$=$ & $=$ & $=$ \\
\hline$=$ & $=-$ & $=$ \\
\hline$=0$ & $=-$ & $=$ \\
\hline$=$ & $=$ & $=-$ \\
\hline$=0$ & $=-$ & $=$ \\
\hline$=$ & $=$ & $=$ \\
\hline$\because$ & $=-$ & $=$ \\
\hline & $=$ & \\
\hline
\end{tabular}

\begin{tabular}{|c|c|c|}
\hline 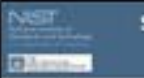 & 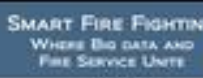 & \\
\hline$=$ & 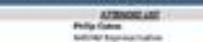 & $=$ \\
\hline$=$ & $=-$ & $=-$ \\
\hline$=$ & $=-\infty$ & $=$ \\
\hline$=-$ & $=-1$ & $=$ \\
\hline$=$ & $=-$ & $=$ \\
\hline$=$ & $=-$ & $=-$ \\
\hline$=-$ & $=-$ & \\
\hline$=$ & $=$ & $=$ \\
\hline$=-$ & $=$ & $\ldots$ \\
\hline$=$ & $=$ & $=$ \\
\hline$=-$ & $=$ & $=$ \\
\hline$=$ & $=-$ & \\
\hline$z=$ & $=$ & $=$ \\
\hline$=-$ & $=$ & $=$ \\
\hline$=$ & $=-$ & $=$ \\
\hline$==-\infty$. & $=-\infty$ & \\
\hline
\end{tabular}
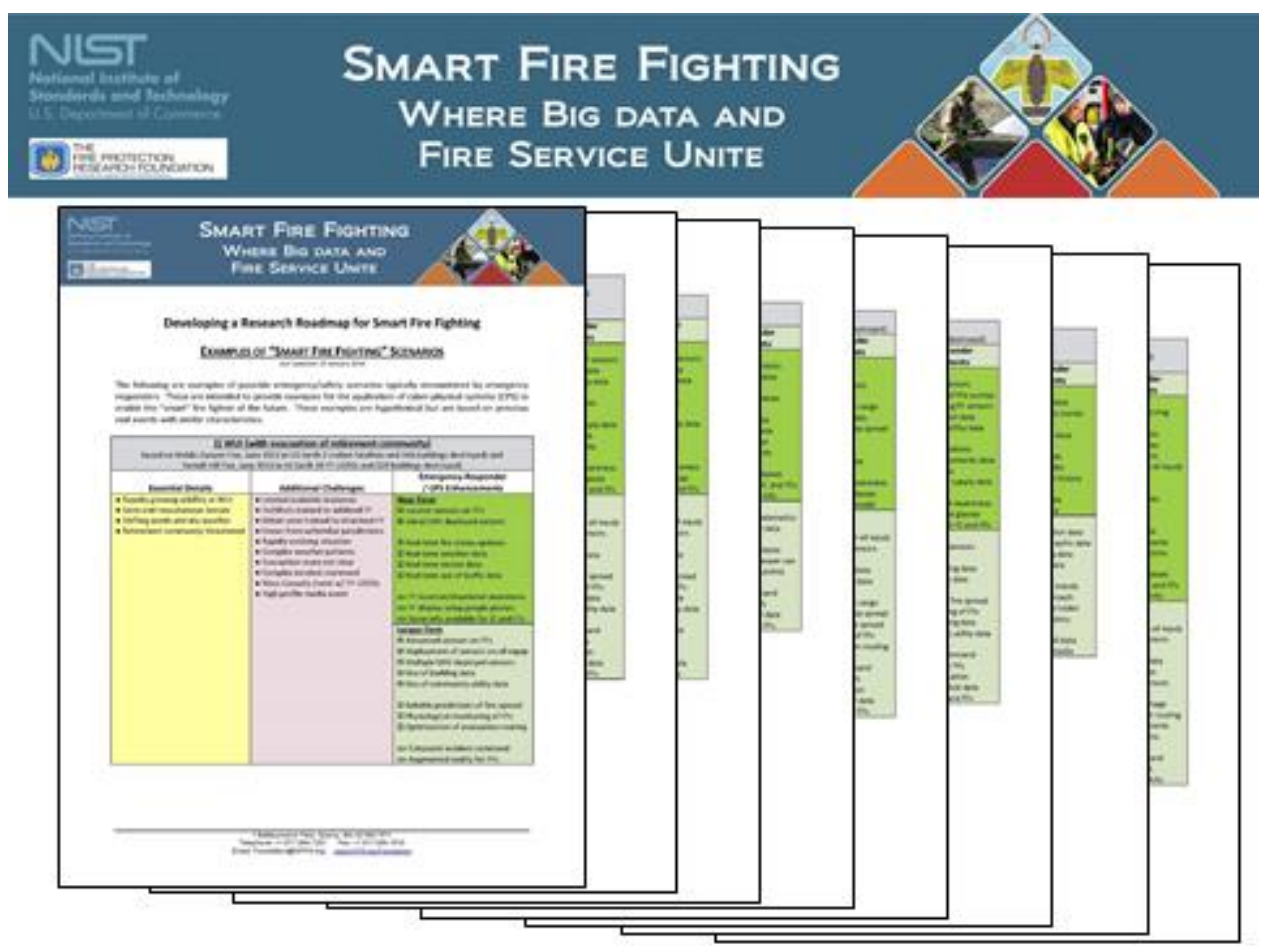

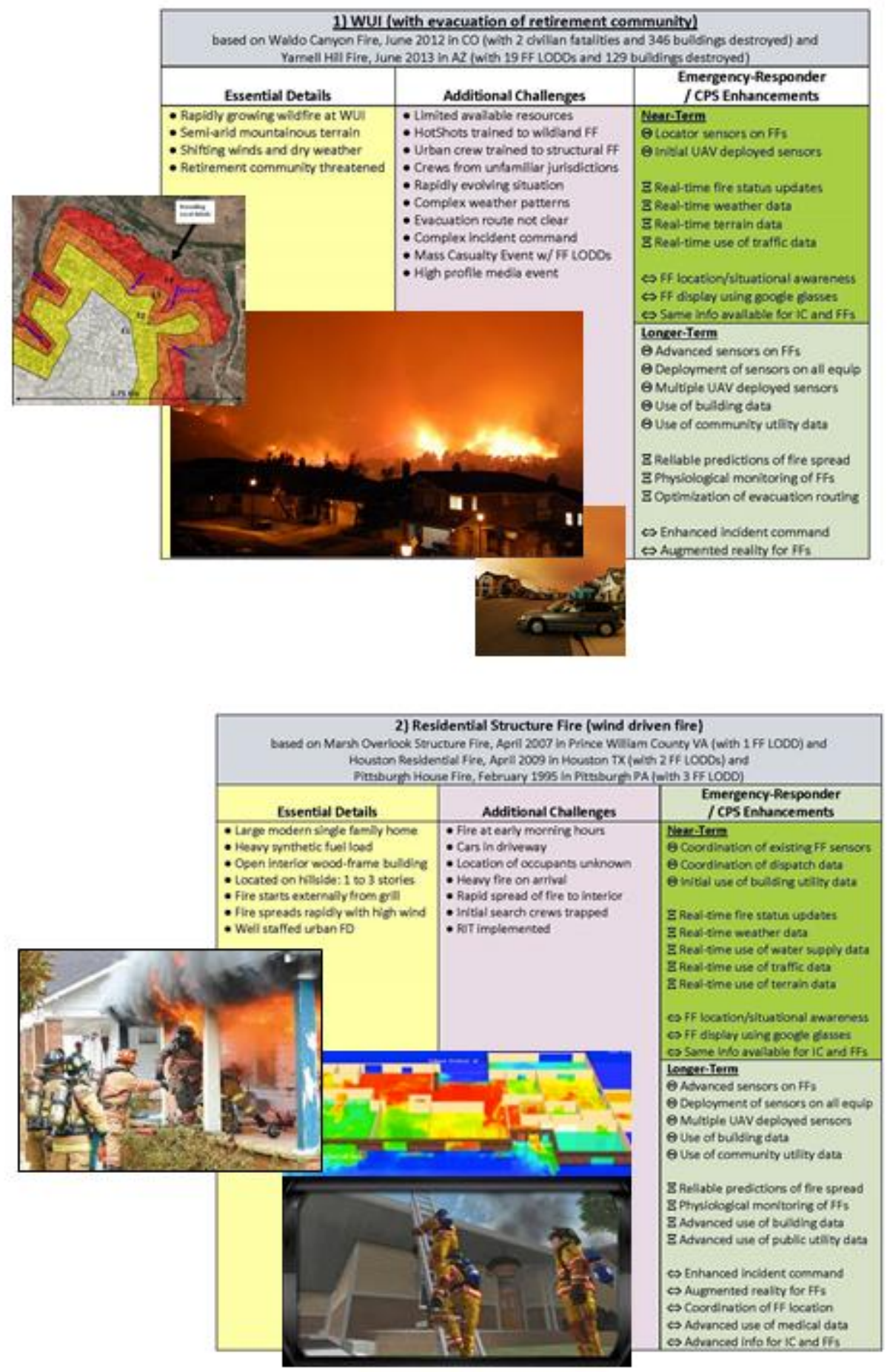


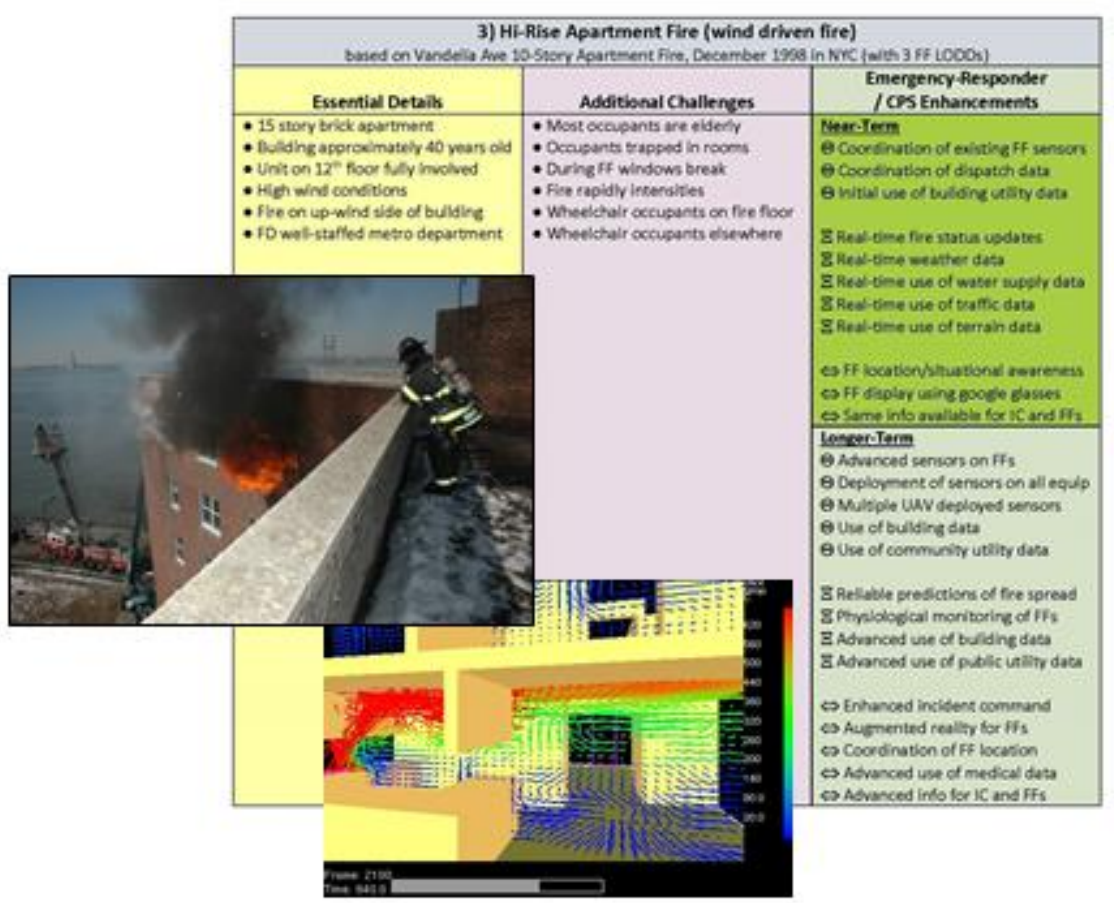

4) Vehicle Crash (ICEV and EV with entrapment)

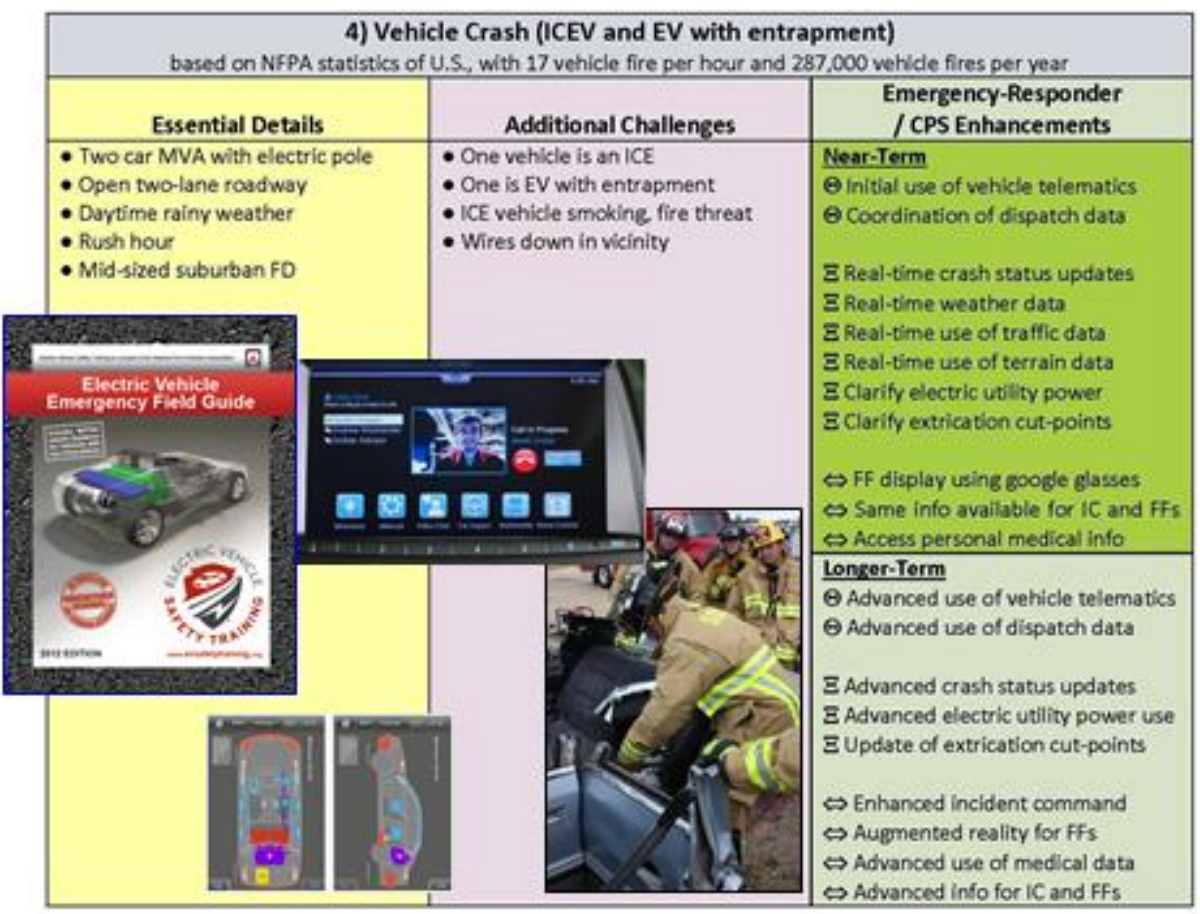



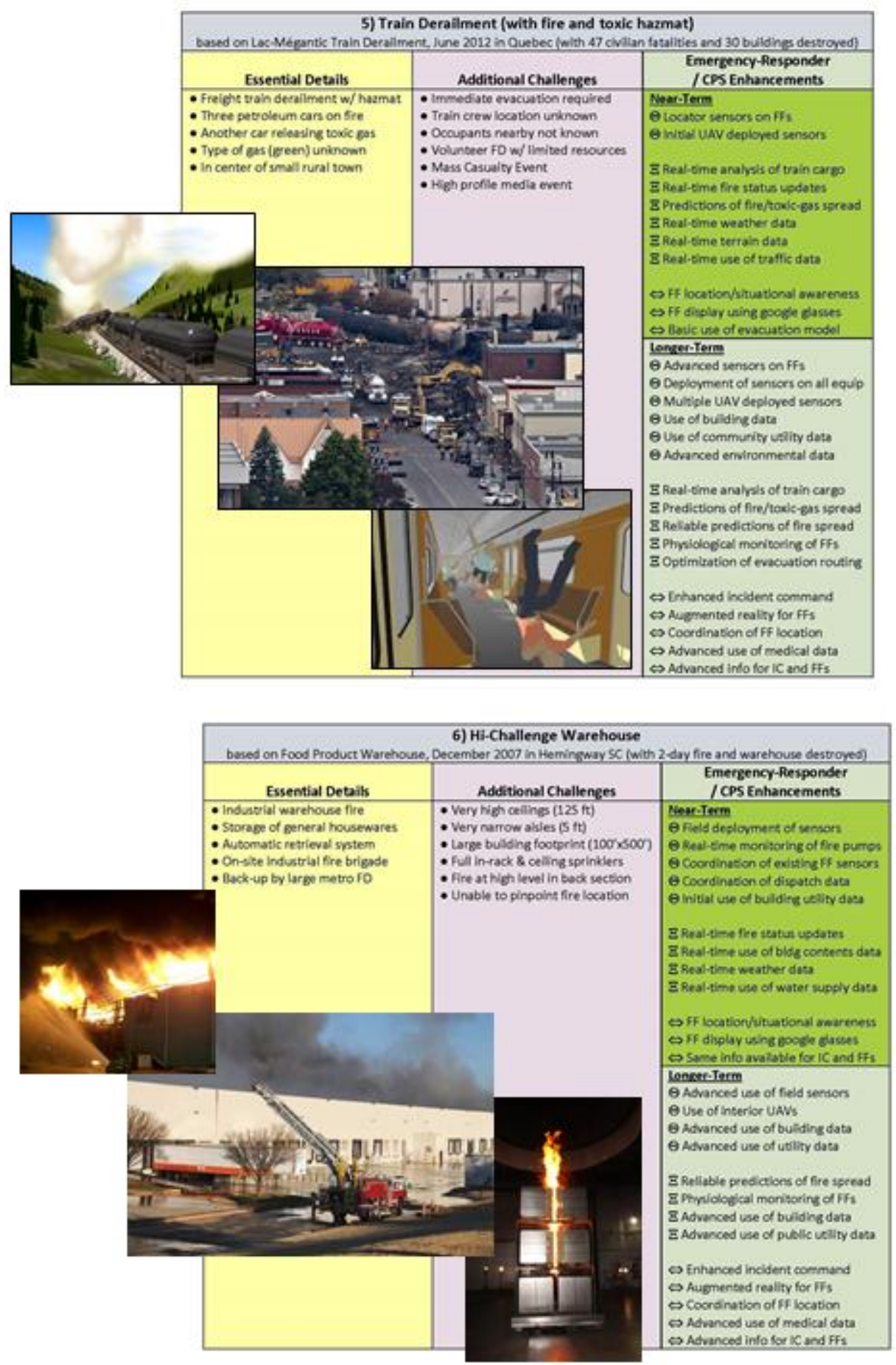

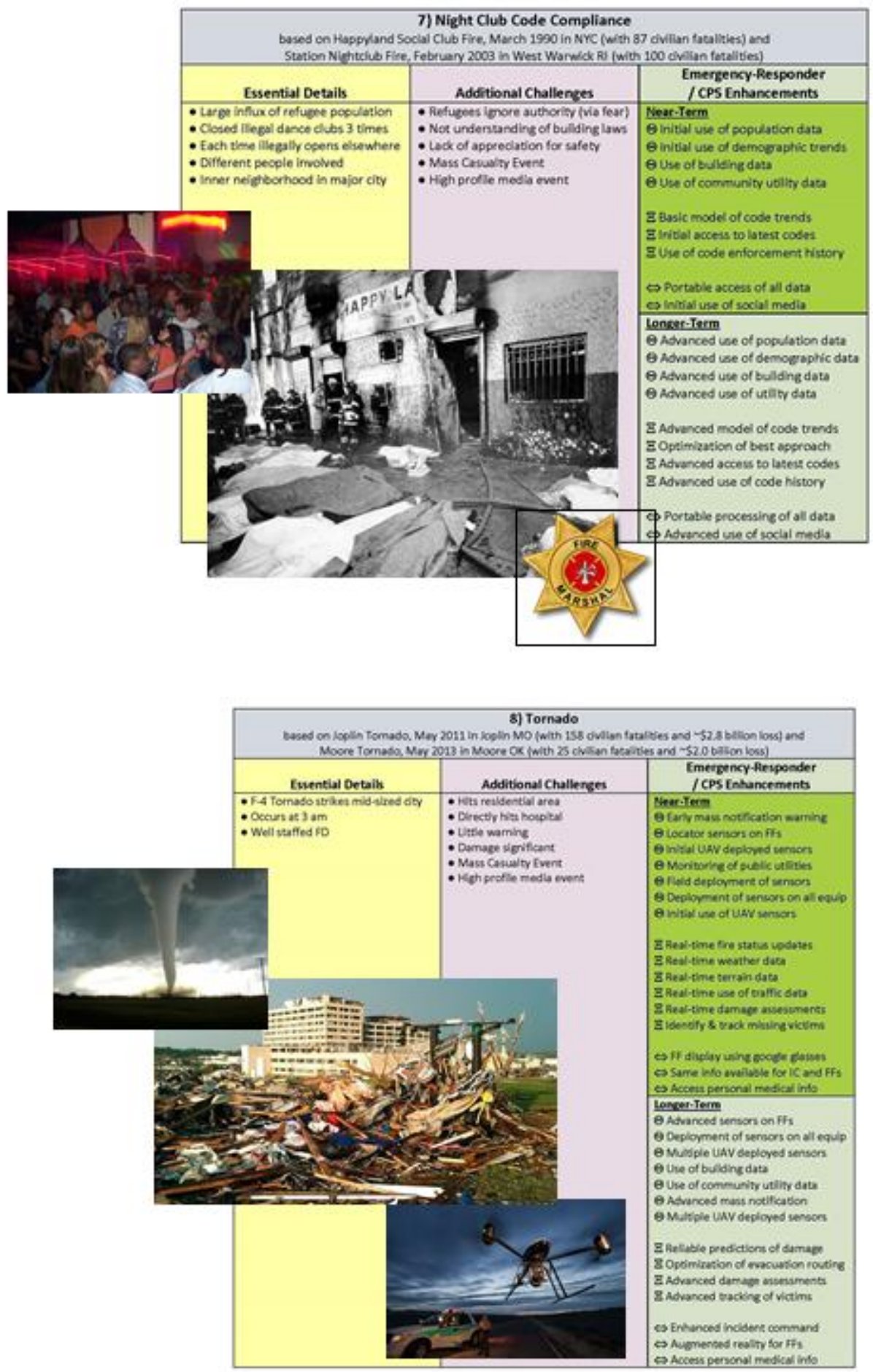

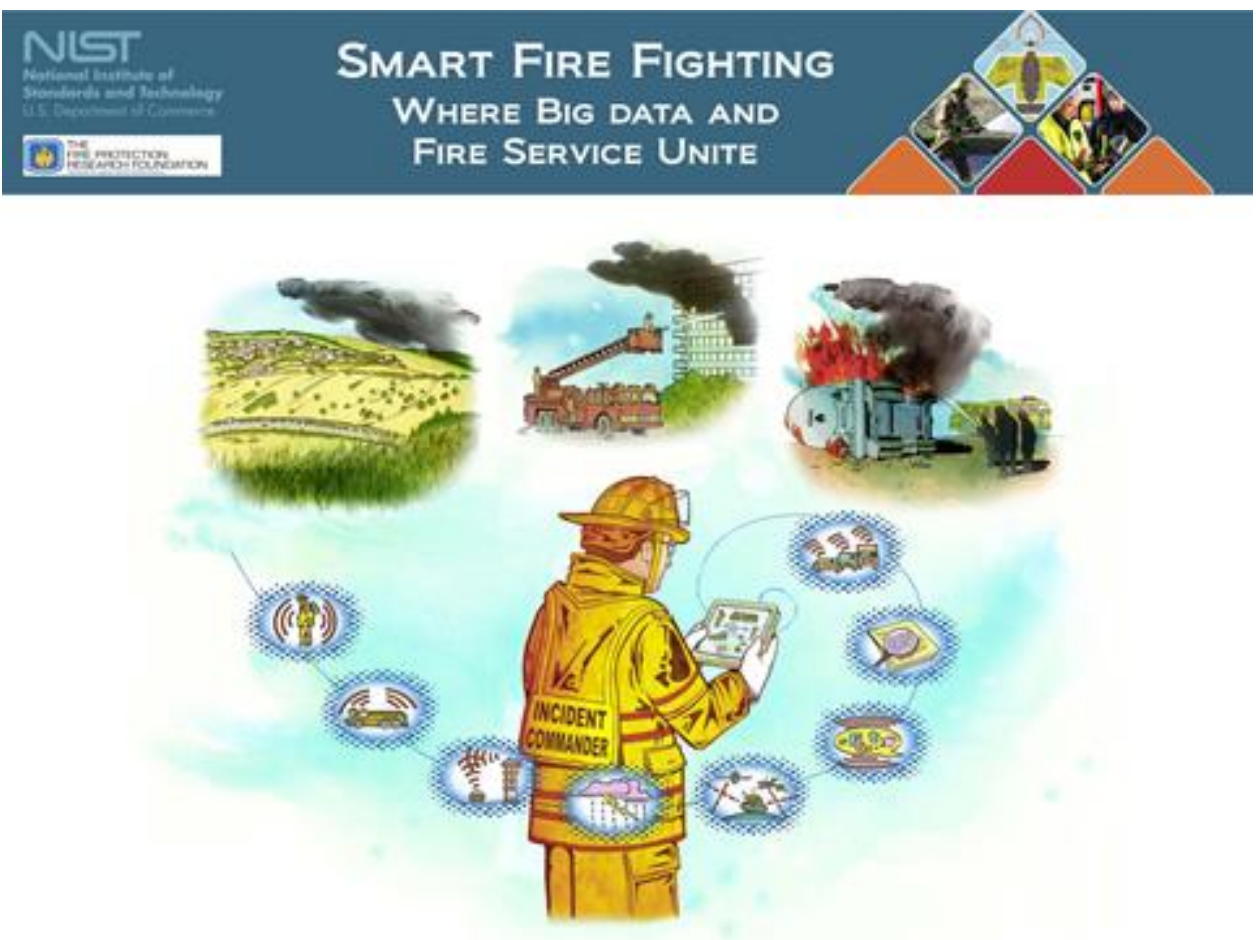

Contact Information:

Casey C. Grant, P.E

Fire Protection Research Foundation

One Balterymarch Park, Quircy, MAUSA02169-7471

Phone:617-9847284 Email:cyrart@rfpaorg

FPRF Website: www.nfpaorgfounctation
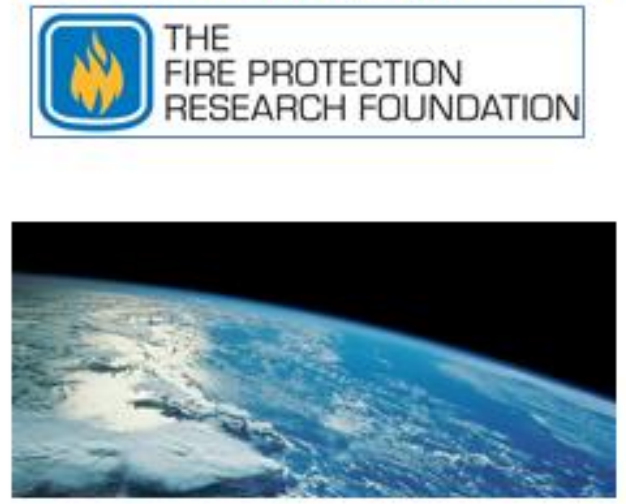

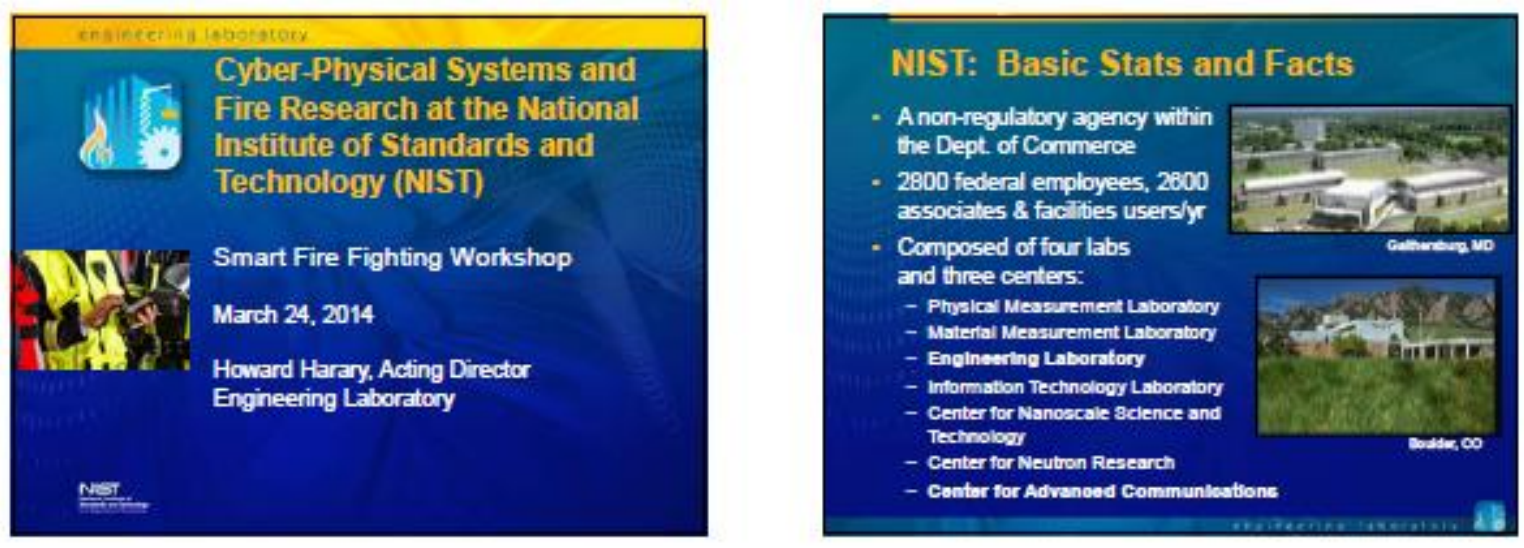

NIST's Engineering Laboratory

(EL) Mission

To promote U.S. innovation and industrial competitiveness in areas of critical national priority by anficipating and meeting the measurement science and standards needs for technology-intensive manufacturing, construction, and cyber-physical systems in ways that enhance economic prosperity and improve the quality of life.

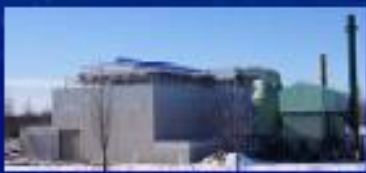
Eponded Notbonal Fre
Resarth Lob Sile phato fireh and 9
What are Cyber-Physical Systems?

Massive integrated wireless networks, advanced sensors. 3D simulations, and cloud services that enable a new generation of Simart Systems

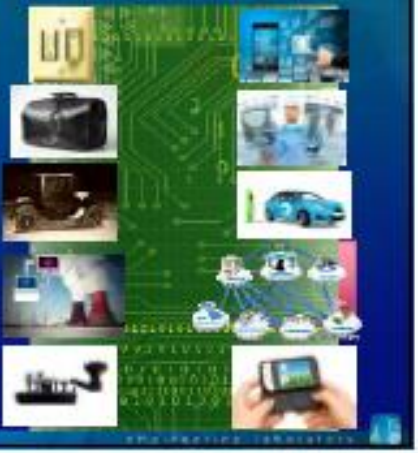

EL Strategic Goals

Measurement Science and Standards for.

1. Smart Manufacturing. Construction and CyberPhysical Systems

2. Sustainable and Energy-Eficient Manufachuring. Materials and Infrastructure

3. Disaster-Resilient Buildings, Infrastructure and Communities
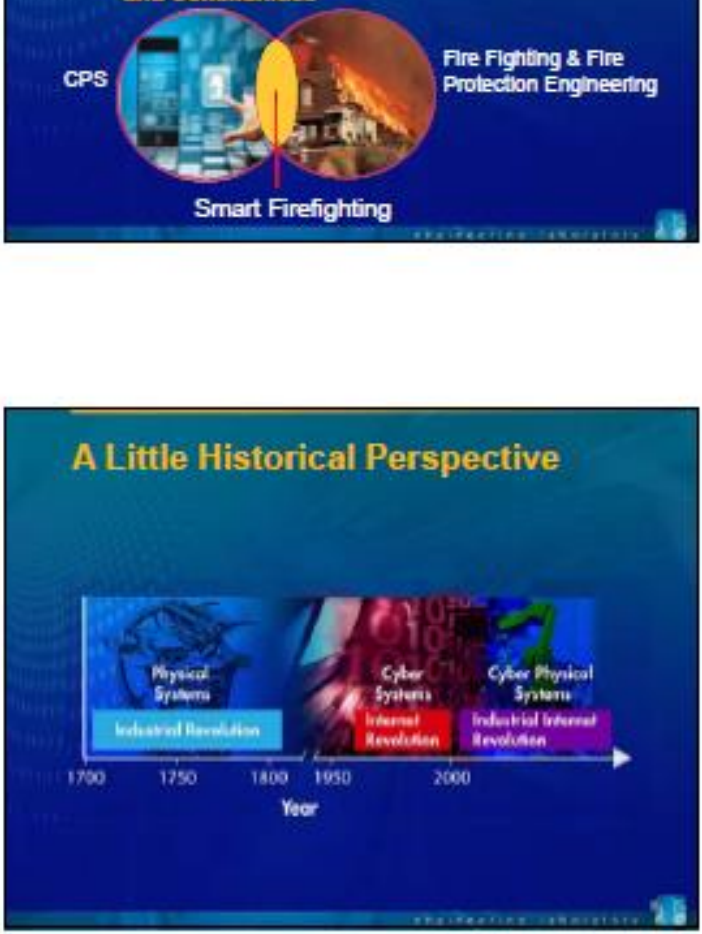
NIST is invested in CPS

- Smart Grid - Inking information technologies with the electric

power grid - to provide

electricity with a brain"

- Smart Grid Interoperability Panel (SGIP)

- 13 Smart Grid projects including:

- amart Grid Communicabon Networts Prectalon Timing

- amart Grid aystems

- Bmart Grid 3ystem Teathed Faclity

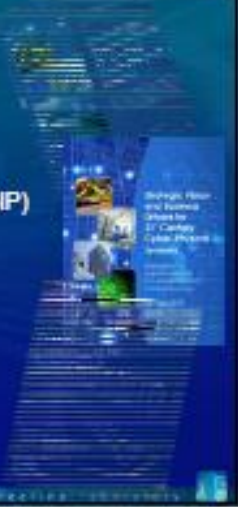

Thank You

For Your Participation!

\section{NIST is Invested in Fire Research}

Fire research at NIST

began in1904 with

standarulzation of fire hose couplings

- Today, 2 major programs and $20+$ projects are working to Reduce the Risk of Fire in Buildings and Communities

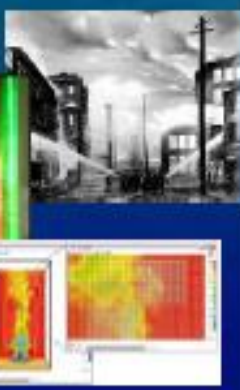

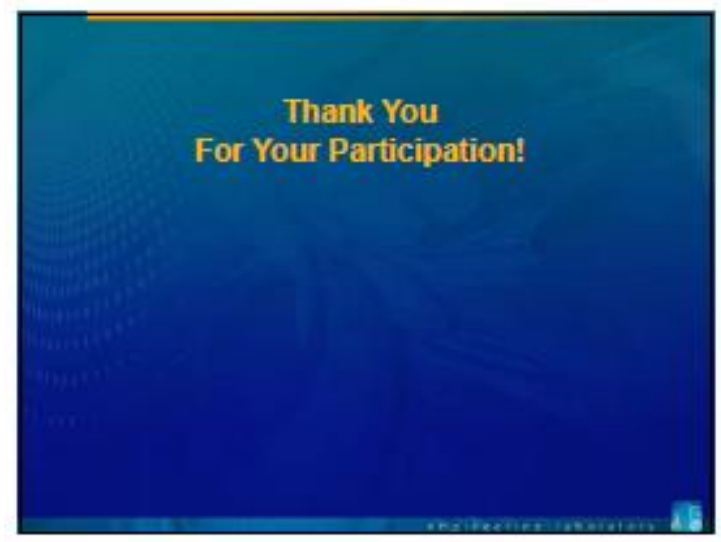

D-10 


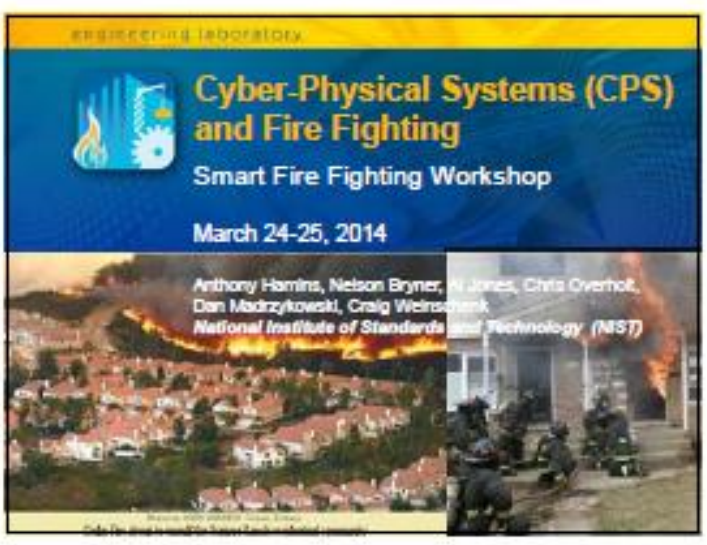

\section{Workshop Objectives}

Inform the development of a Roadmap that identifies the research needed to enable Smart Fire Fighting and improve the safety/effectiveness of fire fighters

- Brainstorm strategies that exploit Cyber-Physical Systerns to reduce fire losses and improve cost-effective fire protection

- Identify the high-priority research needed to enable key standards, codes, technologies and best practices to accelerate Smart Fre Fighting

- Document Workshop outbomes in a proceedings
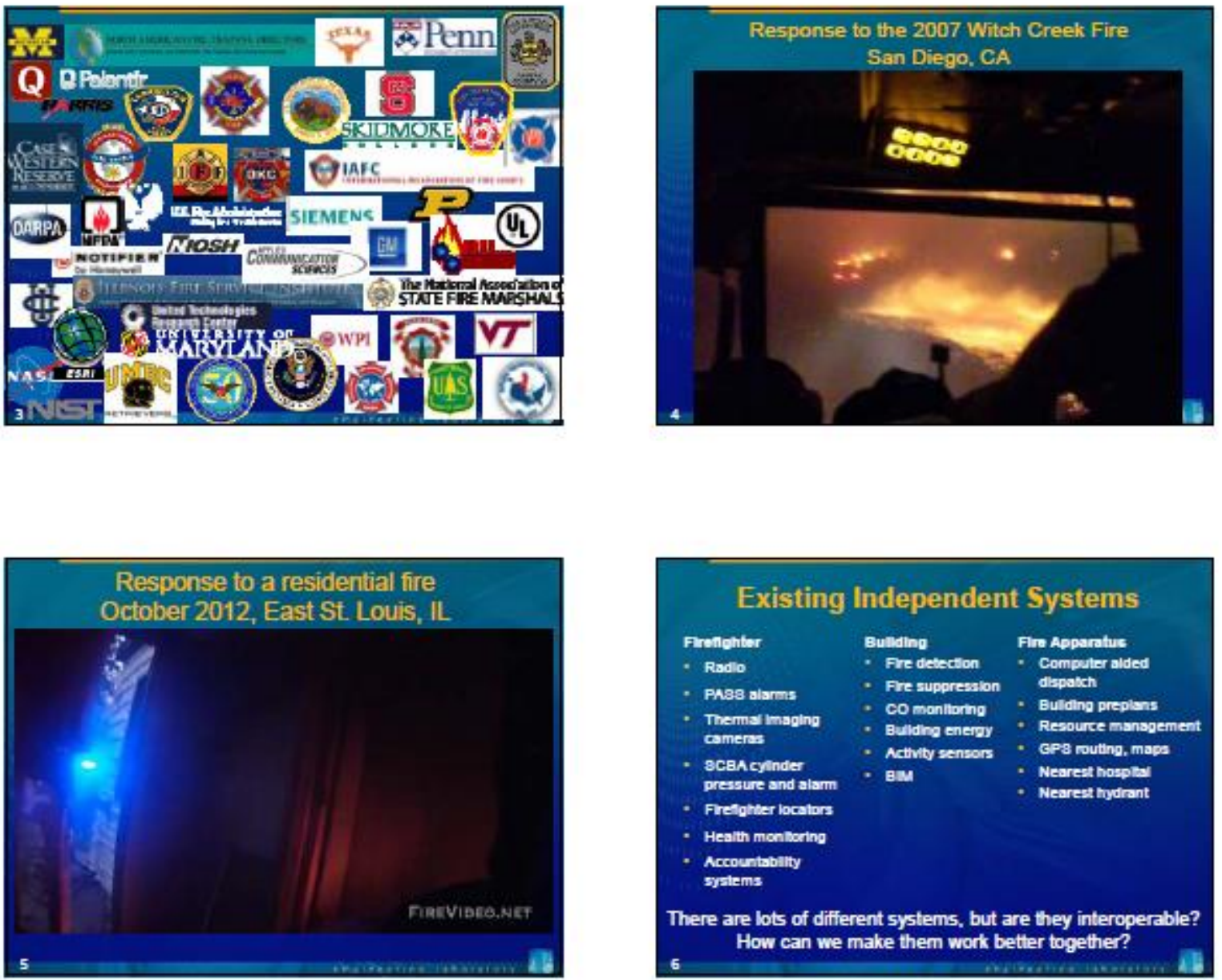

D-II 
Current State of Fire Fighting:

- Fire losses and costs are too large

- Fire fighting is hazardous

- Decision-making on the fire ground is data limited

\section{Future State}

- Providing critical real-time information to support decision making for fire service activities- where and when it is needed; using information from sensors in buildings, on fire apparatus, and on the fire fighter coupled with external databases and computer programs
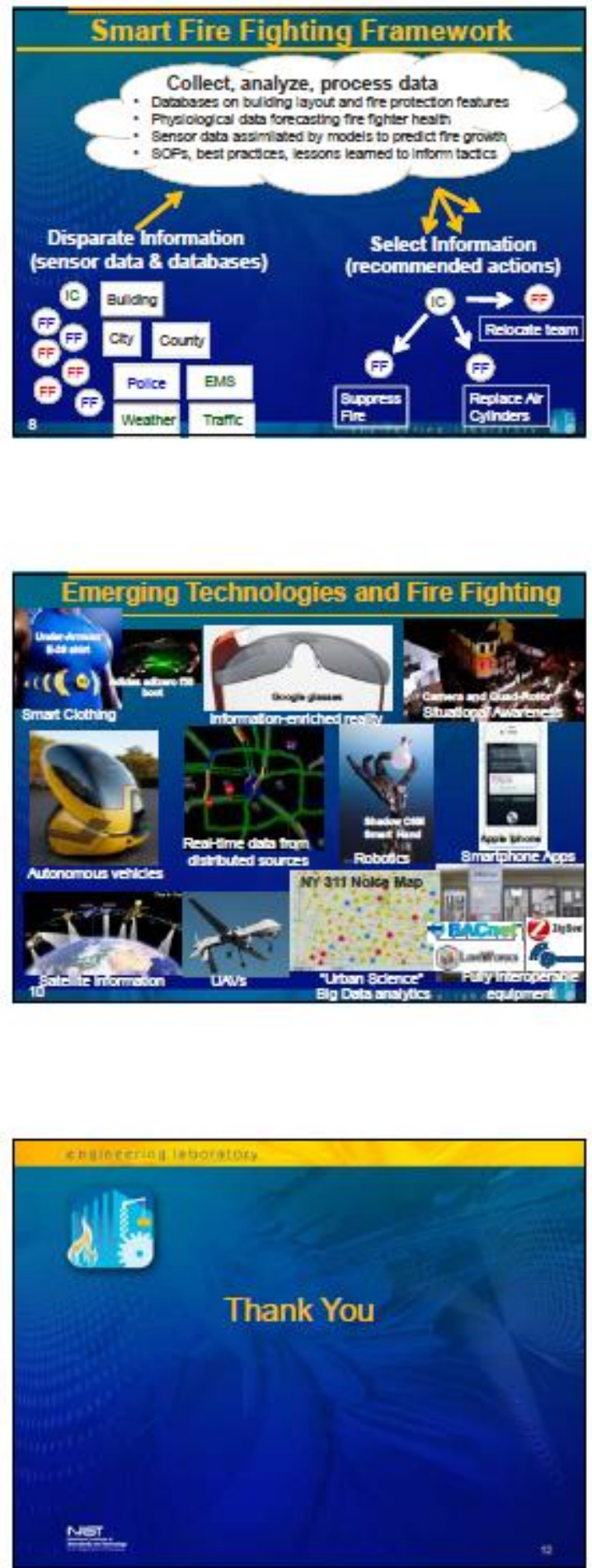

\section{Workshop Questions}

- How can CPS best be used to improve fire protection and the safety and effectiveness of firefighters?

- What key CPS developments are needed to enable smart firefighting?

- What is needed in terms of:

- standards and codes

- protocols

- sensors and sensors fusion

- data preparation and analytics

- What are the highest priorities for CPS development?

- What are low hanging fruit for CPS in FF applications?

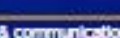

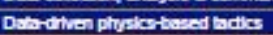

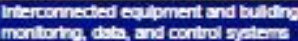

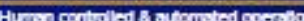


Integrating Cyber Physical Systems with the Fire Service

Riclara Vuyles

Assistant Director

Robotics and Cyber Physical Systems

Office of Science and Techuology Policy

Executive Office of the President

\section{(1)}

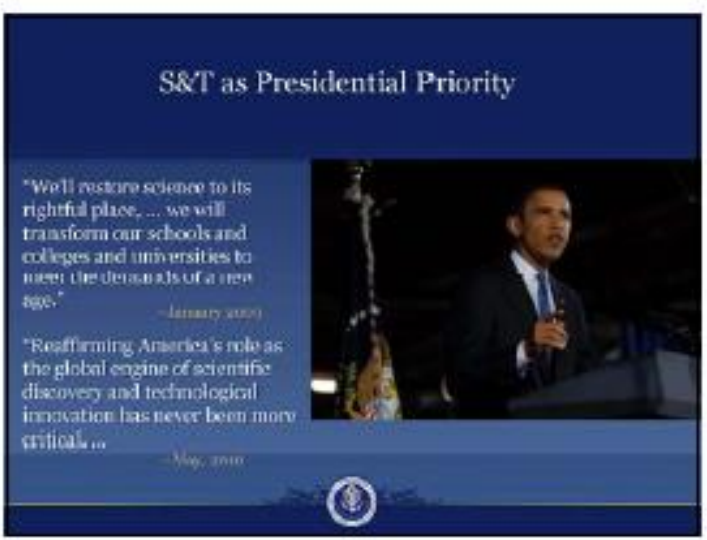

\section{Recent OSTP led R\&D Initiatives}

- Advancod Manufacturing

- Robotics

- US IGNTTE

- Big Data

- STEMar Rdueation

- Opera Data

- Materials Cenome

- Grand Challenges

-Prizes

\section{(1)}

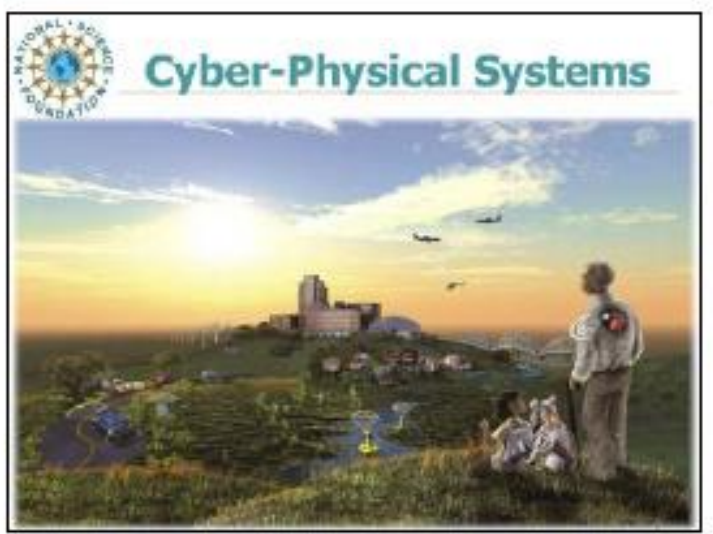

White House

Office of Science and Technology Policy

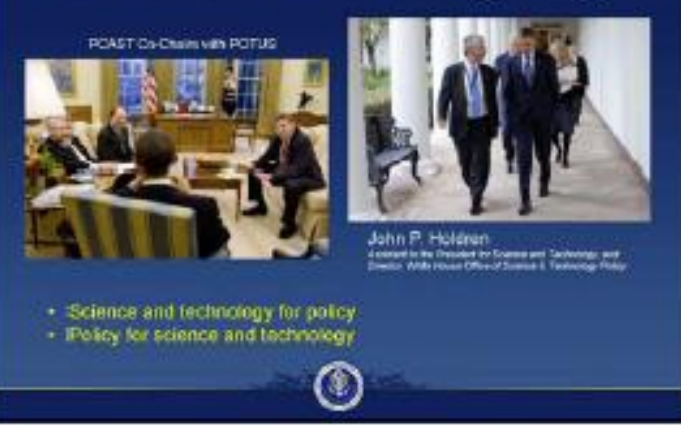

\section{PCAST Report 2007}

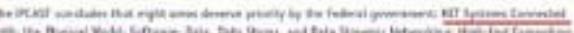

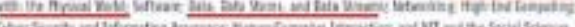

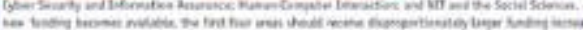

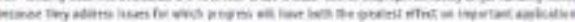

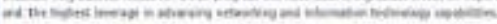

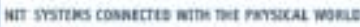

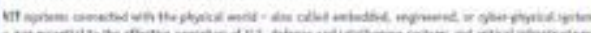

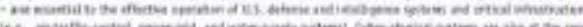

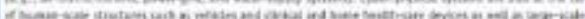
T.

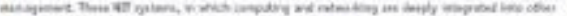

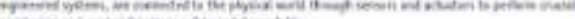

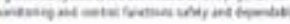

\section{(1)}



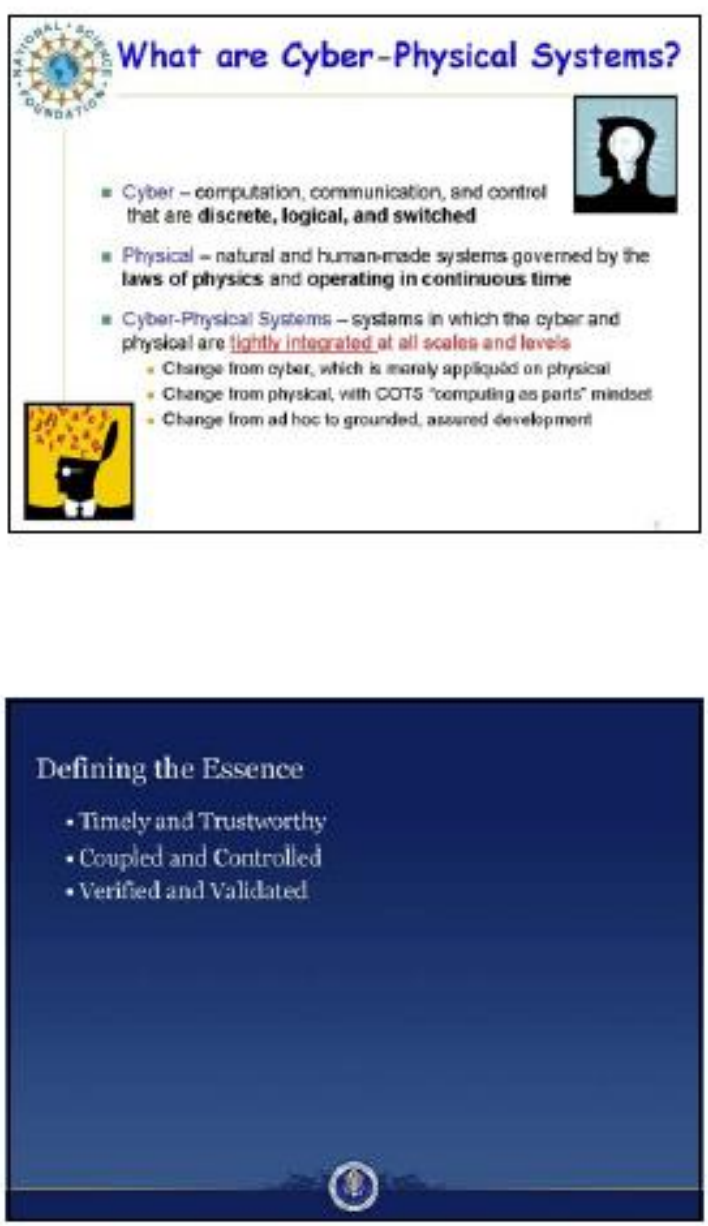

Ideas for Consideration:

Fire Fighting Grand Challenges

Some suggestions:

- Reduce Fire Fighter Deaths to Zero

- Mediam-Teraicont

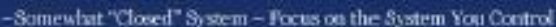

- Clear Opsortunitios for improvernori by CPS

- Reduce All Fire Deaths to Zero

-Long-Teru Cal

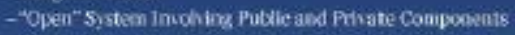

- Mrat sddrass Privecy Comscras and Modeling Conserns

- Cloar Opportunitis for Improsemant by COS

\section{(3)}
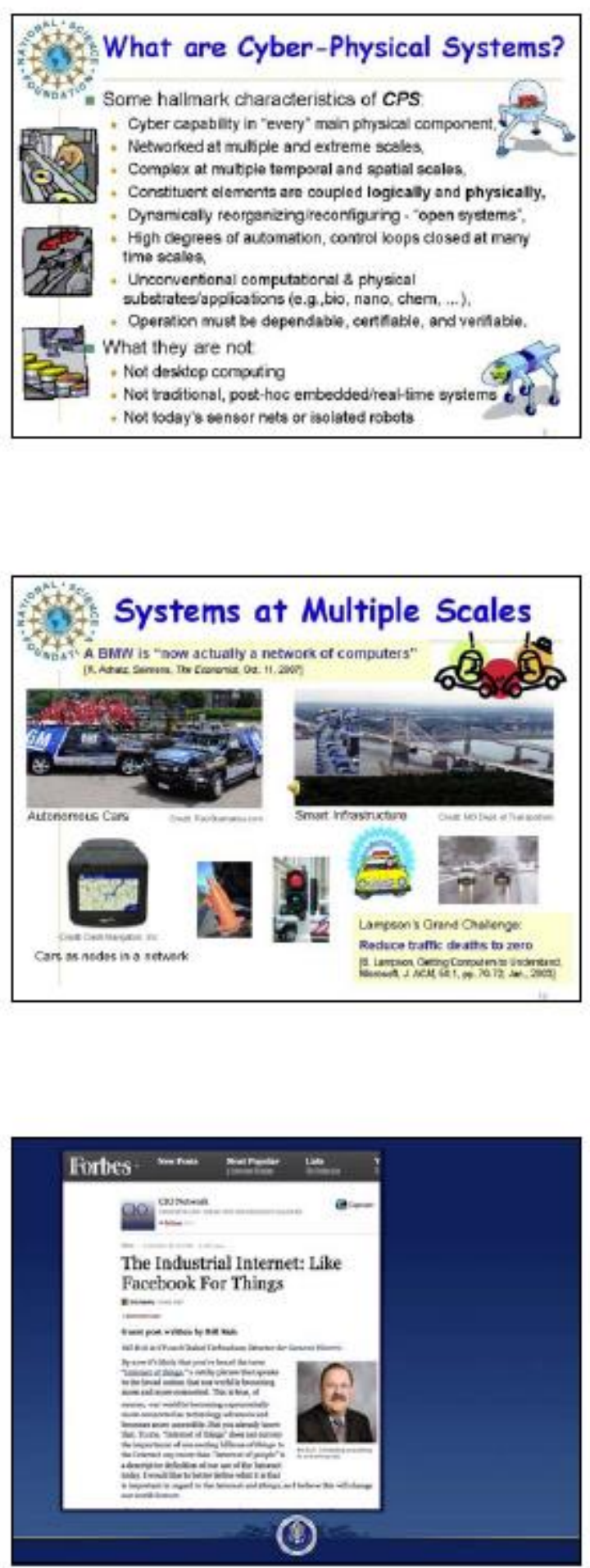

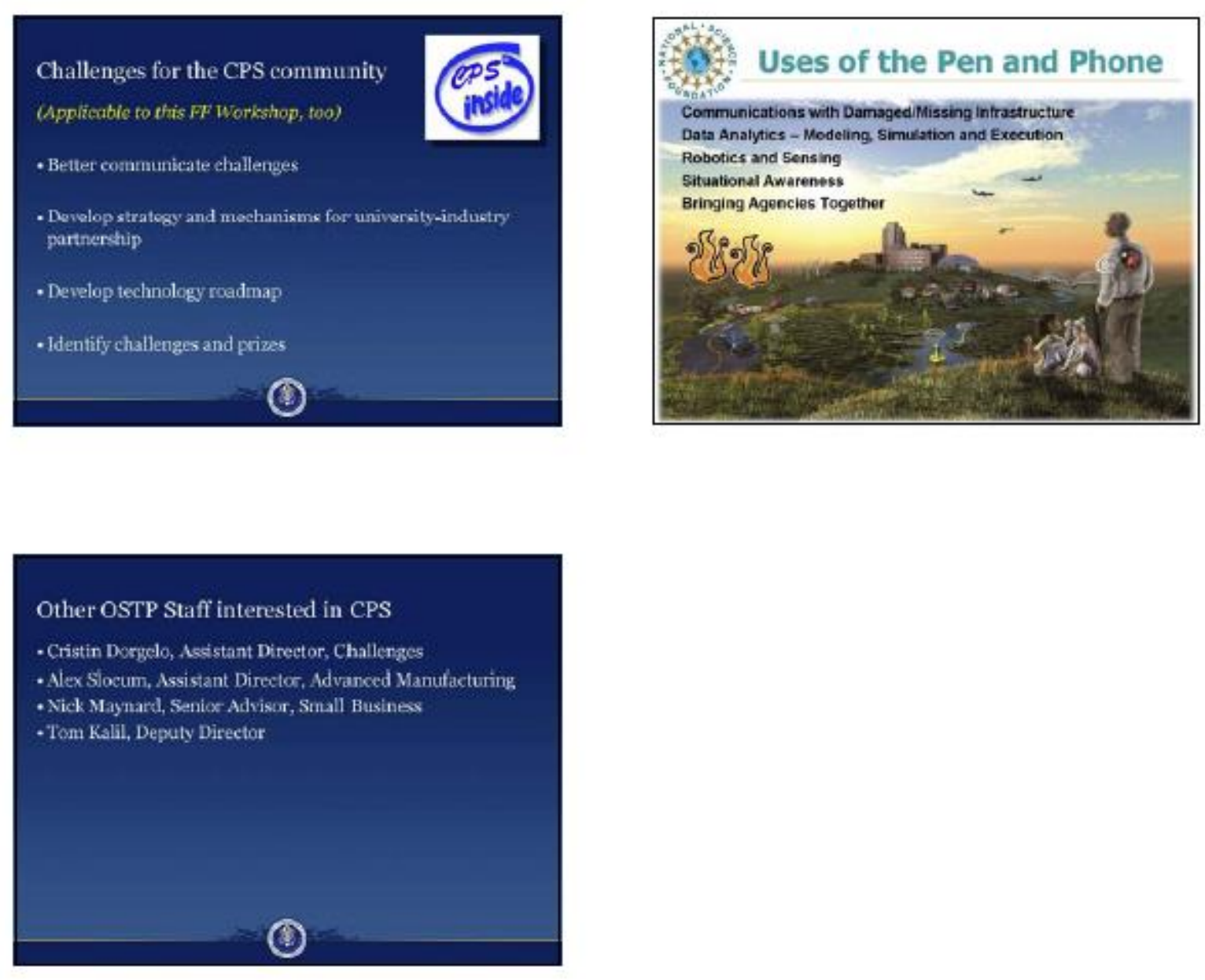

D-I5 

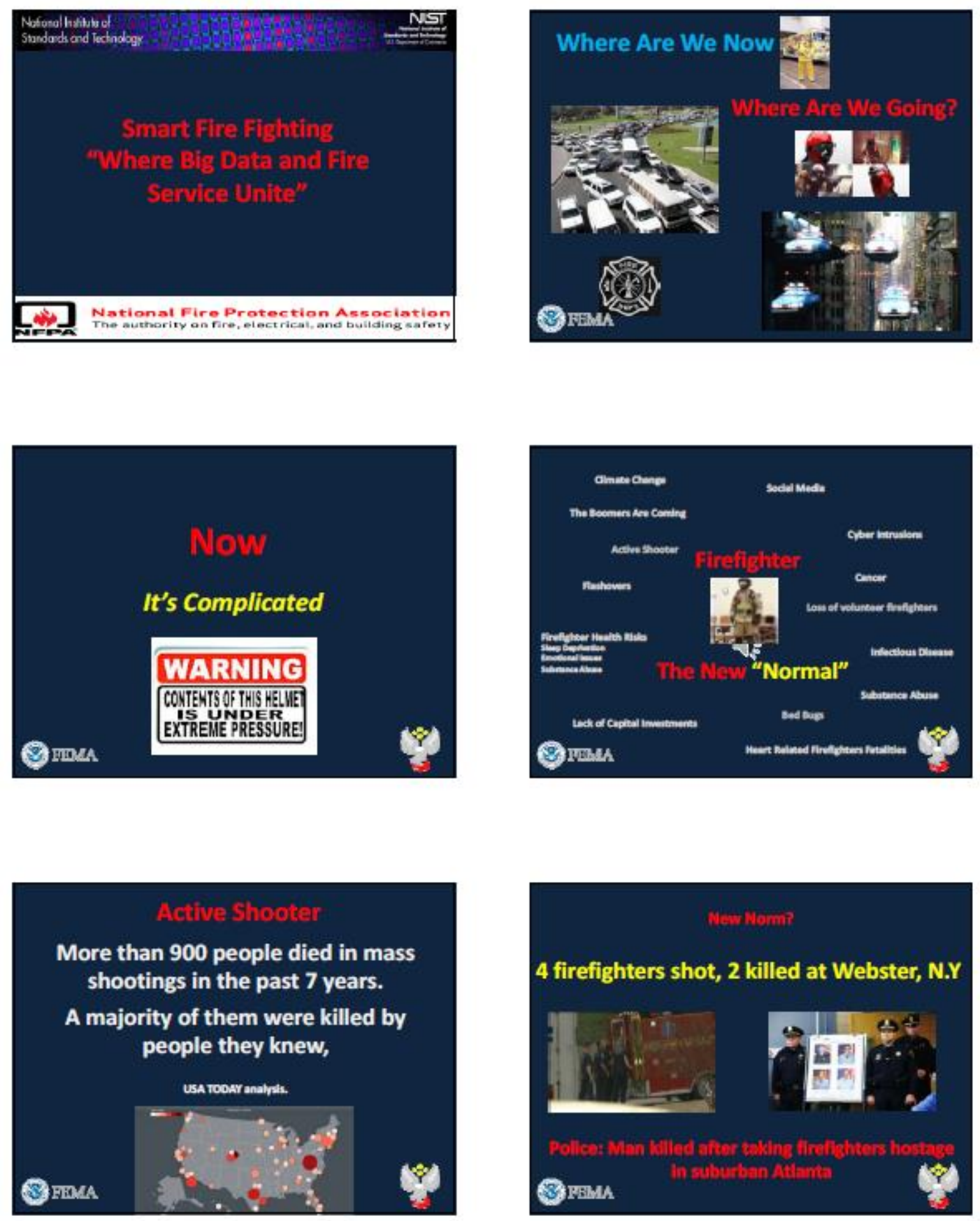

D-16 

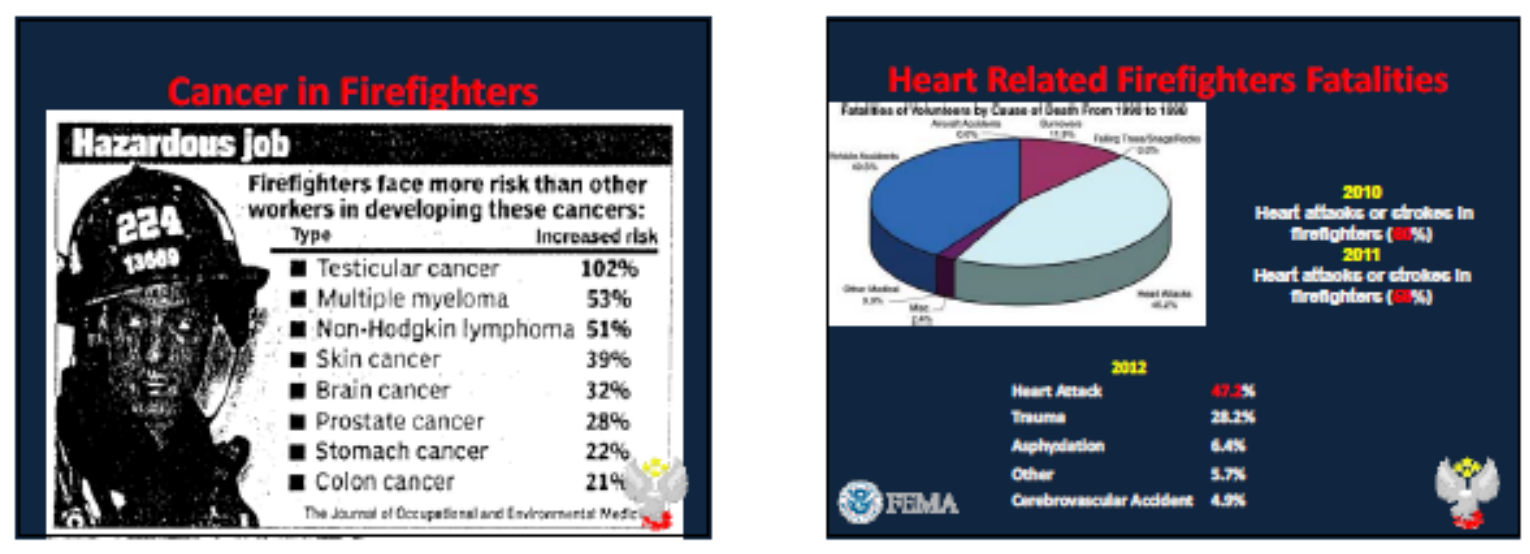

\section{The Last Ten Years}

- Terrorism comes to the U.S.

- IPod and ITunes released

- The first BlackBerry phone was released.

$201482 \%$ of population owns a mobile

phone

2009 H1N1

VCR out - DVD/Blue Ray in

- Facebook launches.

- Facebook opens to the masses.

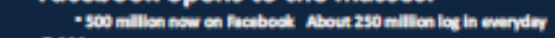
- 2 Wars
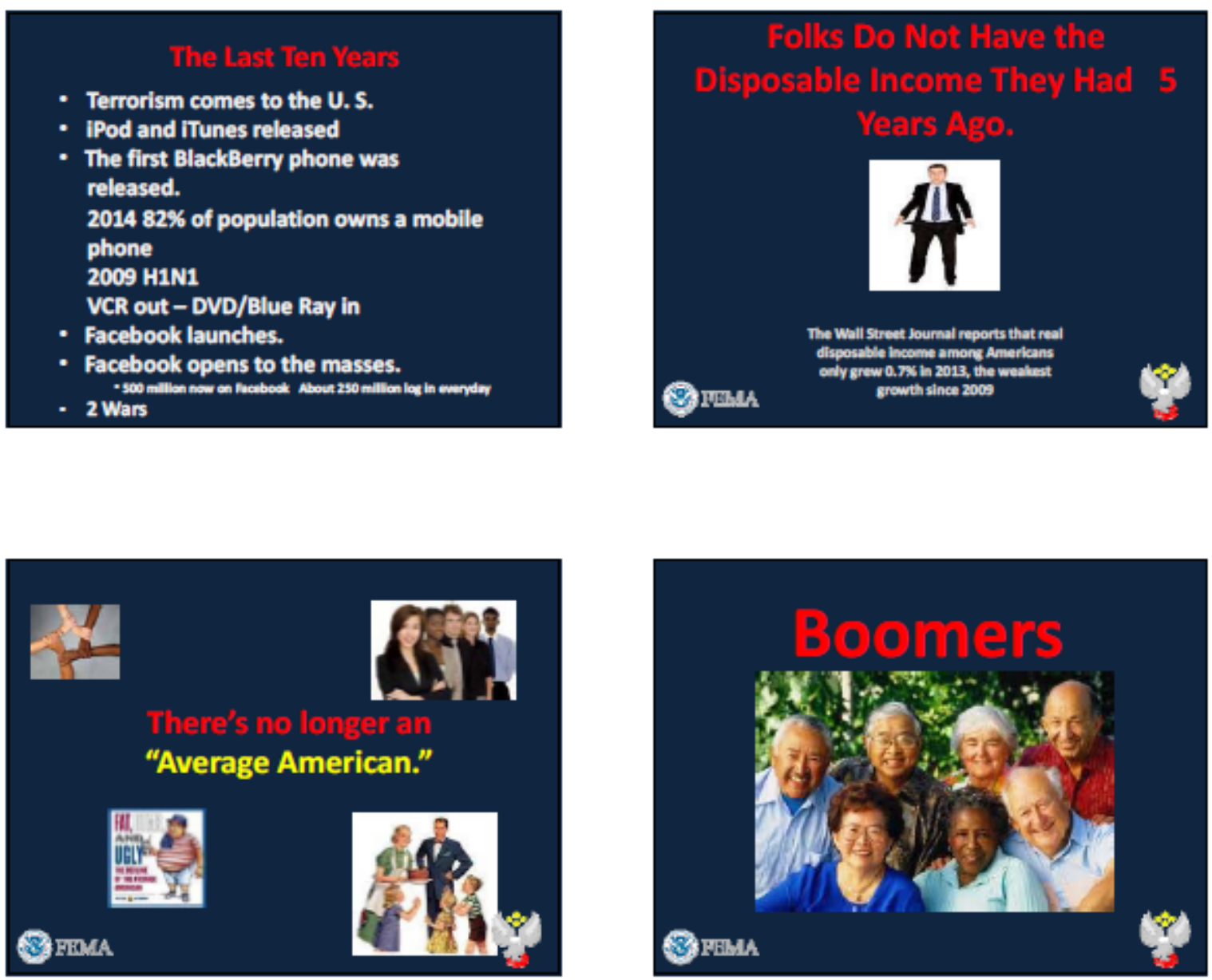


\section{Elderly Population Projections}

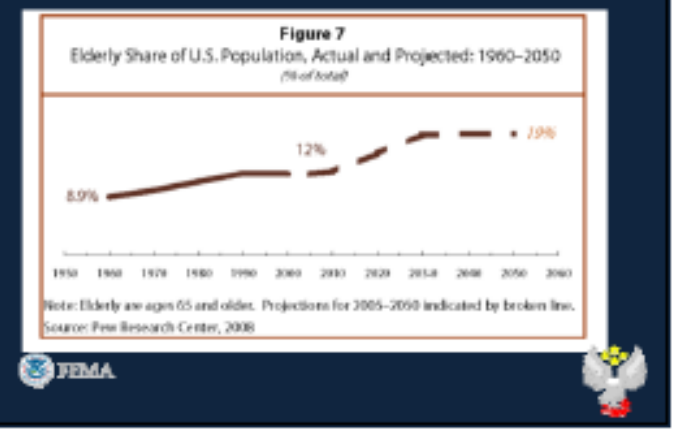

\section{Demographic Emerging Issues}

Older Adult Fatalities in Home Fires.

- 75> age group 3 times as likely to suffer a fire related death.

- 85> age group $\mathbf{4}$ times more likely suffer a fire related death.

8) IIII $_{1}$

Forward to the Future

Forecasting -- It Isn't Easy

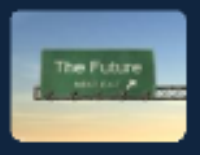

Wilbur Wright, no-Imventer of the alrplane, quoted in

1801

"Man will not fof for 50 years."

Bimat

Orville and Wribur First Successful Flight December 17. 1903
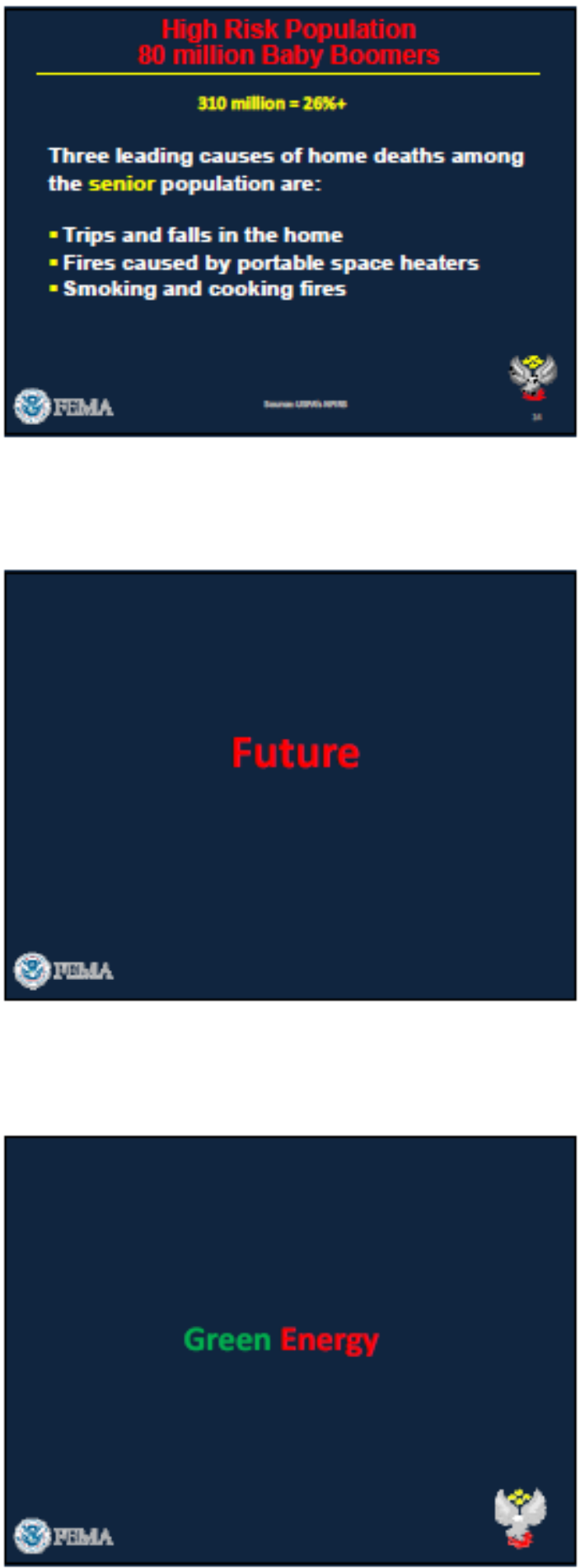

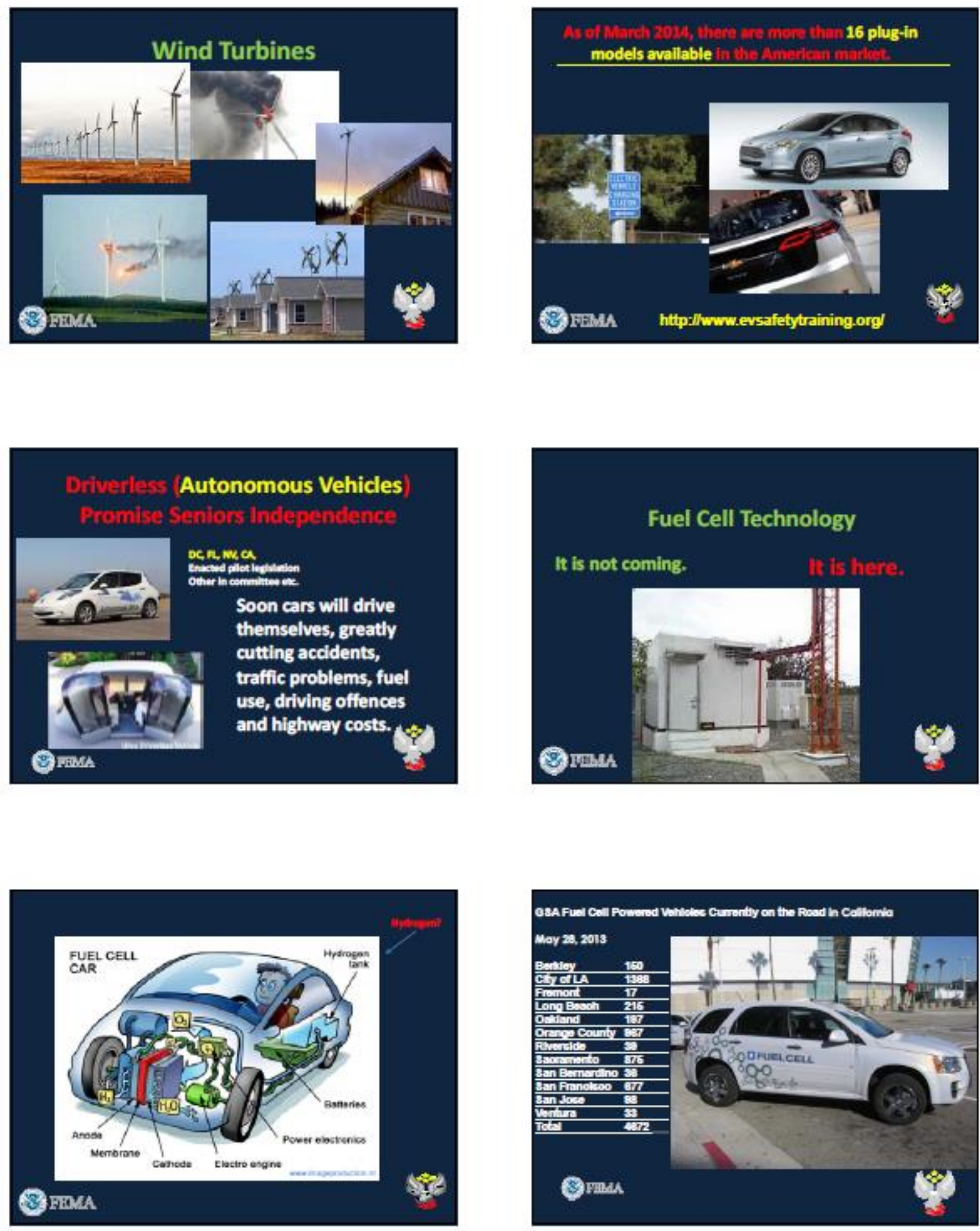

D-19 


\section{Home Fuel Cells}

Home fuel cells can generate eight times more energy per year than the same size solar installation, even in the best solar locations
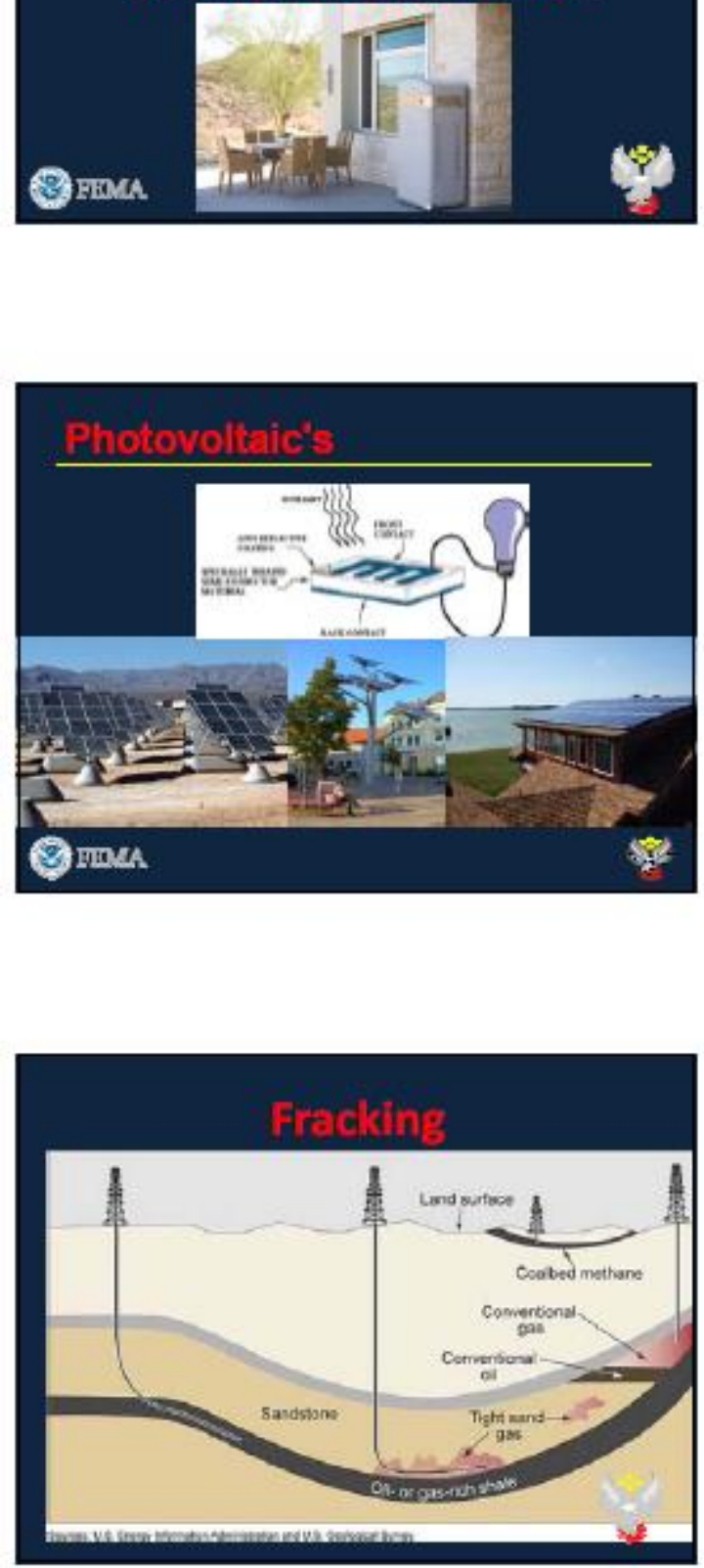
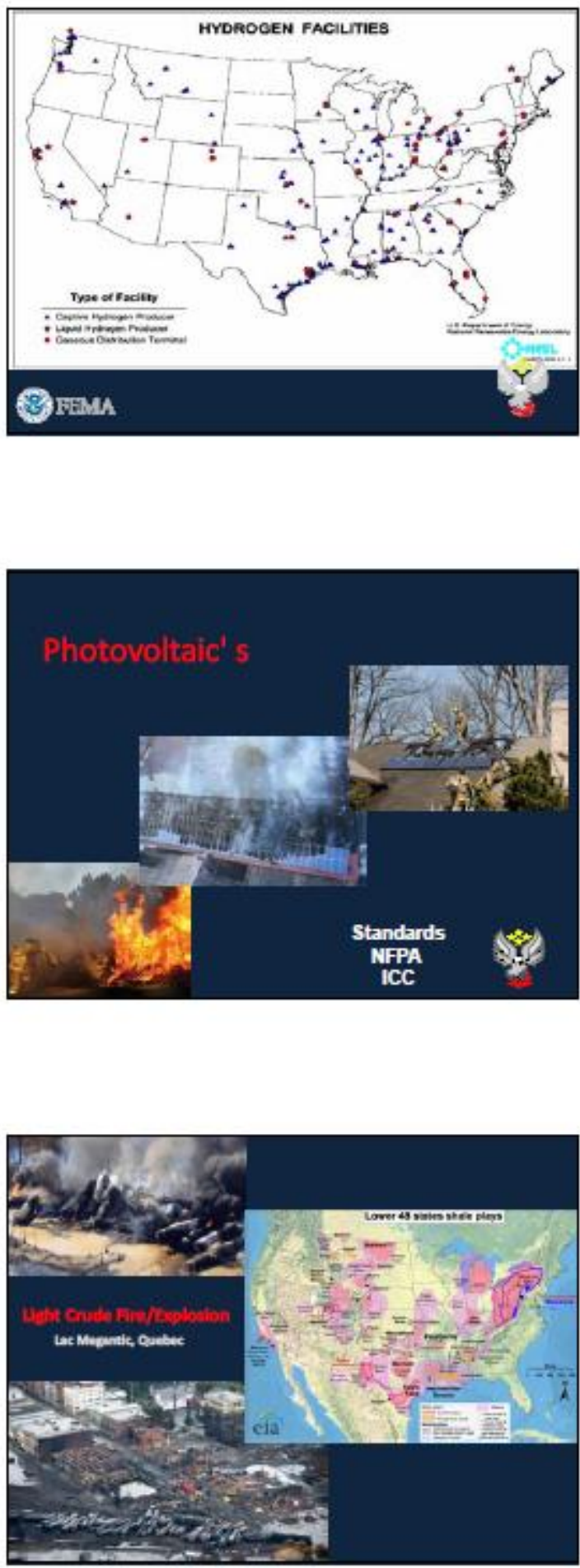
Residential Fires Are Changing
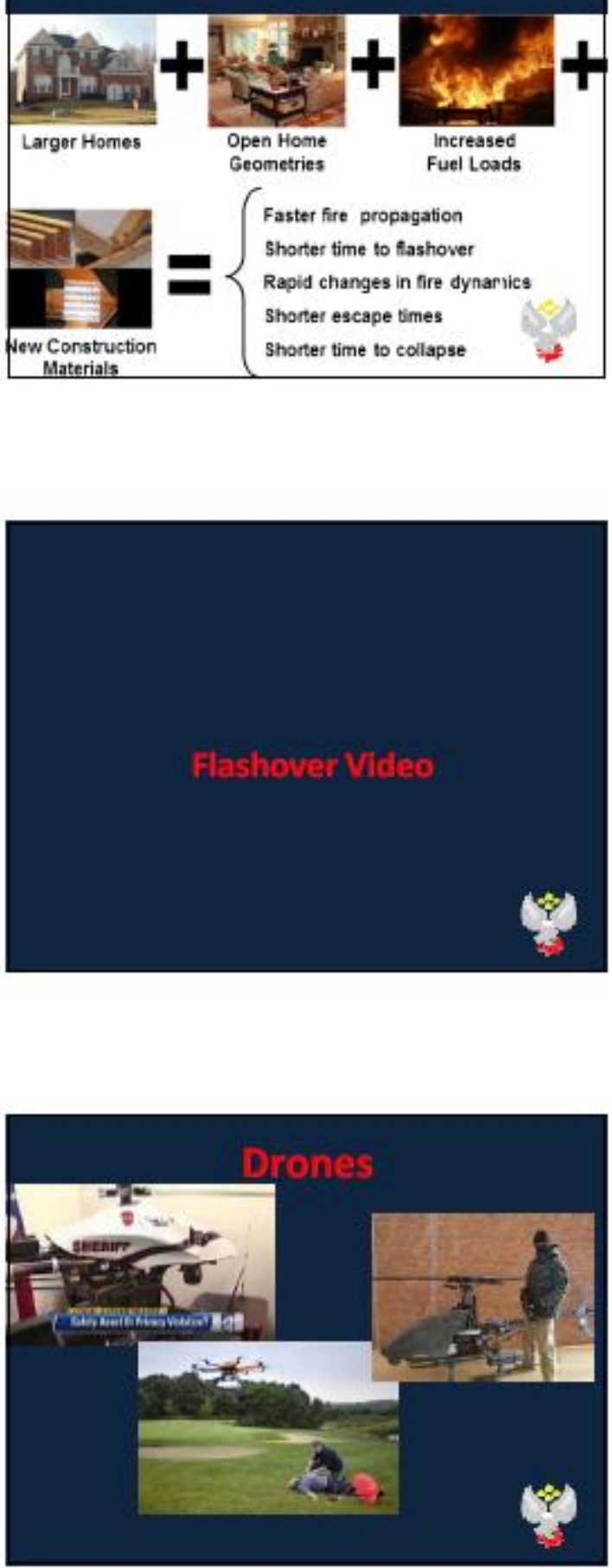
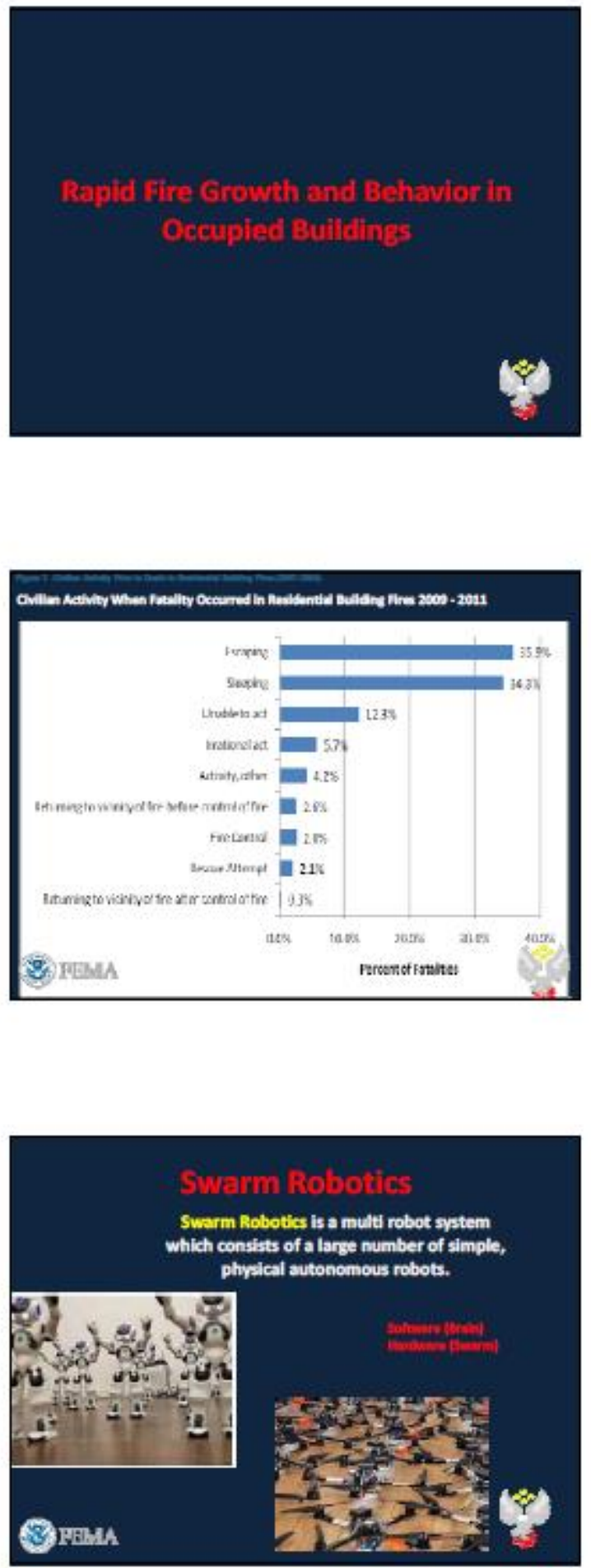

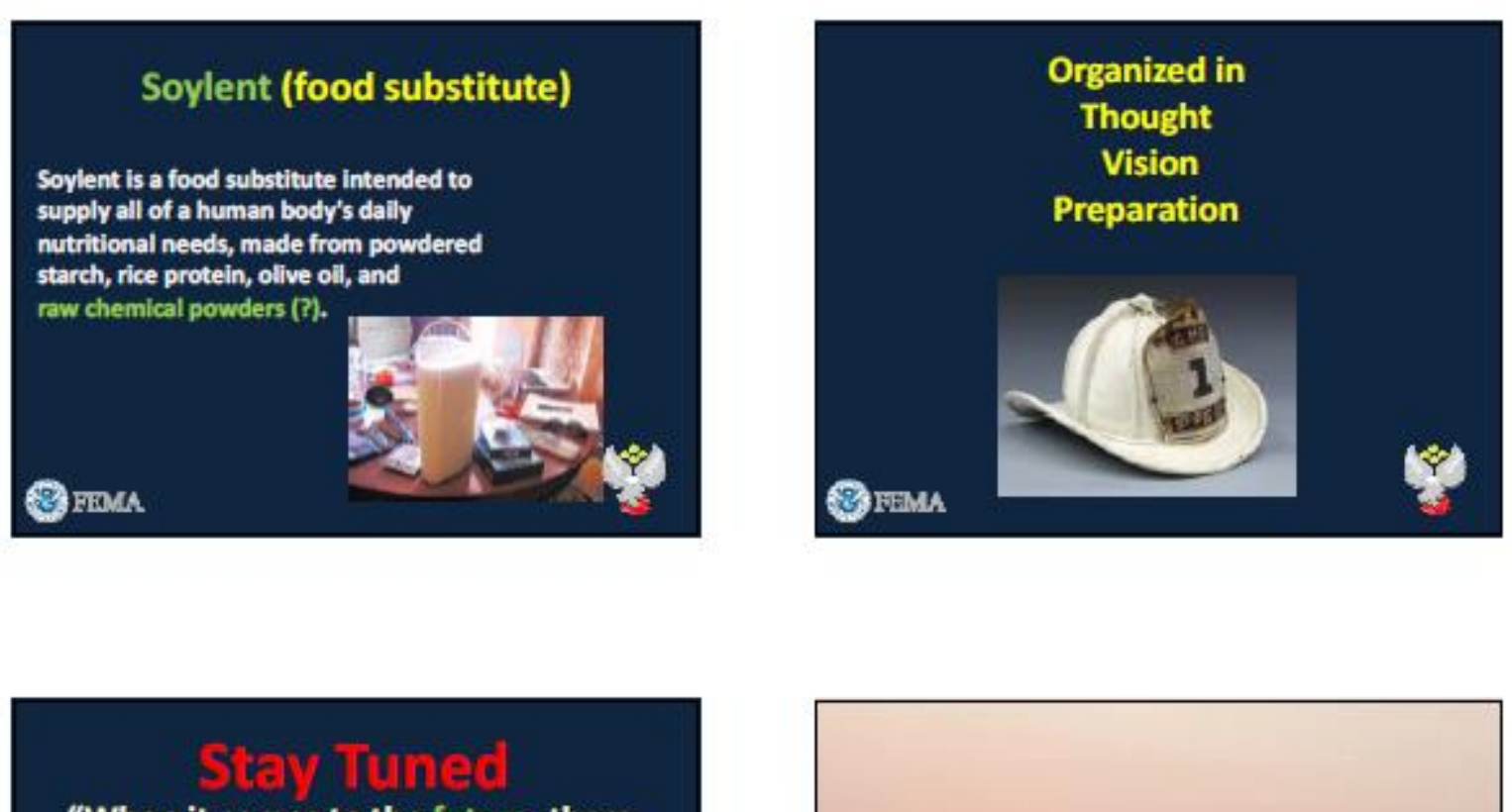

"When it comes to the future, there are three kinds of people:

- those who let it happen

- those who make it happen and

- those who wonder what happened."

9)

\section{Thank You}



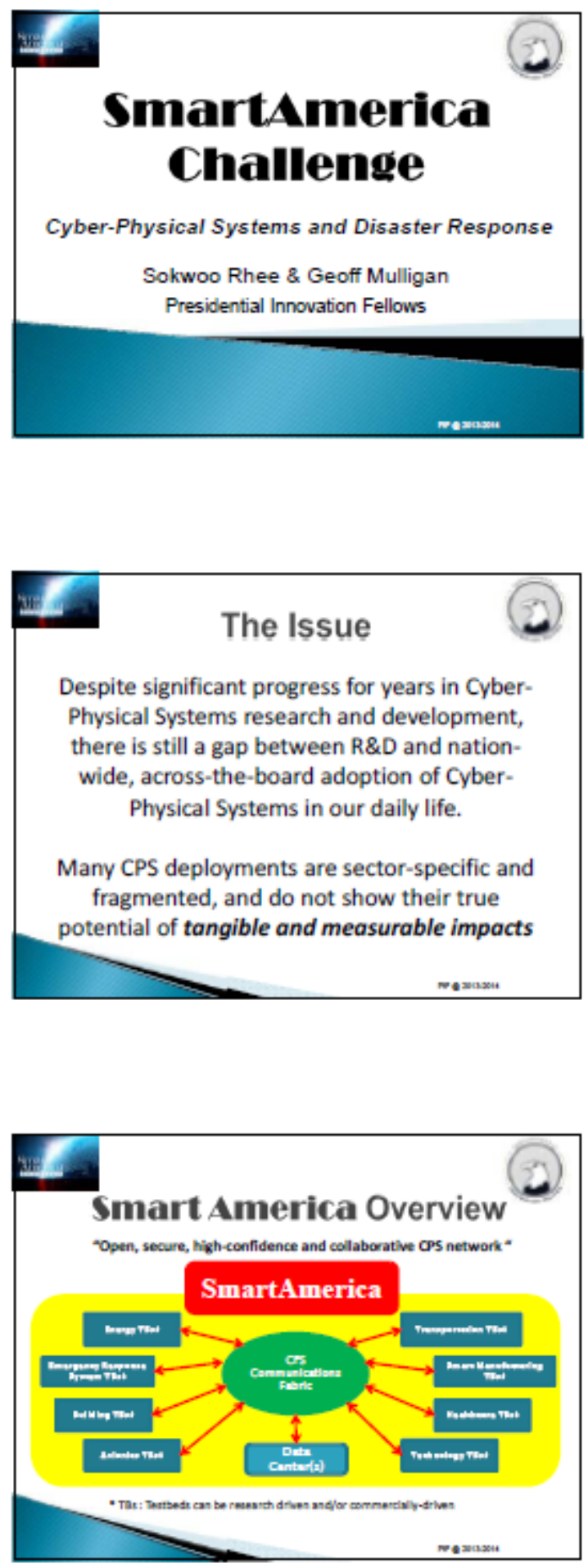
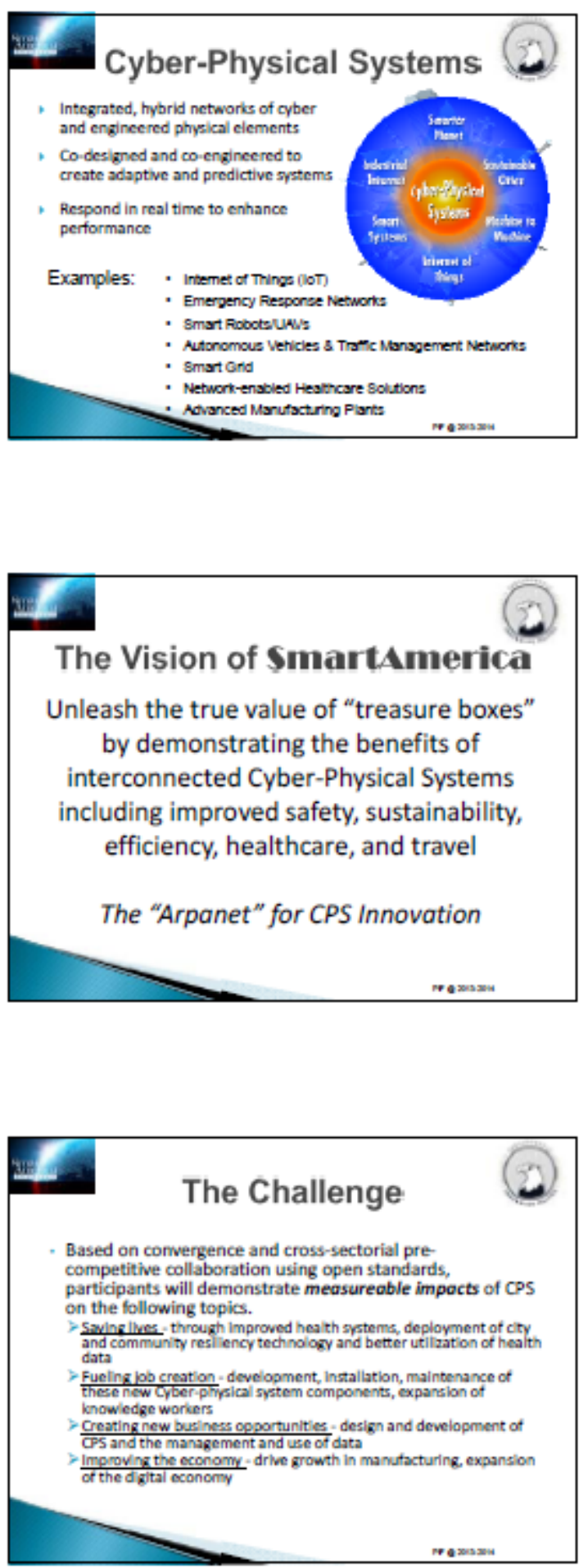

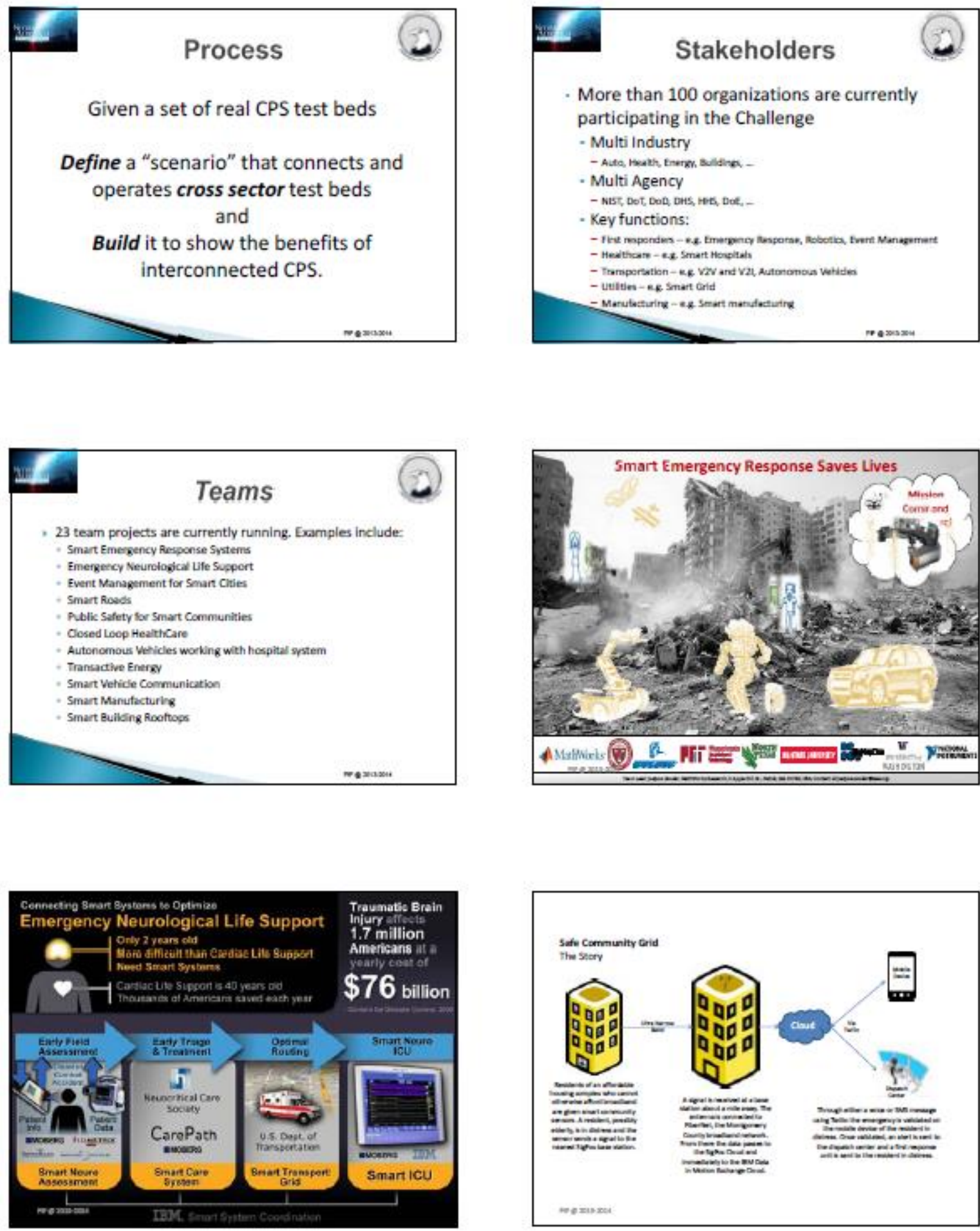

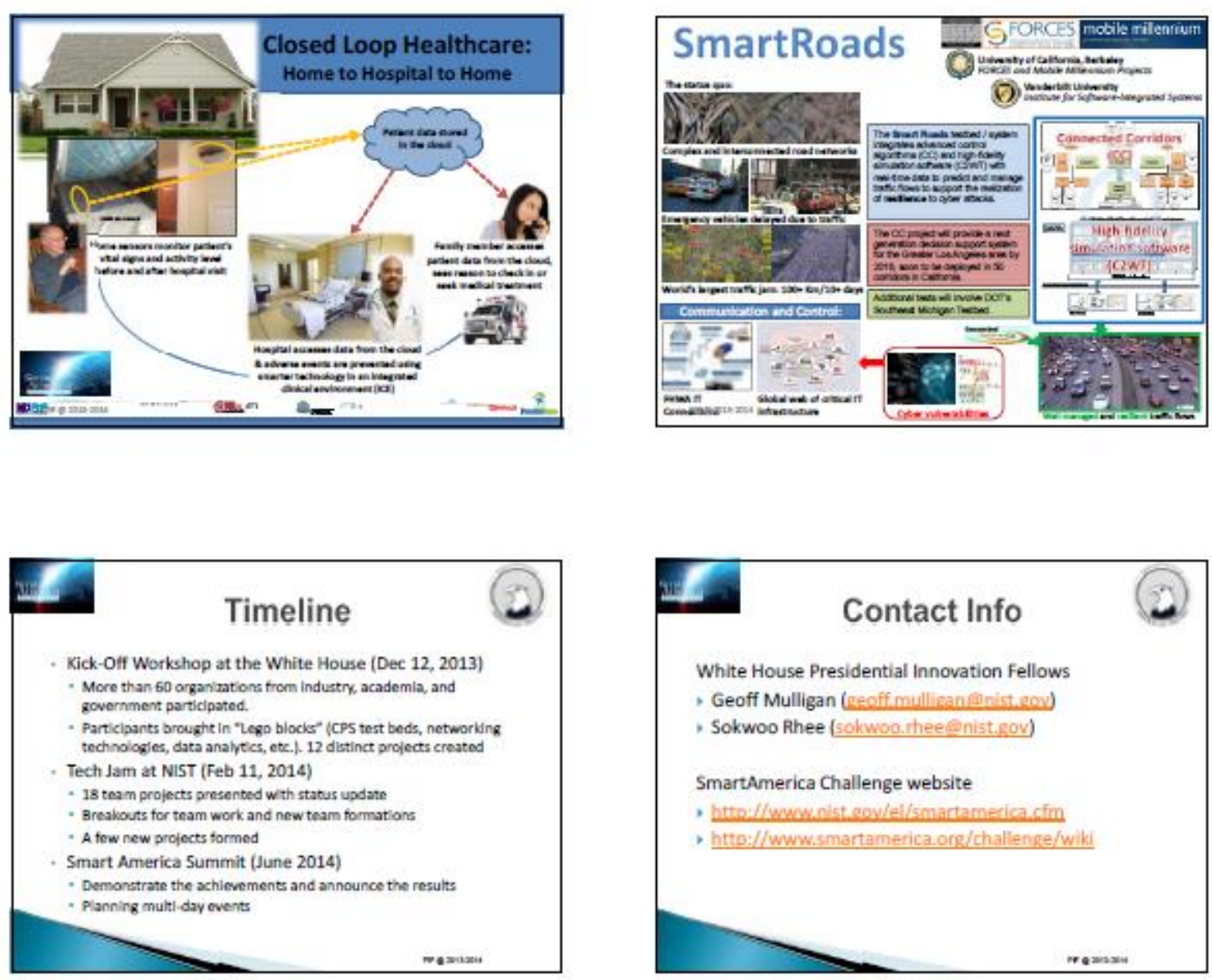

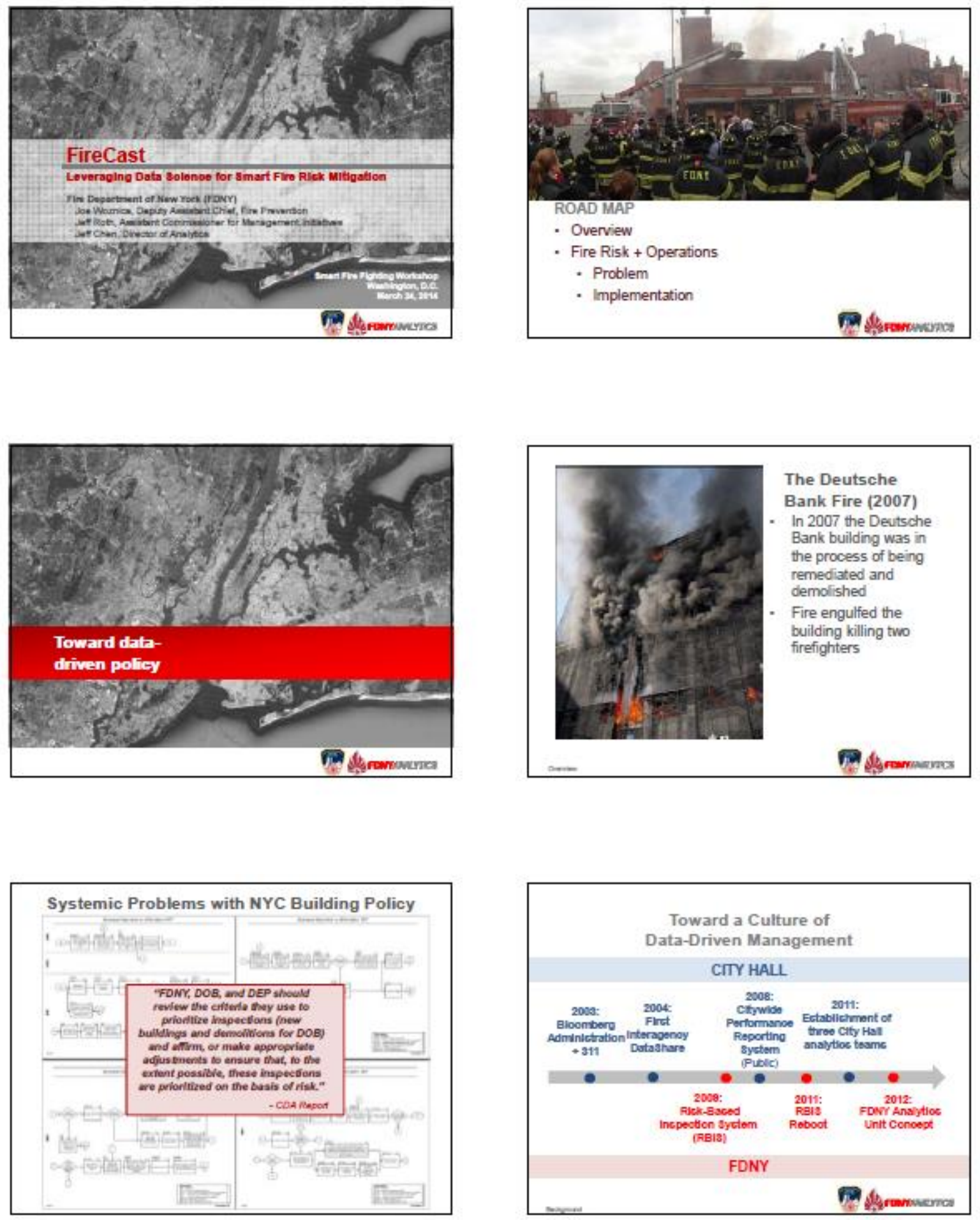

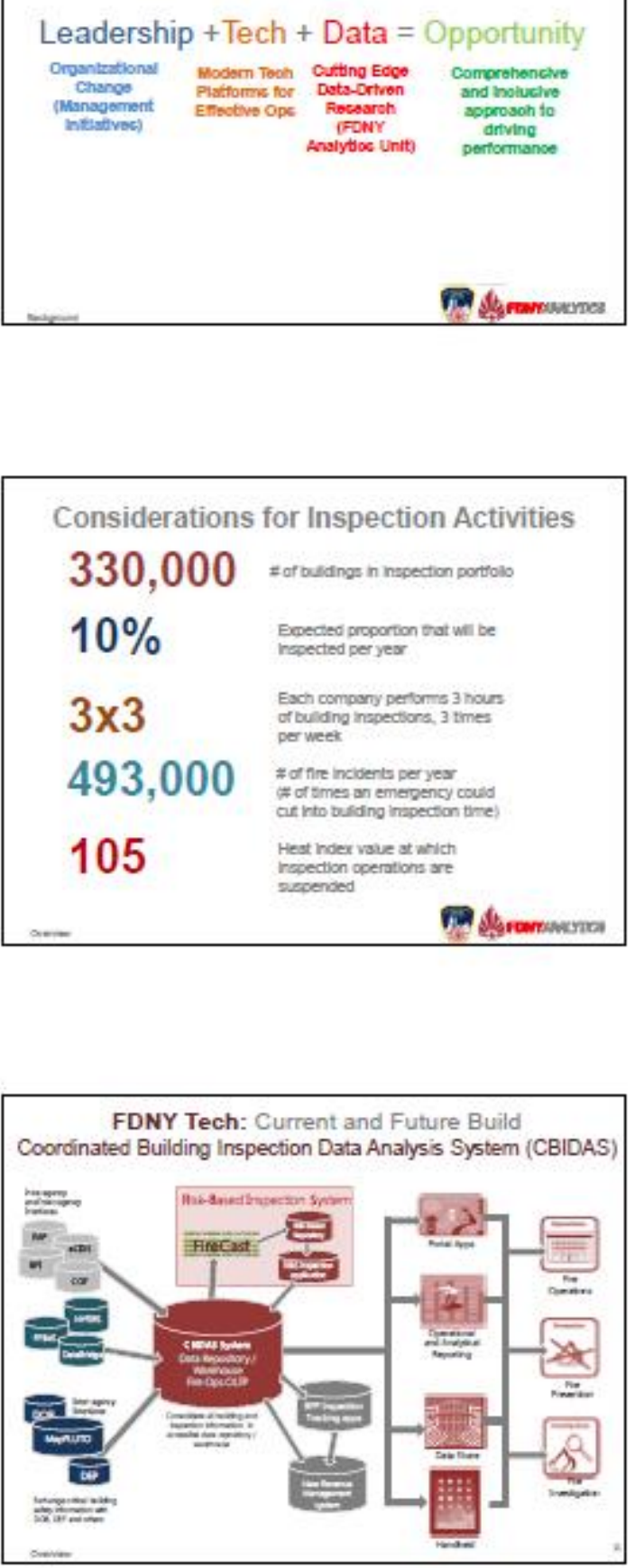

Risk Mitigation Philosophy

Fires will happen. It's just a matter of time. We need to get our units to inspect the buildings of highest risk so they're ready.

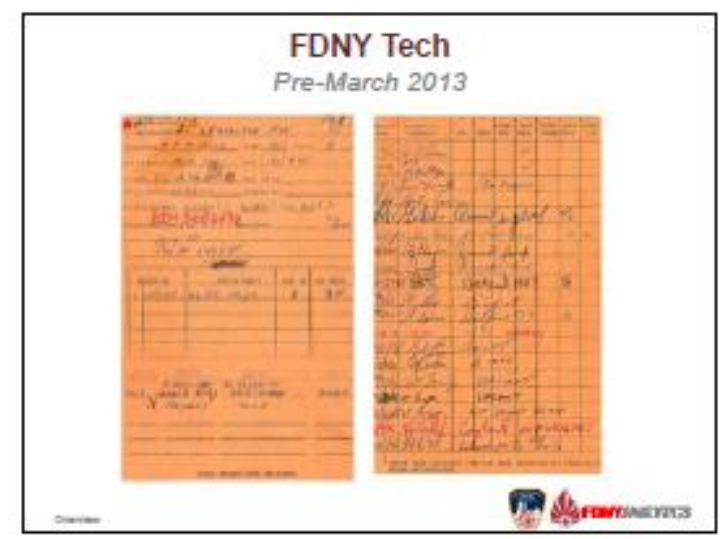



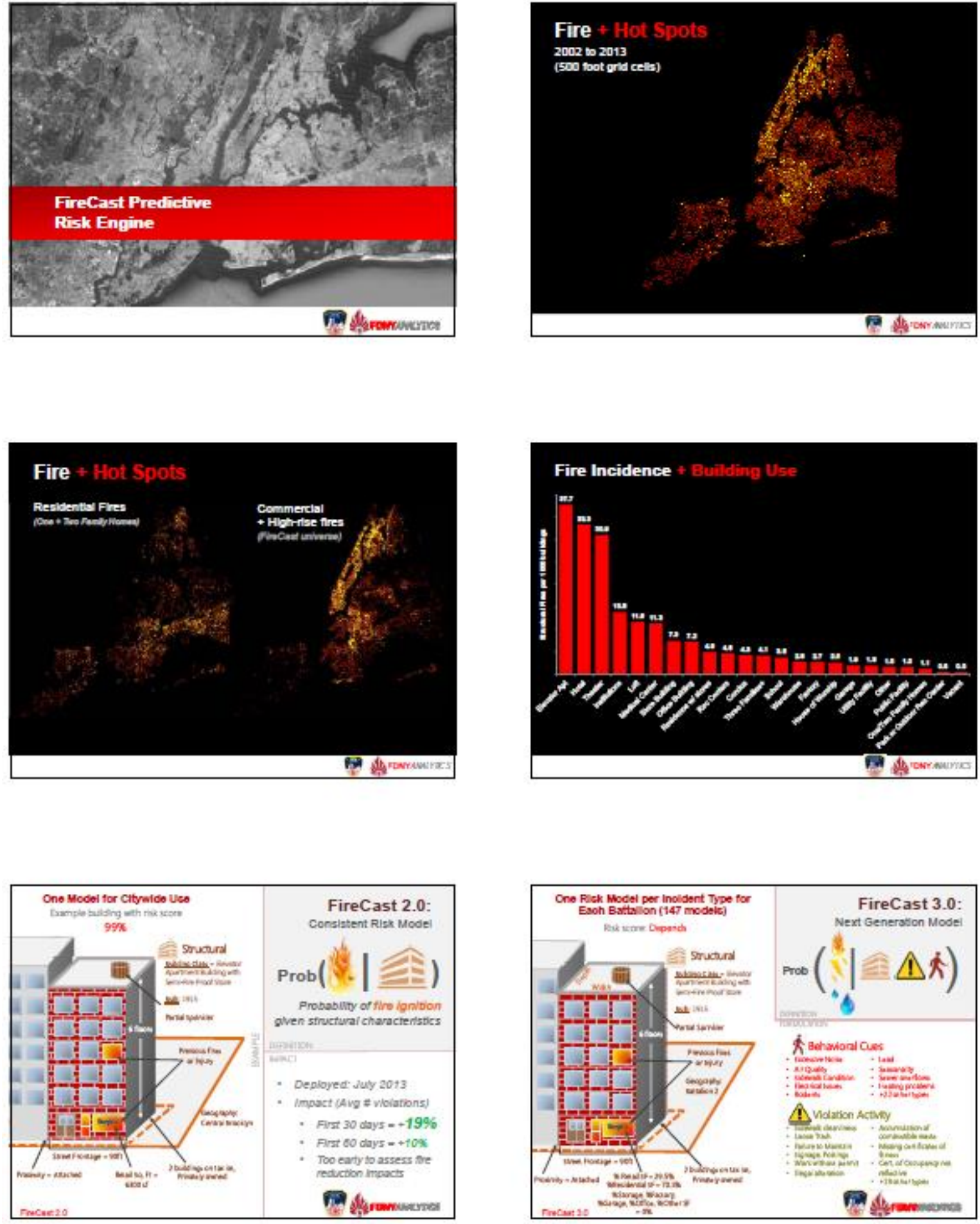

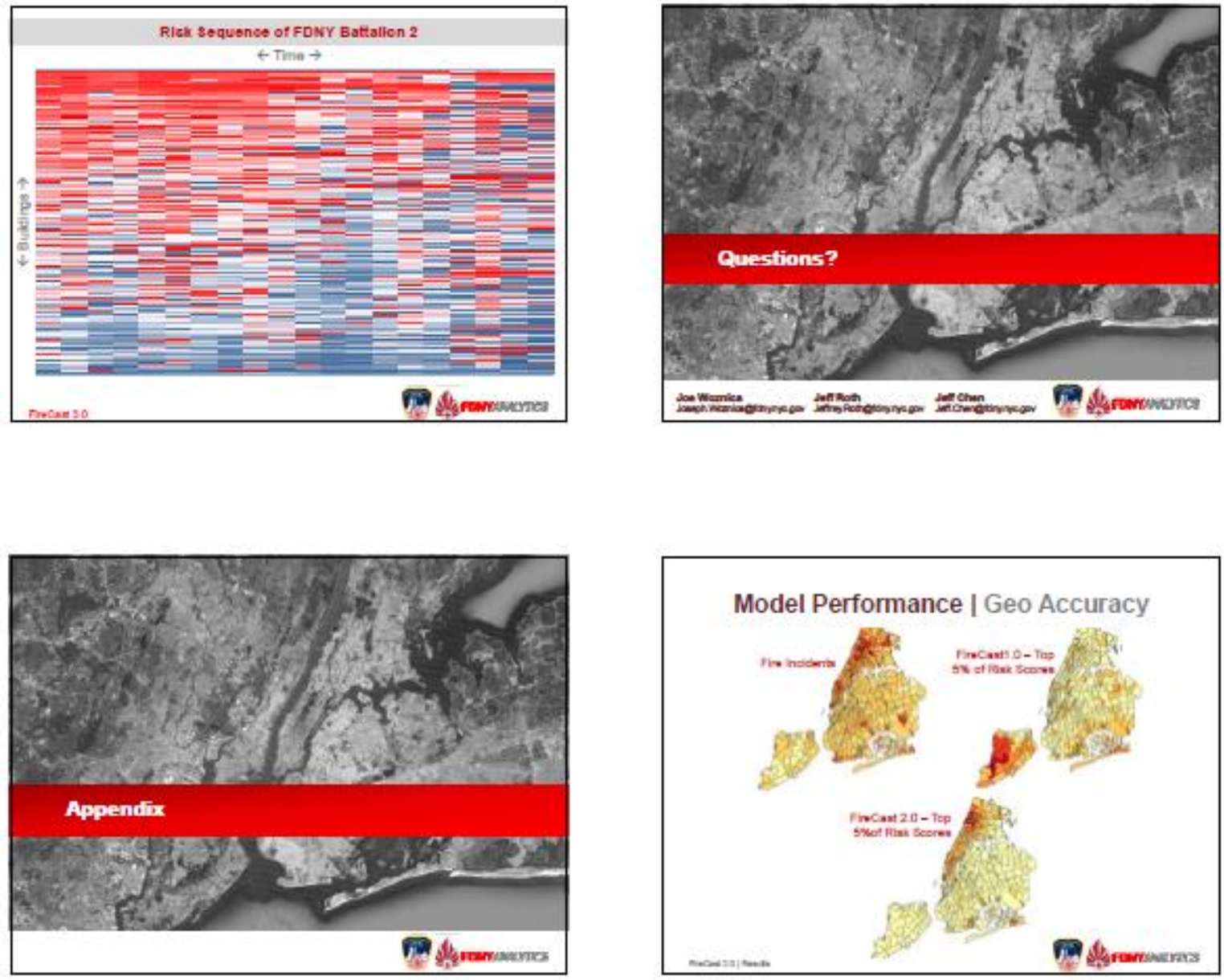

Evaluating the Risk Mitigation Strategy

Successen

Ohatacies

Raiaing technical sklls of entre

Rasiaing technical skllla of entire

in-depth analytics worktore

$10 \%$ to $19 \%$ incresse in per. Data infrastructure not dealgned bullaing violstion issuance for this wort

Higher hat rate of raky

bulling:

enoortunites

- Approsech can be applied to

Cltywlde data share QAQC nearly any rak outcome to

prococob identify crucal weaknesses in

Expanded data colection to | intrastructure to assessing the

leed FDNY z inapection

potentis impact of natural

dessters

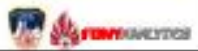



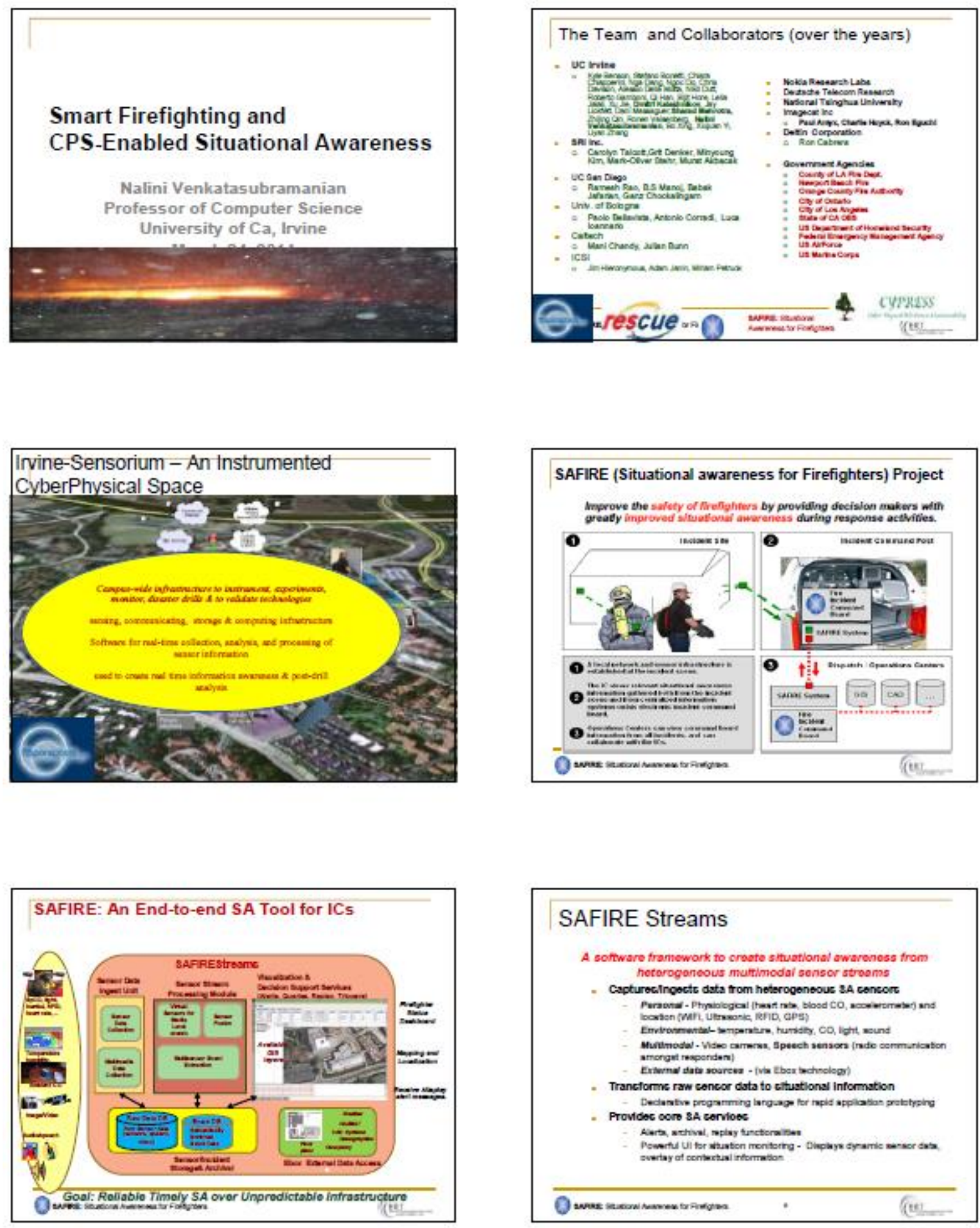

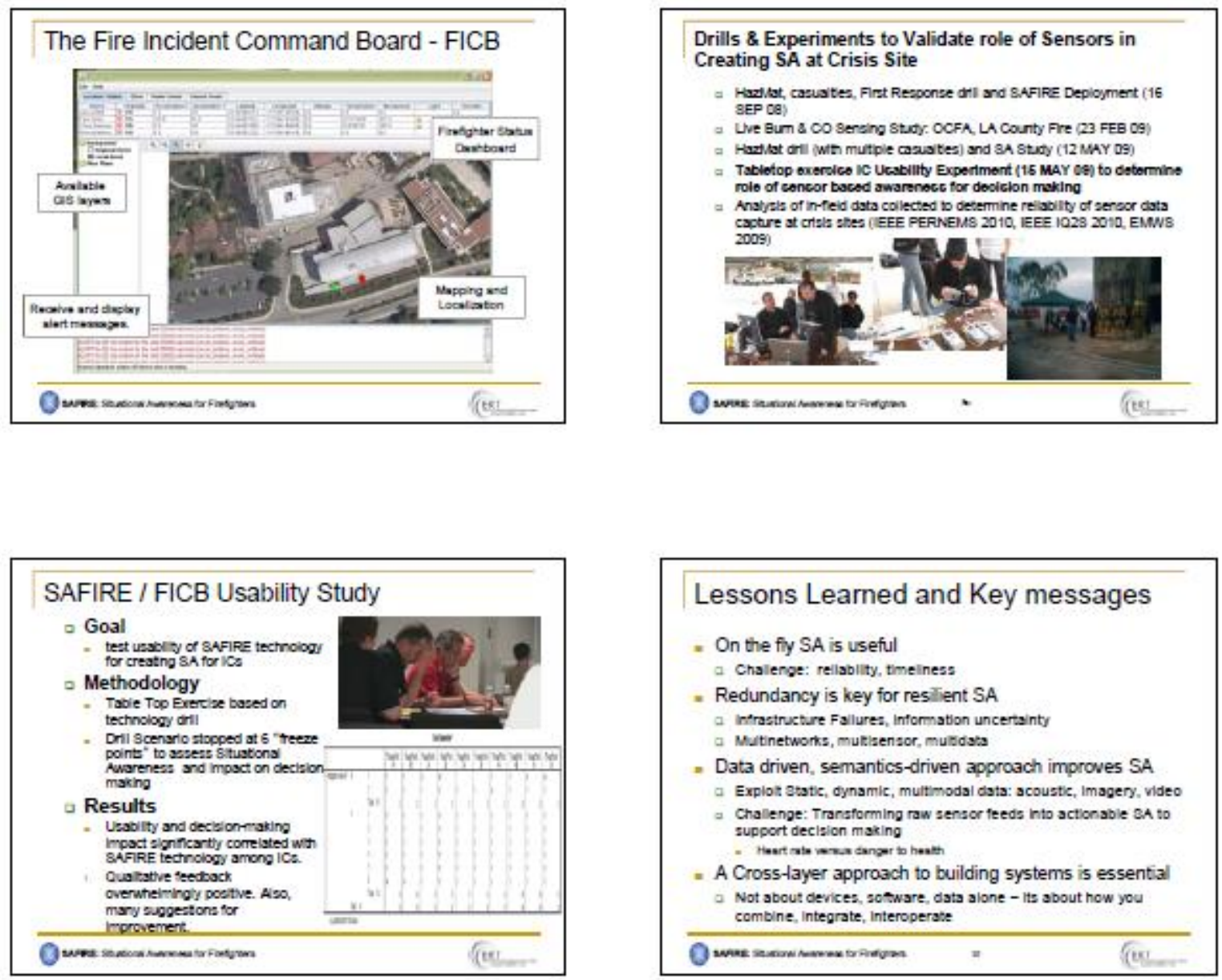

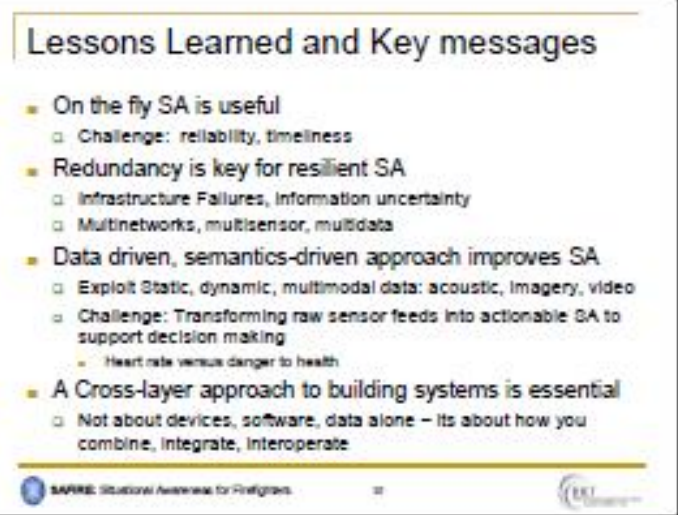

\section{New Directions \\ a Exploit New Sensing Modalities: Radio communications between responders as a source of situational information \\ - ODsTak: DARPA funded project with ICSI and SRI \\ - "On-the-fly" Information Integration: \\ = Ebox concept that provides dynamic access to sthe-specinc Information through web service interisce and integrates it}

Robust communications: Crisis site communication requires "best effort" networking using multinetworks

- MNA-Multinetwork Management ayatem

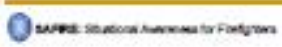
$\sqrt{(x)}$

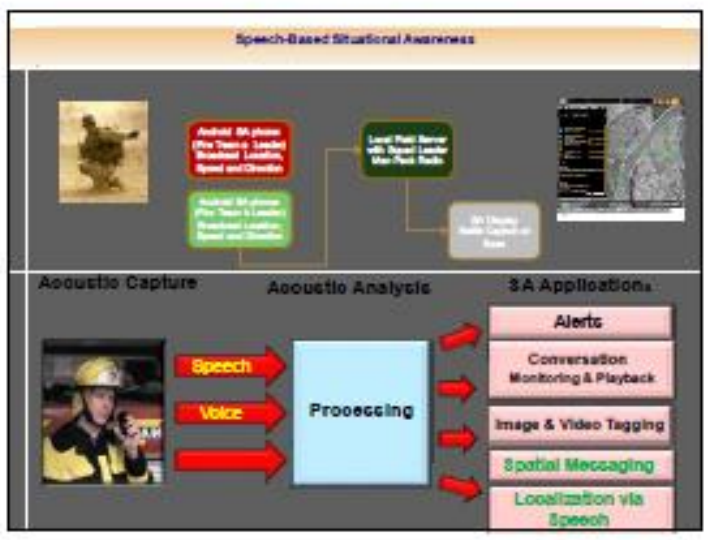



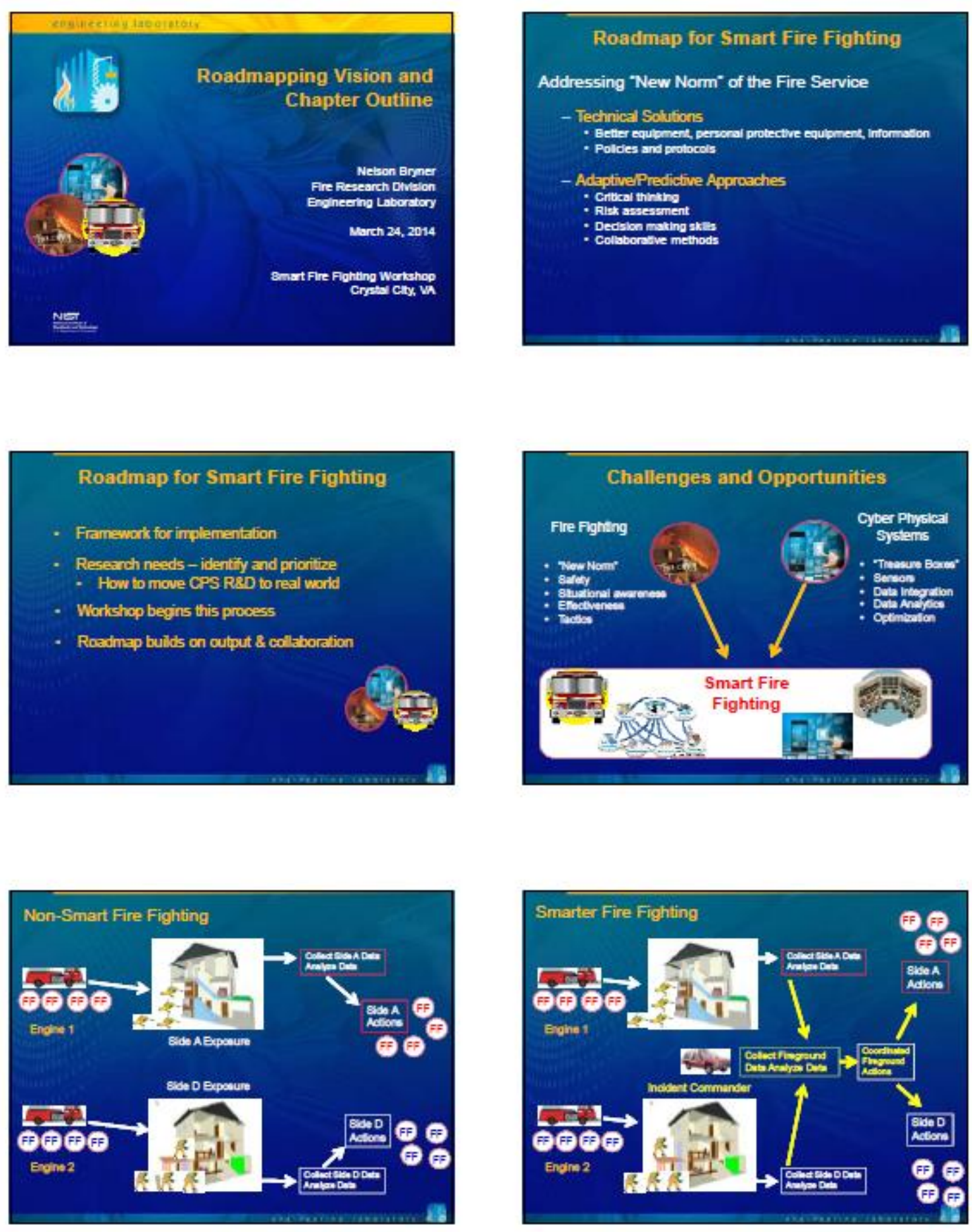

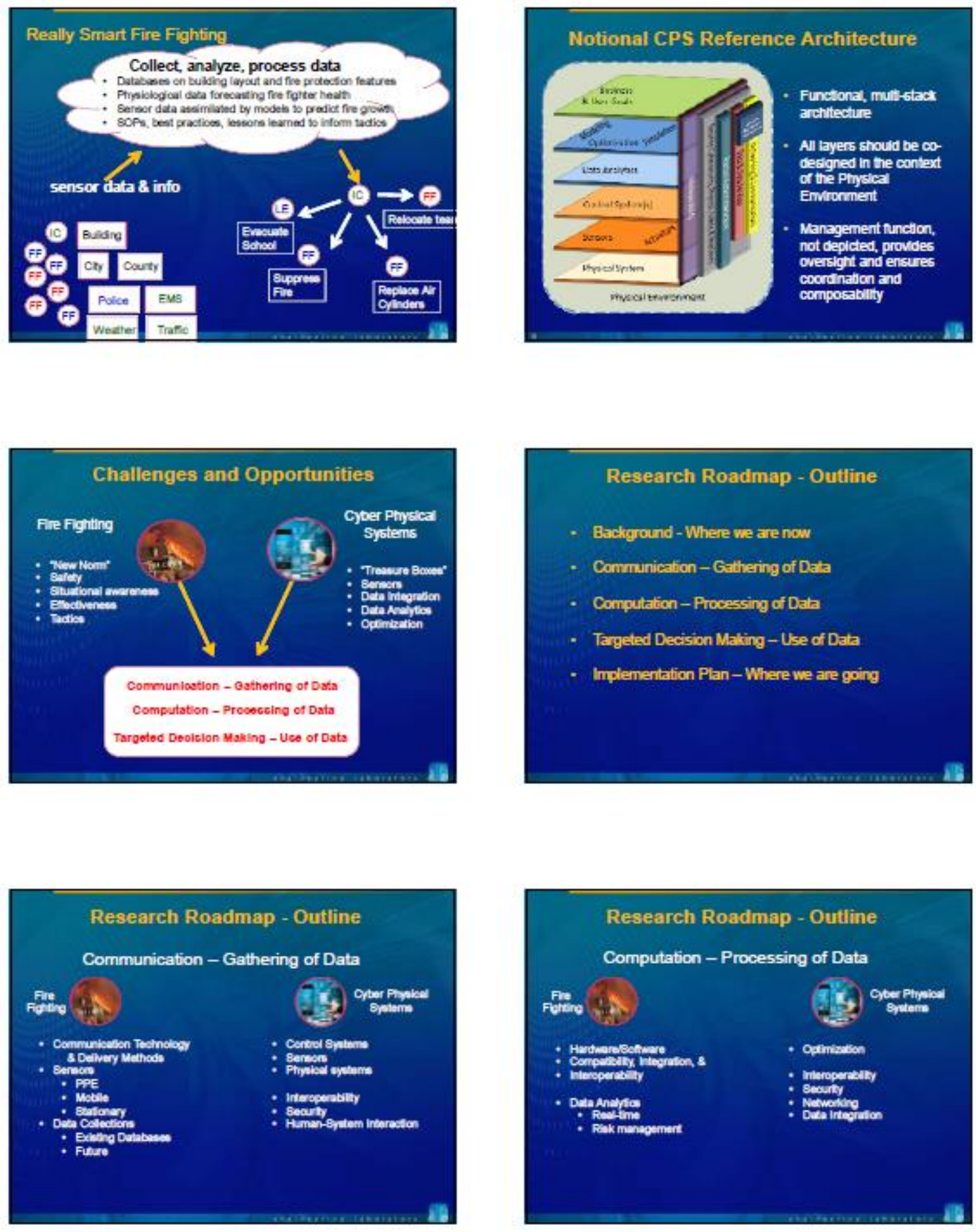

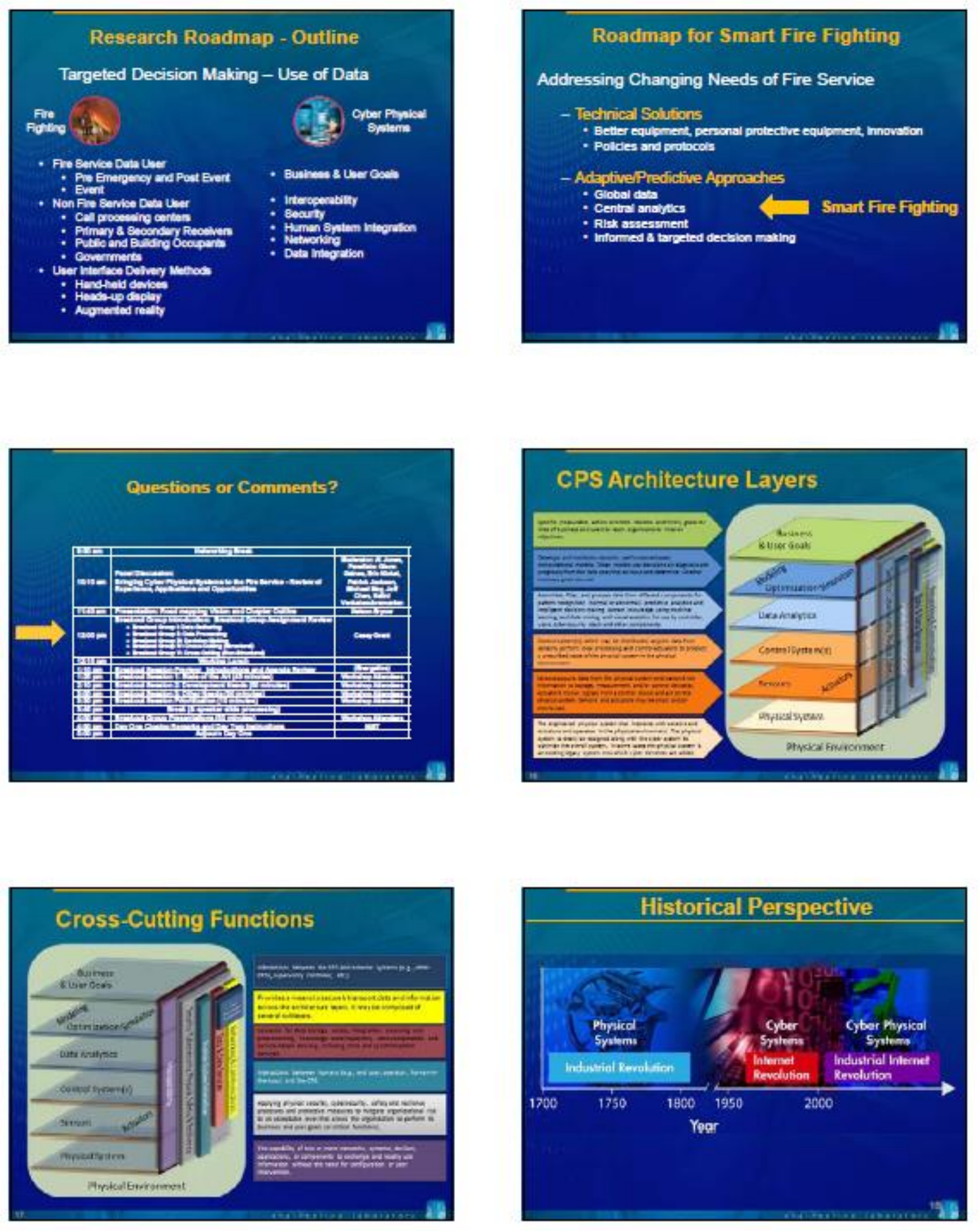